Portland State University

PDXScholar

\title{
How Do Youth and Adults at a Rural High School Conceptualize the Role of Student? An Investigation of the Student Role Identity Standard at the Intersection of Student and Teacher Perspectives
}

Joseph M. Zenisek

Portland State University

Follow this and additional works at: https://pdxscholar.library.pdx.edu/open_access_etds

Part of the Educational Methods Commons, and the Social and Philosophical Foundations of Education Commons

Let us know how access to this document benefits you.

\section{Recommended Citation}

Zenisek, Joseph M., "How Do Youth and Adults at a Rural High School Conceptualize the Role of Student? An Investigation of the Student Role Identity Standard at the Intersection of Student and Teacher Perspectives" (2014). Dissertations and Theses. Paper 1829.

https://doi.org/10.15760/etd.1828

This Dissertation is brought to you for free and open access. It has been accepted for inclusion in Dissertations and Theses by an authorized administrator of PDXScholar. Please contact us if we can make this document more accessible: pdxscholar@pdx.edu. 
How Do Youth and Adults at a Rural High School Conceptualize the Role of Student?

An Investigation of the Student Role Identity Standard

at the Intersection of Student and Teacher Perspectives

by

Joseph M. Zenisek

A dissertation submitted in partial fulfillment of the requirements for the degree of

Doctor of Education

in

Educational Leadership: Curriculum and Instruction

Dissertation Committee:

Emily de la Cruz, Chair

Christine Chaille

Samuel Henry

Yves Labissiere

Portland State University

2014 
(C) 2014 Joseph M. Zenisek

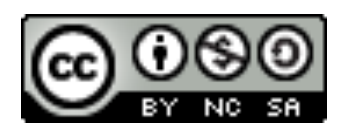

An Investigation of HS Student Role Identity

by Joseph M. Zenisek

is licensed under a

Creative Commons Attribution-NonCommercial-ShareAlike 4.0 International License. 


\begin{abstract}
Over the past decade, engaging student voice has emerged as an approach to increasing meaningful student involvement in schools towards meeting adolescents' developmental needs for agency, efficacy, and sense of belonging. Central to student voice work is the re-creation of student-teacher and student-organization relationships, generating student identity roles that are fundamentally different from the roles traditionally allocated to students. Conventional concepts of student roles by both adults and youth can act as barriers to increasing student voice. The goal of this study was to develop a better understanding of student role identity. Applying a critical ethnography approach in the context of participatory action research, a situated description of the student role within the organizational context of a rural high school was developed from the perspectives of students and teachers through the use of an online software platform. Keeping with student voice values and participatory action research protocols, students took a central role in developing and piloting survey questions, interpreting and organizing responses, reviewing the results, and presenting them to the school community. The data revealed both the aspirations and limitations of the student and teacher conceptions of the student role. Conventional notions of student identity dominated the role descriptions, and were generally consistent across student and teacher responses. Significant areas of divergence between student and teacher constructs included the explicit temporal orientation toward the future exclusive to the student responses, the engagement in academics that dominated the teacher submissions and rankings, and the conception of the student as a citizen/community member that was
\end{abstract}


found only in the teacher responses. The results suggested an inclination on the part of both students and teachers to increase opportunities for students to inform and influence policies and practices at all levels of the school organization. Presentations of the study results to the school community by the student researchers have induced some systemic reform toward promoting student voice. 


\section{Dedication}

This work is dedicated with love and gratitude to my family: my parents, in honor of their memory; my beautiful bride and muse, Renelia Mellejor Zenisek, who walked with me even before we met, accompanied me throughout this journey, and continues to walk by my side into the unknown and unknowable; and my son and fellow life-long learner, Sergio Francis Zenisek, whose off-hand remark provided the trajectory for this research. And also to my advisor and friend, Emily de la Cruz, who has guided and supported me throughout this project and never doubted that I would complete it. Finally, I dedicate this work to all my students - past, present and future - for all they have taught and continue to teach me.

To all of you, may I forever honor the trust you have given me. 


\section{Acknowledgements}

First and foremost I wish to thank the student researchers - J, L, and S, who partnered with me and generously offered their time and insights toward the successful completion of this study and communicating the results.

I am grateful to the students and teachers who participated in this research and to the administrators, Randy Dalton and Dave Luce, who supported it.

I give my thanks to the late Dr. Peggy Hiatt, a model scholar and teacher, who first inspired me to pursue this degree so many years ago.

I want to acknowledge the many researchers who have endeavored to support youth voice and an expanded vision of the student role, and whose work has informed this research.

And I offer thanks and appreciation to my committee members, Christine Chaille, Samuel Henry, and Yves Labissiere, for their enthusiastic guidance and support in the completion of this study and their encouragement to pursue its implications. 


\section{Table of Contents}

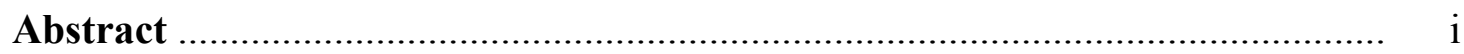

Dedication ....................................................................................

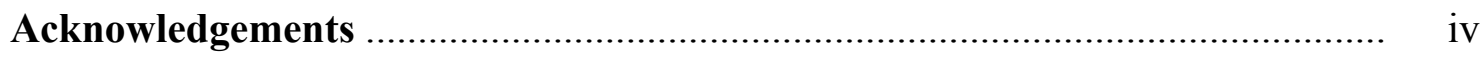

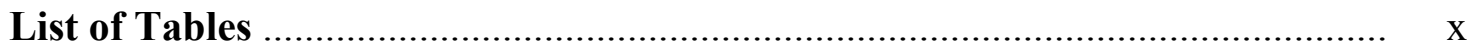

List of Figures ......................................................................................

\section{Chapter I: Introduction}

Introduction ...................................................................................

Research Questions ..................................................................... 4

Rationale ................................................................................... 4

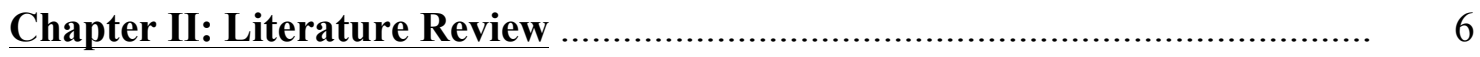

Problem Statement ....................................................................... 6

Conceptual Framework ................................................................... 8

A System Approach ..................................................................... 9

Role Theory …......................................................................... 15

Role Acquisition ........................................................................... 17

Adolescent as Complex Adaptive System .............................................. 20

Organizational Context of the School .................................................. 26

Student Voice ......................................................................... 29

Where does it come from? Past Inceptions ................................. 30

What does it mean? Definitions .............................................. 32

What does it look like? Current Topography ............................... 33

Why do it? Justifications ........................................................ 40

Psychological Development .......................................... 41 
Organizational Dynamics .................................................. 44

Citizenship Preparation ...................................................... 48

Human Rights ............................................................... 52

Critical Pedagogy ......................................................... 56

What complicates it? Polyphony and Positionality ......................... 59

Student Voice and the Student Role Identity Standard ................................ 61

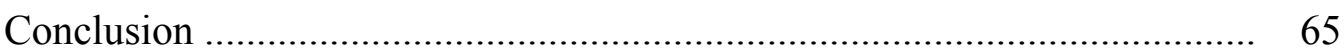

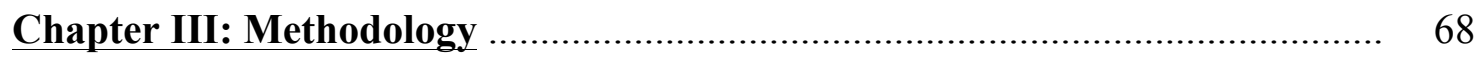

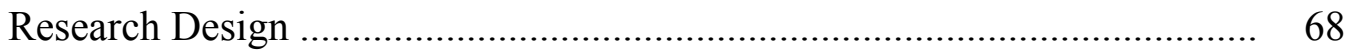

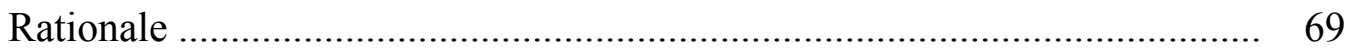

Research Questions .............................................................................. 71

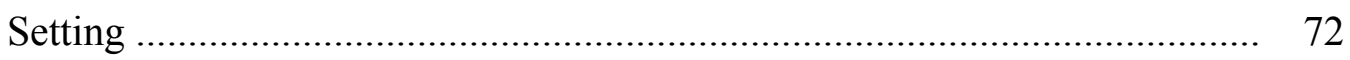

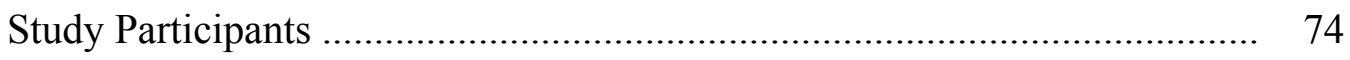

Student Research Team .............................................................. 75

Student Participant Group ............................................................. $\quad 76$

Teacher Participant Group ........................................................... 76

Parent Participant Group .............................................................. 77

Role of Researcher .............................................................................. 77

Data Collection Strategies ........................................................................ 79

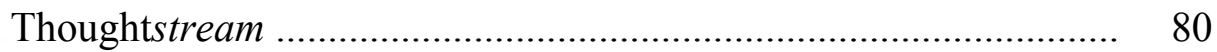

Data Collection Process and Timeline …………………………...... 81

Student Research Team (SRT) Activities ........................... 81

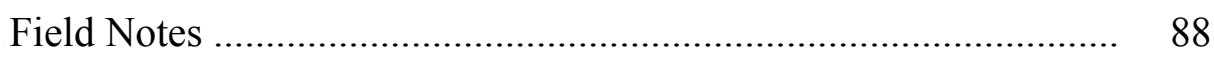

Student Research Team Participant Interviews ............................... 89

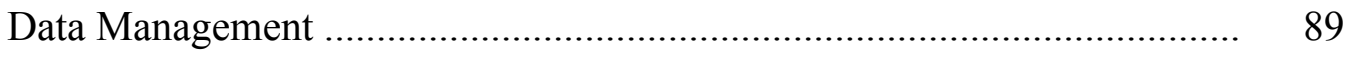




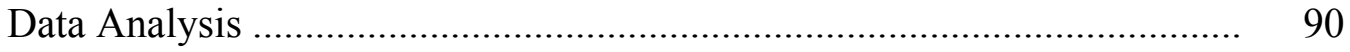

Participant Protection ................................................................................ 93

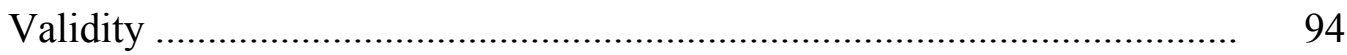

Personal Bias ............................................................................. 94

Immersion ....................................................................... 95

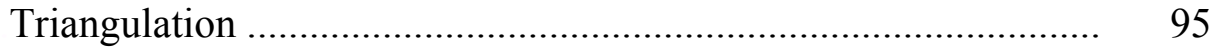

Quasi-statistics ................................................................... 96

Respondent Validation ............................................................... 96

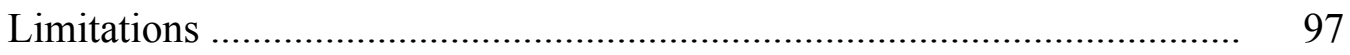

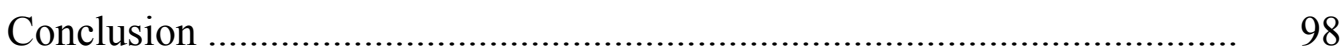

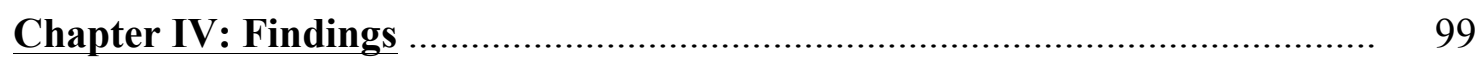

Question 1: What does it mean to be actively involved in high school? .... 100

Question 2: What opportunities should high school students have to have their voices heard in order to influence classroom and/or school policies and practices?

Question 3: How would you describe the role of a student in high school?

Chapter V: Analysis

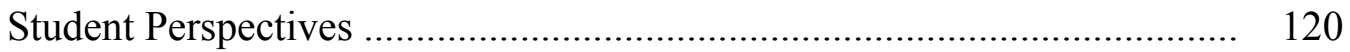

Teacher Perspectives ..................................................................... 125

Comparison of Student and Teacher Perspectives ..................................... 129

A Synthesis of Characteristics of the Student Role Identity Standard ....... 136

Student Conceptions .................................................................. 137

Teacher Conceptions ................................................................ 140

Comparing Student and Teacher Student Role Attributes .......................... 143

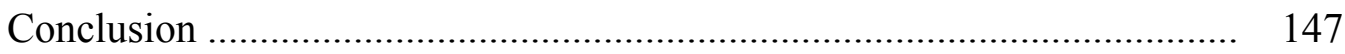


Student Role Identity Standards: Comparisons and Conclusions

Conclusion 1: Student as participant

Conclusion 2: Student as co-constructor of meaning 160

Conclusion 3: Student as partner 162

Conclusion 4: Student as citizen 164

Conclusion 5: Student as agent of change 168

Conclusion 6: Shared values 170

A Review of Student Engagement 171

Recommendation 1: Create a culture that empowers students .... 171

Recommendation 2: Build youth-adult partnerships 174

Recommendation 3: Build capacity 177

The Impact of the Study on the Status of Student Voice at RHS 179

Assumption 3: Impacts of participation on the SRT members

Assumption 2: Participation validates the power of student voice

Assumption 1: Community participation fosters dialogue on student voice

Limitations and Recommendations 185

Issue 1: SRT abilities 186

Response 186

Recommendations 187

Issue 2: Use of an online platform 187

Response 187

Recommendations 188

Issue 3: Self-selected participation 188 


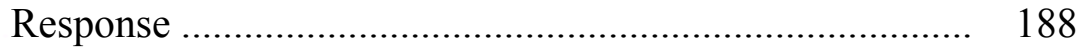

Recommendations …………………………………... 188

Issue 4: Low ICF return rate ................................................. 188

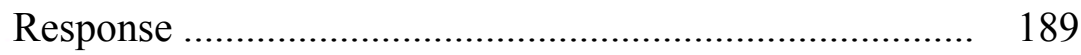

Recommendations ........................................................ 189

Issue 5: Lack of participant crossover ........................................... 189

Response ……........................................................ 190

Recommendations ………………………………….... 190

Issue 6: Limits of generalizability ................................................ 191

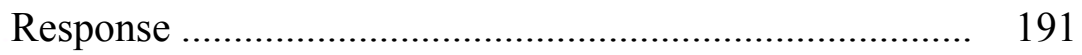

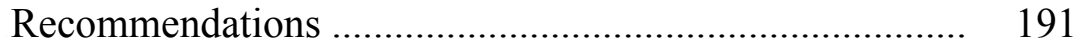

Additional Recommendations .............................................................. 192

Conclusions .................................................................................. 193

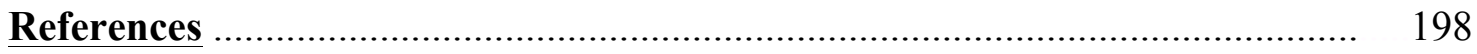

\section{Appendices}

Appendix A: Student Research Team Application ..................................... 211

Appendix B: Student Research Team Informed Consent Packet ................ 213

Appendix C: Student Participant Informed Consent Packet ...................... 220

Appendix D: Parent Participant Informed Consent Form ........................... 224

Appendix E: Teacher Participant Informed Consent Form ......................... 226 


\section{List of Tables}

Table 1. A Summary of Student Role Characteristics Derived from the Student Voice Literature

Table 2. Thoughtstream (Ts) Implementation Timeline and Activity

Summary

Table 3. Study Acronyms

Table 4. Question 1: Summary of Student and Teacher Categorized

Responses

Table 5. Question 1: Summary of Student and Teacher Category

Rankings

Table 6. Question 2: Summary of Student and Teacher Categorized

Responses

Table 7. Question 2: Summary of Student and Teacher Category

Rankings

Table 8. Question 3: Summary of Student and Teacher Categorized

Responses

Table 9. Question 3: Summary of Student and Teacher Category

Rankings

Table 10. Systemic Typology of Student Response Categories

Table 11. Systemic Typology of Teacher Response Categories

Table 12. Comparison of Student and Teacher Student Role Categories ...

Table 13. Summary of Student Voice Themes in Student and Teacher Responses to Questions 1 and 2

Table 14. Summary of the Student Role Characteristics According to Students

Table 15. Summary of the Student Role Characteristics According to Teachers

Table 16. Alignment of the Student Role Characteristics in Student and Teacher Responses

Table 17. Alignment of Student Role Characteristics Derived from the Student Voice Literature and Student and Teacher Responses ... 
Table 18. Alignment of Student and Teacher Response Categories with a Typology of Student Engagement ........................................... 172 


\section{List of Figures}

Figure 1. Schwab's Commonplaces ................................................. 10

Figure 2. Properties of Systems ......................................................... 14

Figure 3. Identity Control Theory (ICT) Model ...................................... 19

Figure 4. Adolescent as Complex Adaptive System ............................... 22

Figure 5. Ecological View of Adolescent Development .......................... 25

Figure 6. Pyramid of Student Voice .................................................... 33

Figure 7. The Ladder of Student Voice ................................................. 39

Figure 8. Justifications for Student Voice Viewed Systemically ............... 41

Figure 9. Student Role Identity Standards from Three Perspectives: Students, Teachers and the Student Voice Literature ................ $\quad 68$

Figure 10. The Thoughtstream Process ................................................. 80

Figure 11. Summary of Student Role Categories' Thoughts and Rankings by Student Participants ......................................... 121

Figure 12. Summary of Student Role Categories' Thoughts and Rankings by Teacher Participants ..................................... 126

Figure 13. Summary of Student Voice Submissions ............................... 134

Figure 14. Summary of Student Voice Category Rankings ..................... 134 


\section{Chapter I: Introduction}

"In the end, learning is strongly linked to a sense of efficacy and belonging, and these in turn imply an active engagement with the organization, nature and forms of learning” (Levin, 2000, p. 164).

"A single term has emerged to signal a range of efforts that strive to redefine the role of students in educational research and reform: student voice" (Cook-Sather, 2006b, p. 360).

The issue of student engagement has become increasingly central to the discussion of education reform not only in the United States (Levin, 2000; Smyth, 2006a; Yassie-Mintz, 2007), but internationally (Organization for Economic Cooperation and Development (OECD), as cited in Mitra \& Gross 2009; McInerney, 2006). The need to address student engagement has been brought into sharper focus by a variety of concerns including: continuing alarm over high dropout rates (Bridgeland, Dilulio \& Morison, 2006; Smyth, 2006b; Chapman, Laird, Ifill \& KewalRamani, 2011), flat standardized test scores (Stedman, 2009), and declining performances on international assessments (Mathis, 2011). These indicators are even more problematic when viewed in the context of more than a decade of national educational reform under No Child Left Behind, the most radical transformation of political control of the educational system in the history of American schooling (Labaree, 2006; Apple, 2004).

Many researchers have concluded that effective reform that aligns with the constructive nature of learning, increases academic motivation and achievement, and 
prepares students for active citizenship, is contingent upon increasing meaningful student involvement in all aspects of the educational system (Levin, 2000; Lundy 2007; Sands, Guzman, Stephens \& Boggs, 2007; Fletcher, 2004). The term student voice has come to represent the spectrum of such student involvement, from sharing opinions about effective pedagogy, to collaborating with adults to identify and address problems in schools, to taking the lead on researching and initiating systemic change (Cook-Sather, 2006; Mitra \& Kirshner, 2011).

The idea that students may have something important to tell us about educational content, structures and processes is not new. For years, youth advocates have recognized the institutional marginalization of students and called for reform on pedagogical, sociological and political grounds (Lincoln, 1995; Lundy, 2006). From Dewey's recognition of the importance of listening to youth and respecting their perceptions and ideas as members of a collaborative community (Dewey, 1938), through the emancipatory work of activists such as Freire and Giroux (Freire, 2003; Giroux and Simon, 1988; Giroux, 2010) and codified in the United Nations Declaration on the Rights of the Child (Lundy, 2007), there has been a gradual convergence of thought and action that is repositioning youth as agents whose opinions and participation we should not only solicit - but must if we are to create a responsive educational system that supports both individual and societal aspirations (Levin 2000).

The impetus for this research flows from a lifetime of working with youth. Over the course of twenty seven years of teaching adolescents in grades seven-to-twelve, I have become increasingly concerned with the extent to which the organization, 
curriculum and practices of middle and high school fail to adequately recognize and support the developmental needs of adolescents for connection, increased autonomy, respect, and agency (Mitra, 2004; Eccles \& Roeser, 2011). Within the context of ongoing educational reform, currently dominated by the standards and accountability movement (Labaree, 2005), I have witnessed the narrowing of curriculum, the ongoing exclusion of students from the conversation of school improvement, and the restrictive roles and responsibilities students are given within the school community. In light of the complex challenges we face socially, politically, economically, and environmentally, I have grown alarmed by the degree to which we are failing to sufficiently prepare students to be critical thinkers, active in their responsibility as citizens in a democratic society (Rudduck \& Flutter, 2004).

In response to these concerns, student voice emerged as a guiding concept that aligns with my fundamental values, assumptions and beliefs about teaching and learning. For several years now I have worked to facilitate the development of authentic student voice in various instructional settings to the point that the concept has now become part of the professional vernacular at my high school, as well as a goal in our current School Improvement Plan (River High School, SIP, 2012).

As such I was taken aback some time ago by the reaction of my then-adolescent son, Sergio Francis, to my interest and dedication to student voice principles. At the time of our discussion Serge was an enthusiastically engaged student in a demanding collegepreparatory high school. His response to my explanations of student voice and its focus on increasing youth involvement and agency challenged my assumptions regarding youth 
engagement. "Why would we want to be more involved in school?" he asked.

Such a dismissive response from a bright, successful student with a strong sense of personal efficacy festered within me for some time, eventually providing the vector around which this research was organized.

\section{Research Questions}

The goal of this research was to develop a situated description of the student role within the organizational context of high school from the perspectives of students and staff. To accomplish this I focused my research on the following questions:

1) How do youth from a rural high school conceptualize the role of "student" in the organizational context of the school?

2) How do teachers and administrators within the same high school community conceptualize the role of "student" in the organizational context of the school? Answers to these two questions allowed me to compare and contrast student role conceptions from the perspectives of the dominant stakeholders within the school organization. It also allowed me to consider how youth and teacher student role conceptions compare, both with each other and with the real and imagined roles of students presented in the literature on student voice and its application to increase meaningful student involvement in school and community reform.

\section{Rationale}

Understanding how youth conceptualize their role as students is significant in a number of ways. Student engagement involves cognitive, psychological, emotional and sociological domains (Newmann, 1992). How students engage in school is related to 
their perceptions of the value of such engagement and their potential success as actors within the school organization (Wang \& Eccles, 2011; Bandura, 2005). Knowing youth and adult conceptions of student role can throw light on points of divergence between adolescent and institutional expectations and aspirations toward identifying possible sources of role conflict and student disengagement. Understanding these conceptions may also reveal points of access for supporting both adolescent and institutional development. Finally, understanding these conceptions is fundamental to both applying and effectively evaluating student voice efforts to increase meaningful student involvement. 


\section{Chapter II: Literature Review}

This chapter begins with a description of the problem of student role identity and the conceptual framework used for investigating it. A summary of role theory and a model for role identity acquisition as a way of understanding student role identity

development is offered. Role acquisition is then considered in relation to adolescent development and the organizational context of school. Some of the implicit and explicit principles around which schools are organized and the implications for informing the student role are suggested.

Next, the literature on student voice is reviewed to trace its historic development. An expanded definition of student voice, examples of its application, and significant implications for the redefinition of role identities for students and teachers are documented.

Finally, justifications for implementing student voice are considered from a variety of domains within a systems framework. Critical theory is offered as an inclusive approach that positions identity as a relational construct at the intersection of all the enveloping systems. Issues arising from a critical interrogation of student identity and student voice are briefly explored. The chapter closes with a description of the student role identity standard derived from the student voice literature.

\section{Problem Statement}

The literature on student voice describes both the conditions that nurture meaningful student involvement, and the impediments to its development. Fletcher 
(2004) identifies three categories of obstacles to creating and sustaining student voice: structural barriers, resistance by educators, and student resistance. Structural barriers include the tradition of administrative control, lack of institutional support in the form of funding, training and ongoing evaluation, and policies that restrict more expansive roles for students (Fletcher, 2004; Fielding 2004a). Resistance by educators also includes issues of power and control as well as narrow definitions of appropriate student roles (Fletcher, 2004; Mitra \& Gross, 2009). Student resistance, meanwhile, is viewed primarily as the result of enculturation, perhaps resulting from the first two conditions. "Schools possess institutional rules, norms, and assumptions about roles" (Mitra, 2009, p. 315). In this environment students' conceptions become bound by traditional models of relationship with adults (Fletcher, 2004) that may lead to opposition to assuming more personal responsibility (Johnston \& Nichols, 1995, p. 95). Student voice work that seeks to reposition youth as change agents within their schools and communities (Cook-Sather, 2006) may run afoul as such conditioned conceptions mediate perceptions and responses to the learning environment (Lowyck et al., as cited in Elen, Clarebout, Léonard, \& Lowyck, 2007).

While institutional barriers and resistance by educators have been more fully vetted in the literature (see Lincoln, 1995; Biddel, 2001; Warwick, 2008), this research sought to expand our understanding of the issue of student resistance by focusing on the boundaries students have constructed regarding their roles in school. And while there is an extensive body of research into students' perceptions of various aspects of learning environments and the variables that shape their relationship to them (see Levine \& Wang, 
1983; Schunk \& Meece, 1992; O'Connell Schmakel, 2008), there is very little in the literature focused on exploring youth conceptions of their roles as students - particularly in relation to school reform (Levin, 2000). My examination of peer-reviewed student voice literature dating back to 1981 revealed only two instances in which the study was framed as an investigation of student identity. The first examined students' perceptions of their preferred role as a learner in traditional or constructivist instructional settings (Kinchin, 2004). The second summarized two qualitative studies looking at the intersection between students' identities and engagement in learning (Faircloth, 2012). Neither study addressed students' conceptions of the role of "student."

\section{Conceptual Framework}

The concepts of student role and student voice both emerge as issues through the recognition of the unique position of youth within larger social, political and economic systems. Therefore, this investigation utilized systems thinking as a tool to explore the intersection of student role identity and student voice within the context of enveloping systems of influence. According to Checkland (1999), the application of systems thinking "can provide a way of conceptualizing the social processes in which, in a particular organizational context, a particular group of people can conceptualize their world and hence the purposeful action they wish to undertake" (p. 54). When applying systems thinking to social organizations such as schools, Boulds (1956) suggests that the "unit of such systems is not perhaps the person - the individual human as such - but the "role" - that part of the person which is concerned with the organization or situation in question" (p. 205). Simon (1990) proposes that organizations are best viewed as systems 
of interrelated roles. Applied to role theory, systems thinking allowed me to explore the internal and external dynamics of role development in school as a social organization.

Likewise, taking a systems lens to the student voice literature provided a means to position and explore the various conceptions of meaningful student involvement and their implications for redefining student roles in relation to the personal, technical and organizational domains that compose schools as "living systems" (Crick, McCombs, Haddon, Broadfoot \& Tew, 2007, p. 269). Student voice, with its focus on reimagining the roles of students in schools and communities, provided the backdrop before which this narrative plays out, while systems thinking provided the organizing principles for understanding the construction and interplay of role and voice.

The next section begins with an overview of systems thinking and further justification for its application as an approach for understanding role development and student voice. A summary of role acquisition theory is then provided before reviewing the student voice literature to explicate the implications for student roles. In the process, definitions of key terminology as applied in the context of this study are clarified.

\section{A Systems Approach}

A system is a functional whole - a product of both its components and their interrelationships (Hirsch, Levine \& Miller, 2007; Parsons, 2007). Schwab’s Commonplaces can be viewed as an example of systems thinking applied to schooling. In it he identifies four fundamental elements - the student, the teacher, the subject and "the milieu", or context - whose interactions inform learning processes in the classroom. Schwab's insight acknowledges that learning is a holistic process emerging from the 
simultaneous interactions of all of the components comprising the educational setting (Schwab, 1973; Fox, 1985). See Figure 1.

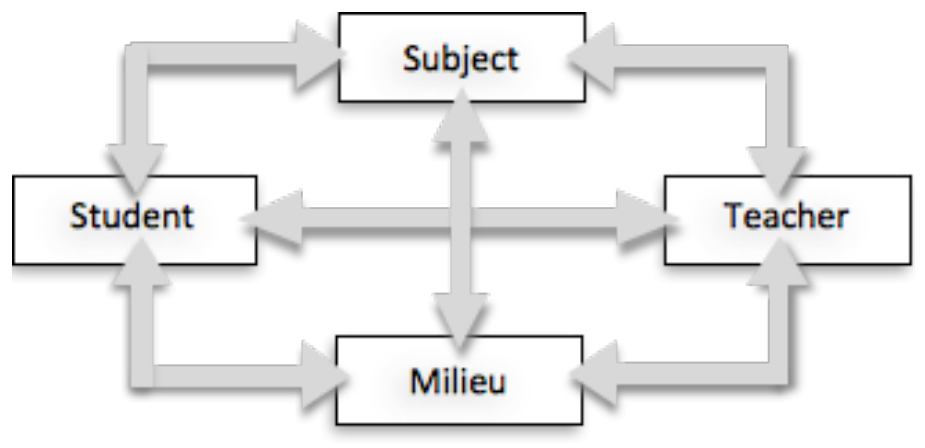

Figure 1. Schwab's Commonplaces (Derived from Schwab, 1973)

Schwab's structure also suggests that students occupy a unique position, and thus a unique role, at the intersection of adult relationships, curriculum, and a "milieu" of enveloping systems.

Systems thinking is therefore an integrative approach to conceptualizing entities that focuses on "wholes" and the internal and external relationships that define their structure, function and history. Checkland (as cited in Jenks, 2004) identifies four categories of systems: 1) Natural systems - such as an ecosystem and the biological subsystems that make it up; 2) Designed physical systems - such as factories, homes, automobiles, or computers; 3) Designed abstract systems - such as instructional theory, the academic disciplines, or literature; and 4) Social systems - such as government bodies, neighborhoods and families.

We can find all four types of systems represented in Schwab's commonplaces. Students and teachers are biological systems embedded in a milieu that includes both the natural systems of the environment, and several designed physical systems - equipment, 
the classroom and the school building. Subject matter and curriculum are designed abstract systems. Finally, the learning environment includes a variety of intersecting social systems - the classroom community, the family, the greater school community. Viewed as the intersection of numerous systems and their relationships, the learning environment and the role of students within it suddenly take on multiple levels of complexity that defy simplistic diagnosis and prescriptions - the kind of complexity that Schwab spent a career articulating (Fox, 1985). "One can not understand nor necessarily 'fix' a system by attending to one of its parts. Systems thinking is the opposite of analytical thinking. But, both are needed to fully understand any entity" (Rowland as cited in Jenks, 2004, p. 201). Consequently, student voice as a facet of student role and education reform can be viewed as arising within the complex interplay of designed abstract and social systems as well as the natural and designed physical systems within which these relationships play out.

In addition to the integration of parts into wholes, Rowland (as cited in Jenks, 2004) identifies hierarchy and communication as characteristics common to most systems. Hierarchy refers to the fact that systems are made up of smaller subsystems their component elements. Simultaneously, systems are also subsystems themselves in the larger systems within which they are embedded and with which they interact. For example, researchers describe four hierarchies or influential systems in which an individual, such as a student, is embedded: microsystems include both the individual and such groups as the family or school; a mesosytem made up of linkages between microsystems such as family-school partnerships; the exosystem of community level 
processes; and the macrosystem of societal level influences from politics, policy, economics, and cultural norms and values (Durlak et al., 2007). This embeddedness creates reciprocal relationships within which the various systems and subsystems interact and influence each other. The strength of these relationships determines the boundaries of the systems and are used to distinguish one system from another (Yolles, 2000). According to Owen and Valesky (1995), in the educational environment such hierarchies can serve as a challenge to the development of an authentic student voice.

The third characteristic of systems, communication, plays the role of integrating parts into wholes. Networks of communication - whether physical, social, or abstract are the links that establish relationships between the components of the system and between the system and its environment - the macrosystems within which it functions. Links can be weak couplings, such as a school mission statement that includes no accountability for teacher or student behavior; or strongly coupled, such as student evaluations of teachers that are included as a component of teacher performance reviews. All such relationships, whether weak or strong, can be understood as putting constraints on the system. For parts to exist in some relation, some constraint must exist between them (Zwick, 2006). For example, the dissemination of a school conduct code is a form of communication that links students, teachers, parents and the school. By necessity it includes some types of information while excluding others and therefore defines - and thus constrains - particular aspects of the relationship between the participants of the school system. In so doing, it serves to define certain aspects of the role each is expected to play within the system. 
As such, networks of communication and the relationships they establish serve to both constrain the system by establishing boundaries while providing resources and opportunities for reciprocal influence. These networks also provide feedback to the system by which it can better integrate its processes, resist change and/or adapt and evolve in response to internal and external conditions (Sterman, 2006) at both the individual and organizational level. This dynamic plays out in school settings as student voice repositions youth as valuable sources of participatory feedback that can revitalize the education system if the system can overcome organizational and educator resistance.

Zwick (2006) identifies three additional qualities fundamental to all systems. As a dynamic and integrated whole linked internally and externally, all systems have structure, function and history. Internal order and integration of components creates the structure - or state of being. How the system interacts with its environment identifies its function - or state of behaving. And because a system operates in a dimension of time that includes a past and a future, it has history - a state of becoming. Conditions in history inform the function of the system - its purpose, as well as the structure the system will have. Likewise, the structure of the system will feed back on its function resulting in alterations or additions to its purpose. As the system operates in time it creates its own history in the form of changes to itself and to the systems with which it interacts and this in turn influences its function and structure. These three properties continuously feedback on each other allowing the system to respond, adapt and evolve. See Figure 2. As an example, let us consider the implementation of the Oregon Small Schools Initiative. At its most basic, the initiative, launched in 2004, was a move to change the 
structure of participating high schools. This was in response to the perceived failure of high schools in recent history - to function effectively by adequately educating and graduating the majority of students. Based on research suggesting that smaller learning communities facilitate higher student engagement and achievement (Bill and Melinda Gates Foundation, 2001), the initiative provided grant money to support the restructuring of schools into smaller communities of learning. After four years, an initial review of attendance, discipline and student performance raised questions as to how effectively the schools were functioning as a result of this structural change (Hammond \& Lednicer, 2008). This review led to additional changes in school structure in hopes of better aligning school function with historically contexted societal needs. Applied to high school youth, the interactions of structure, function and history - of being, behaving and becoming - provide insight into the development of their identities as students, and the role of student and student voice within the structure, function and history of school.

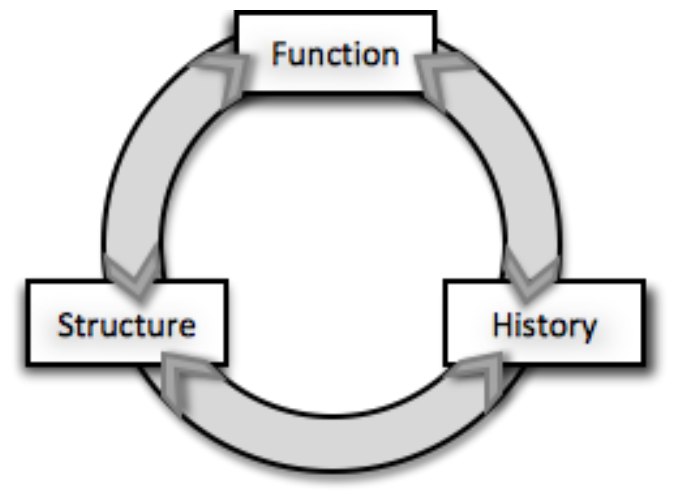

Figure 2. Properties of Systems (Derived from Zwick, 2006)

The benefits of applying a systems approach to understanding student role and student voice include its capacity to counter reductionist thinking, foreground 
relationships, and model complex processes (Garnsey, 1993; Parsons, 2007).

Applying systems thinking to the concept of student voice and student role provided a structure to:

- define both voice and role within the complexity of systems and relationships influencing their development and expression;

- interpret youth and adult conceptions of student role within these systems and relationships;

- describe these system processes, operating from the macro-scale of policy and politics, to the micro-scale of youth-adult relationships as well as internal cognitive systems, using a common set of concepts and vocabulary.

This research agenda is predicated on the hypothesis that the diminishing student engagement that characterizes the adolescent years (Yazzie-Mintz, 2007) stems at least in part from a failure to establish viable roles within the organizational context of schooling that allow youth to meet their developmental needs in meaningful ways. Role theory can provide a framework for investigating how roles develop and are perceived (Brookes, Davidson, Daly \& Halcomb, 2007). Understanding and interpreting how youth and adults conceptualize the student role in the organization of high school is predicated on understanding what a role is and how it is constructed. The next section provides a summary of role theory and acquisition and its relationship to identity development within a systems framework, particularly as it applies to youth and schools.

\section{Role theory}

Roles are social constructions (Collier \& Callero, 2005) that include expectations 
of behavior as well as descriptions of characteristics, norms and values associated with a position (Major 2003; Thomas \& Biddle as cited in Brookes, Davidson, Daly, and Halcomb, 2007). Role theory posits that roles shape human behavior in identifiable and predictable ways depending upon the context (Biddel, 1986). However, role behavior is not merely prescriptive, but also involves the intentional actions of individual agents influencing the social context to meet personal needs (Bandura. 2001). Therefore, a role can be conceived of as a form of negotiated membership within a particular social situation (Biddel, 1986).

Historically, role theory has been dominated by two perspectives: social structuralism, and symbolic interactionism. Social structuralism takes a macro-system view to focus on the social systems within which individuals are embedded and that are seen as shaping individual behavior. From this perspective roles serve established functions in maintaining the social structure of the system (Brookes et al., 2007). A role is seen as "patterned behavior" directed towards others in the organization that emerges from the position one occupies in the social structure (Biddel, 1986; Collier \& Callero, 2005). These positions create a "shared sense of reality" - what Lynch (2007, p. 381) refers to as a social field - which informs the recognition of other positions, and the particular knowledge or agency associated with them.

In contrast to social structuralism, symbolic interactionism takes a micro-system perspective to focus on the individuals that comprise social systems and the negotiated interactions by which they create such systems. In this view, roles emerge from relationships between actors within the system rather than being imposed upon them by 
the system (Hardy \& Conway, as cited in Brookes et al, 2007). "Actual roles, then, are thought to reflect norms, attitudes, contextual demands, negotiation, and the evolving definition of the situation as understood by the actors" (Biddel, 1986, p. 71). While both approaches recognize that patterns of interaction are associated with particular roles, symbolic interactionism emphasizes that such patterns are not merely passive behavioral responses, but created expressions of the self (Collier, 2001; Collier \& Callero, 2005). Conceived in this way, a role becomes a resource for organizational members that informs their perceptions, interpretations, and responses to situations that arise both within and outside the organization (Simon, 1990).

Current conceptions of role theory expand on symbolic interactionism to focus on the reciprocal nature of identity and social structures and the ways in which social roles provide resources for identity development and action (Collier \& Callero, 2005; Faircloth, 2012). Understanding the relationship between role and identity is instrumental in explaining the connection between the individual and larger social structures (Collier, 2001). Taking a cognitivist approach, Collier and Callero (2005) suggest that the development of role identity involves the development of cognitive structures. In summarizing research in this area, they state that "both psychologists and identity theorists have pointed to the existence of schemata that structure knowledge regarding normative behavior associated with particular roles" (p. 48).

\section{Role Acquisition}

According to Collier and Callero (2005) roles serve as resources for creating social identities. They hypothesize that two distinct types of schemata are associated 
with role identity acquisition: role as cultural object and role as identity. As cultural objects, roles exist as social constructs of shared meaning independent of particular situations. The roles of student or teacher are examples of roles as cultural objects. The role of student as cultural object answers the question, "What is a student?"

Role as identity refers to cognitive constructs of the self in a specific role and would answer the related question, "Who am I as a student?" These cognitive structures represent generalizations about the role and the self in particular contexts derived from experience and serve as frameworks for interpreting social events and informing responses (Collier \& Callero, 2005; Lynch, 2007). Development of both types of schemata are fundamental to a process of role acquisition in which "a correspondence between the meaning of the role and the meaning of the self develops as a consequence of using the role to define the self" (Collier \& Callero, 2005, p. 48).

Burke proposes a theory of role identity acquisition in terms of a discrepancyreducing control system by which the individual seeks congruence between a role standard and a role performance based on self-perceptions and external feedback (Collier, 2001; Burke, 2006). In Burke's Identity Control Theory (ICT) model, a role identity consists of a set of self-relevant meanings held as a standard. The standard indicates the level of each dimension of meaning in the set. For example, the role identity of student would include a standard of what it means to be a student and incorporate dimensions such as "academic responsibility," "sociability," "intellectualism," and "personal assertiveness" (Burke \& Reitzes, 1981). Therefore the identity standard is the set of meanings that define the role. In circumstances in which a role is activated, the perceived 
meanings of one's behavior in a particular situation, as derived from both personal reflection and environmental feedback, are compared against the role standard leading to changes in social behavior in order to better align one's perceptions of meaning with the role standard (Burke, 2006). "The link between identities and behavior lies in the shared meanings of each: people engage in behavior to create meanings that correspond to the meanings of their identity standard" (p. 82). See Figure 3.

A role standard is hardly fixed; rather it is a fluid construct subject to change based on new information, shifting priorities, and situational dynamics, as the individual engages in an ongoing process to integrate multiple identity standards in an attempt to maintain a kind of systemic homeostasis (Collier, 2001, Burke, 2006).

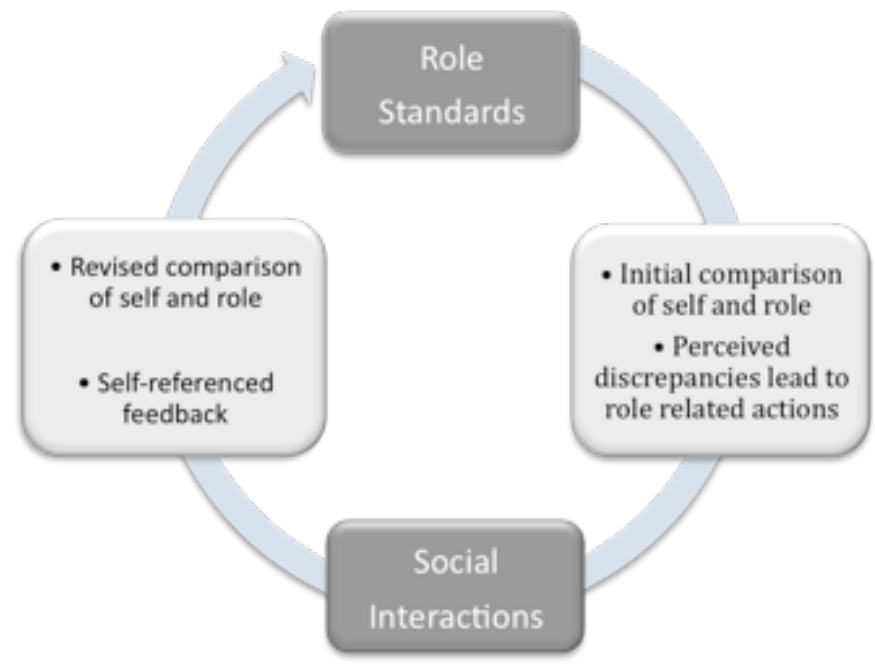

Figure 3. Identity Control Theory (ICT) Model (Derived from Burke, 2006)

Considered further within a systems framework, the development of an identity standard manifests the fundamental systemic properties of structure (being), function 
(behaving) and history (becoming). The self-relevant meanings encoded in the role standard address both states of being - answering, for example, what a student is "academically responsible," and behaving, answering the question, what a student does "assert themselves." As these meanings are dynamic in time, they reflect the concept of becoming. And so the various role identities can be conceived of as subsystems, nested and networked in a hierarchical identity structure that is the "self."

The key purpose of this research, then, is to distinguish the self-relevant meanings of being, behaving, and becoming that comprise the role standard of "student" as currently encoded in the schemata of students and teachers at a rural high school.

This section summarized role theory and offered a model for role identity acquisition as a process of gradual correspondence between role as cultural object - a role standard, and role performance - the perceived meanings of one's behavior in specific situations. In addition, the development of a role standard was framed as demonstrating the systemic properties of structure, function and history as a subsystem of the "self." The next section will look at role acquisition in the context of adolescent development and then consider the organizational context of school and its impacts on this development.

\section{Adolescent as Complex Adaptive System}

Adolescence is a period during which young people undergo their most dramatic changes in psychological, social, biological, and cognitive development - all with critical implications for their future well-being (Steinberg, 2005; Bandura, 2005). Over the past decade, developmental scientists have made significant gains in understanding how 
school experiences influence these developments (Eccles \& Roeser, 2011). Current research has applied systems ideas to take an "ecological perspective" in order to gain a better understanding of adolescent development in relation to the macro, meso- and micro-systems in which it occurs (Steinberg \& Morris, 2001; Eccles \& Roeser, 2011). Some of the significant developmental challenges adolescents face include: a further exploration, integration and expression of personal identity; an increased capacity for abstract reasoning; and an expansion of relationships within social, economic, political and biological spheres (Baer, 1999; Steinberg 2005). Considered from a systems perspective, adolescents responding to these demands can be seen as manifesting the features of complex adaptive systems.

Complex adaptive systems are characterized by emergence, integration, selforganization, and adaptability (Nolfi 2005; Yolles 2000; Fenwick 2004). Emergence refers to a development of properties arising from system interactions that cannot be inferred from the initial conditions - such as the development of identity. Through selforganization, emergent properties are retained by an adaptive process based on exploration and selection. Adaptability addresses an ability of a system to change form and behavior in response to changes in an environment while maintaining stability. Finally, couplings between elements of a system are strengthened by means of integration, such as the integration of role standards. The adolescent acting as a complex adaptive system interacting with its environment is graphically represented in Figure 4.

The figure exemplifies the dynamic and holistic relationships that exist between an adolescent as an emerging system with her own identity and characteristics, and the 
environment from which she distinguishes herself and within which she acts. The model is divided into three subsystems - the body, the nervous system including the brain, and the mind. These subsystems localize significant aspects of learning: observed behavior, the internal construction of knowledge, and the development of identity within a sociocultural framework that includes school. The body-environment boundary highlights the biological interface across which the adolescent acts and is acted upon. The environment provides inputs, subject to biological, cognitive, and cultural - processing, interpretation and response. Mind as the locus of identity and cognition, is an emergent subsystem arising from the physicality of the nervous system (Bandura, 2001). Learning as adaptive behavior can therefore be understood as an emergent property arising from the continuous feedback between the cognitive, behavioral and environment domains (Chiel \& Beer, 1997; Yolles, 2000).

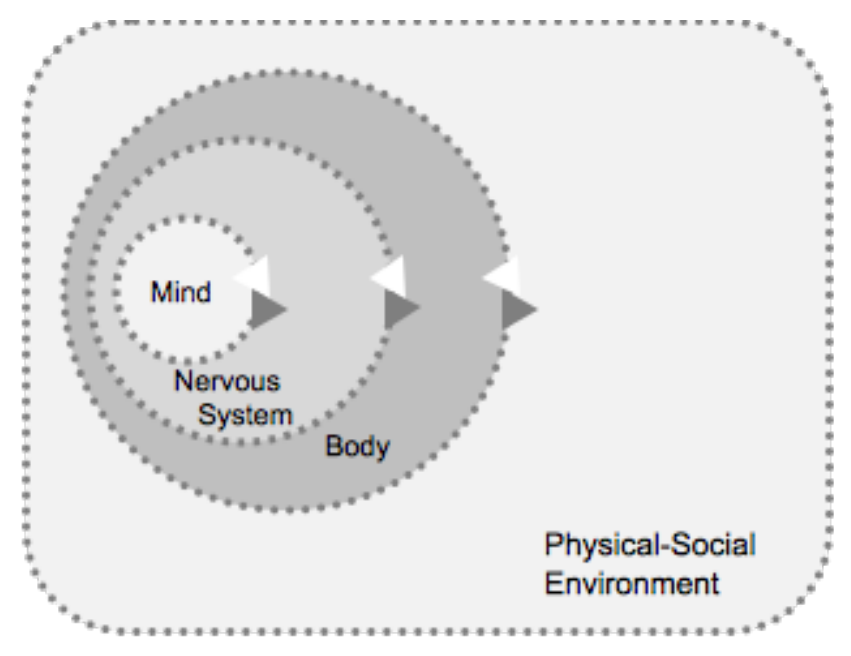

Figure 4. Model of adolescent as Complex Adaptive System (Adapted from Nolfi, 2006 and Yolles, 2000)

Significantly, this model, by its simultaneous rendering of the systemic properties 
of being (structure), behaving (function), and becoming (history), reinforces the idea that learning - whether by response strengthening, assimilation and accommodation, information processing, or social interaction - is always taking place. This takes on particular importance in schools where the focus on a formalized curriculum and instruction typically ignores other meanings being constructed by students as they interact with the milieu of school culture that encodes acceptable behavior, values, and beliefs (Eccles \& Roeser, 2011; Owen \& Valesky, 1995) - the "hidden curriculum" referred to by Apple and Beane (1995). Consequently, a teacher can not teach a lesson on civil rights and free speech, for example - without the student simultaneously creating meanings, from the classroom and school context within which the lesson is taught, regarding their own rights and freedoms, the value of their voice, and the role they are expected to play within the school organization.

This ongoing meaning-making has other important implications in view of the biological, cognitive and social transitions undertaken during adolescence. The onset of physical maturity, the development of higher-order thinking skills, and the expansion of social roles combine to redefine an adolescent's identity and function in the world (Steinberg, 2005; Bandura, 2005). From a learning perspective, the adolescent continues the developmental process of establishing a growing repertoire of behavioral responses appropriate to a variety of contexts, combined with increasingly sophisticated and expanding knowledge and cognitive constructs enhanced by an increased capacity for abstracting new constructs from internal and external environments (Steinberg, 2005). At the same time, this progressive systemization creates new opportunities and 
potential for expanded engagement - physically, mentally and socially. On a physical level, biological and sexual maturation creates new ways to act in the environment - new role identities. The growing spatial sphere in which the adolescent, more mobile than ever, can operate parallels this development. Cognitively, the adolescent is developing more sophisticated internal models of the world and is therefore better able to abstract future actions and anticipate consequences. Socially, she is becoming ever more adept at adjusting to the shifting roles necessitated by moving between her positions as family member, student, friend, employee, teammate, partner, or citizen (Erikson, 1968; Steinberg, 2005; Bandura, 2005). Considered from a systems perspective, she becomes ever more integrated and therefore constrained through an expanding network of relationships within and between enveloping metasystems. See Figure 5.

The simultaneous expansion and consolidation of identities implied in this developmental process have important implications for how students conceive and act on their roles in schools. As described previously, role identity acquisition is a dynamic process in which the individual simultaneously elaborates and aligns role schemata and role performance through ongoing internal and external feedback loops (Burke, 2006). As the quantity and nature of adolescent relationships expand, so do the quantity and nature of role identity options likewise expand, posing challenges to role and identity integration (Erikson, 1968; Burke, 2006). Challenges to role identity and performance can manifest themselves as role ambiguity, role insufficiency and/or role conflict (Biddel, 1986; Brookes et al., 2007). 


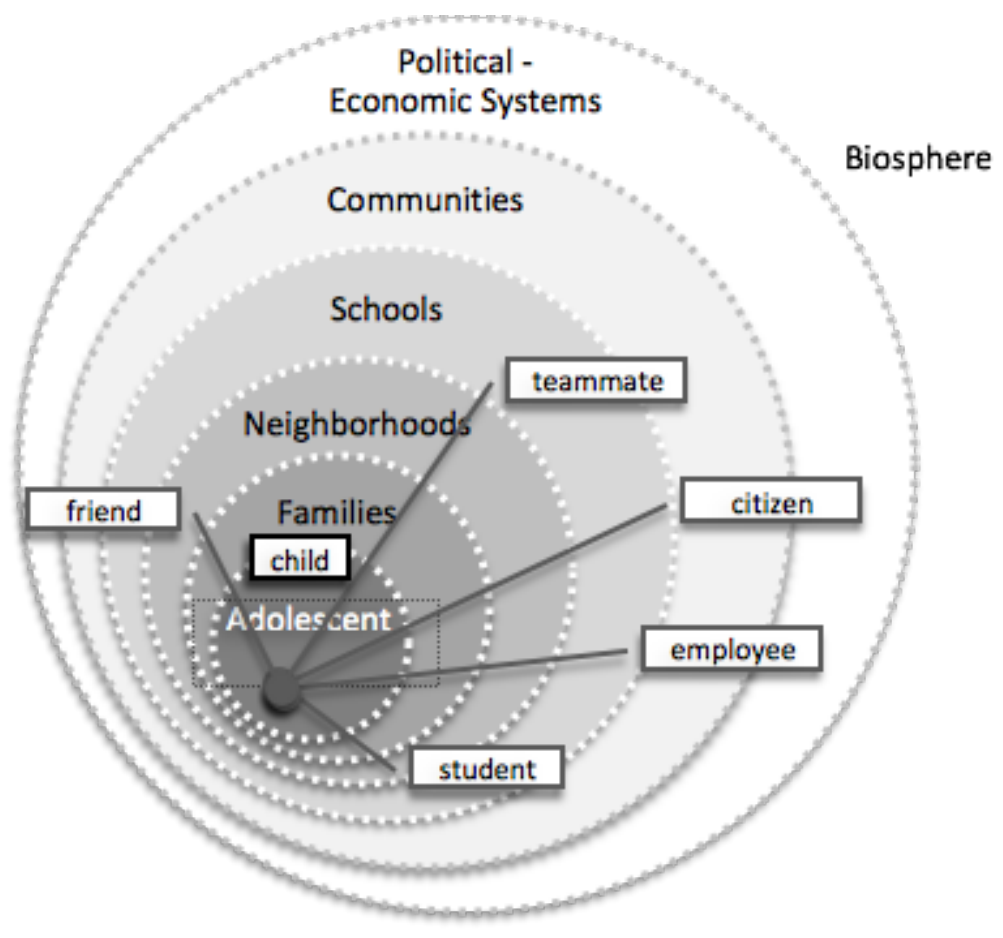

Figure 5. Ecological View of Adolescent Development

(Adapted from Brofenbrenner as cited in Steinberg, 2005, p.314) The adolescent is embedded in an increasingly complex web of reciprocal relationships shaping her identity.

Role ambiguity refers to a lack of clarity of shared role expectations (Hardy \& Conway, as cited in Brookes et al., 2007). In a school setting, this situation might arise as a student transitions from the expectations of middle school to those of high school. Role insufficiency is a condition in which the role performance does not match the role standard as perceived by the individual or significant others (2007). This situation is acted out daily as teachers manage student behavior. Finally, role conflict occurs when the identity standards of different roles are perceived as exclusive or incompatible (Burke, 2006). For an adolescent in high school this might occur as she attempts to integrate multiple role identities that include gender, peer, child, student, teammate and other roles. 
The significance of viewing the adolescent as a complex adaptive system embedded in an ecology of metasystems is that we can no longer adequately describe either the adolescent or the enveloping environment in isolation from each other (Nolfi, 2006). Considered holistically then, the negative perception of adolescent attitudes and behavior, the difficulties many adolescents manifest in school, the persistent view of adolescence as a problematic period (Steinberg \& Morris, 2001), must be reframed as symptoms of a systemic nature. Considered from a developmental perspective, the adolescent can be considered as carrying out the same impulse to act on the environment in order to develop and elaborate the accuracy and utility of their cognitive maps as younger children do. Considered further in the context of role identity acquisition, the adolescent is in an ongoing process of clarifying role standards and behavior and therefore integrating the self-subsystems consisting of multiple identity roles. This continuous cycle of learning should be an asset to adolescent success in schools and for schools - if appropriately engaged.

\section{Organizational Context of the School}

Schools include social systems composed of hierarchical networks of roles and relationships (Bould, 1956; Bandura, 2005). As designed abstract and social systems, schools have demonstrated remarkable stability over time. Resistance to change is embedded in strong allegiances to the status quo in such areas as: curricular goals, course offerings, student evaluations, the materials used in classrooms, and expectations for student performance and behavior (Cuban, 1993). Current policy efforts to create stronger couplings between national, state, district, and classroom levels are having, for 
perhaps the first time, a significant impact on school practices (Labaree, 2006). But it is the generally unspoken complex of norms, beliefs, and customs that compose school culture (Owen \& Valesky, 1995) that remains out of reach of reform efforts typically targeted at the functional level of schools (Cuban, 1993). Significantly, these often unexamined assumptions serve as dominant organizing principles defining the boundaries of appropriate student involvement. The ubiquitous enculturation of students into the system plays a significant, albeit unspoken, role in shaping their attitudes, habits and beliefs, composing the "hidden curriculum" that reinforces established norms, including relations of power and authority (Apple \& Beane 1995; Stone 2002; Jenks, 2004). This places limits on the roles students can take up within the educational system and on the opportunities to more fully engage it on their own terms. From a systems selfmaintenance standpoint this stability of schools may be unremarkable, but in relation to meeting the developmental needs of youth who collectively and rhetorically are posited to be their central concern, this intransigence might be seen as pathological.

How then are we to make sense of the student-centered organizing principles often enshrined in educational mission statements (Weiss \& Piderit, 1999)? Perhaps these organizing principles do not function as operational mandates, but rather as what Bolman and Deal (2003) refer to as organizational myths that provide cohesion, justification and comfort, as well as simplicity and ease of management. Such a primal myth as an organizing principle of educational ethos embedded within the role standard of school staff would make schools particularly resistant to change - especially changes which call into question the long established power relations between teacher and 
student. This may help to explain why, while educating students about power and politics in political systems, the most immediate manifestation of these dynamics - the school system itself, is rarely the focus of classroom investigation and discussion (see for example, The National Curriculum Standards for Social Studies, National Council for the Social Studies, 2010). That this is a reflexive, not a conscious omission, just further attests to the structural depth of this constraint.

And so, in the case of schools, their resiliency in the face of constant efforts to reform them can be understood by considering their history, structure and function. Beliefs and norms become institutionalized over time and become part of the internal structure as self-referential principles. Those invested in the status quo mutually reinforce these current beliefs, suppressing disconfirming points of view (Sterman, 2006). Reform efforts that focus on how schools function have little effect on these deep internal structures, as such attempts are interpreted and responded to within this generally unexamined framework of organizational principles. Eventually some such reforms may become internalized if they do not push the system too far into disequilibrium - otherwise they will be ignored, not unlike Piaget's notion of accommodation and assimilation, only operating at the metasystem level of the school as a designed abstract and social system. Current attempts to reform schools at the structural level are not unheard of - such as the Small Schools initiative mentioned earlier, or the creation of Site Councils made up of teachers, parents, classified staff and even students. Efforts such as these may be potentially more effective at catalyzing change, but are not exempt from the challenges of assimilation and accommodation. But for systemic change toward reinventing the 
student - teacher - school relationship, the deeply held norms, values, and beliefs that shape schools as social systems must be addressed (Parsons, 2007).

In this section role acquisition was described, first in the context of adolescent development and then within the organizational context of school. A model of the adolescent as a complex adaptive system engaged in an ongoing cycle of role elaboration within multiple contexts was presented. Some of the implicit and explicit principles around which schools are organized and the implications for informing student and teacher role standards were pointed out. It has been suggested that deeply held institutional beliefs, including the notion that schools are child-centered institutions designed to meet the needs of students, operate as organizing principles - systemic role standards, which paradoxically make them more resistant to change. Ironically, it may be that the students, if their voice and capacity for agency are encouraged and engaged, hold a key role in rejuvenating schools and concurrently liberating educators to more freely act on the belief that supporting student development truly is a primary operational function of schools.

In the next section the literature on student voice is reviewed to trace its historic development, examples of its application, justifications for its use, and the complexities regarding its implementation - all within a systems framework. In so doing, the attributes of the student role identity standard suggested in the literature will be elaborated.

\section{Student Voice}

The idea of student voice has a traceable history, beginning with early 20 th century notions of giving students an active role in schooling, and evolving into current 
conceptions that find justification in cognitive psychology, organizational dynamics, citizenship preparation, human rights, and critical pedagogy. During this development, applications of student voice have varied, from its origins in student-directed learning, through the authentic expression of self in the writing process, to current conceptions of student activism, adult partnership, and youth leadership. This trajectory of meaningful student involvement is summarized here.

Where does it come from? Past Inceptions. Current student voice work can be traced back to the child-centered theories of education reformists in the early 20th century that grew out of nineteenth century Romanticism (Reese, 2001; Hirsch as cited in Labaree, 2005). Reframing the student-teacher relationship, these early activists considered it a core tenet that the child play an active role in the learning process with the teacher acting as guide, not master (Reese, 2001, p. 23). From this beginning the dominant features of modern progressive education eventually took shape: utilizing a constructivist approach that supports discovery and self-directed learning; basing instruction on the needs, interests and developmental stage of the child; promoting values of community, cooperation, tolerance, justice and democratic equality (Labaree, 2005).

However, while the rhetoric of progressive pedagogy provided an ideology and language to describe teaching and learning and the roles of teacher and student, it had little lasting impact on actual educational practice (Labaree, 2005; Cuban, 1983).

In the 1960's and 1970's in response to the civil rights movement and in tandem with the anti-war movement, the idea that students had a right to participate as decisionmakers in their own education was introduced. This generated some ongoing changes on 
college campuses - such as student representation and evaluation of teachers, but like the progressive ideology that embraced it, it had little influence on policies and practices at the elementary or secondary level (Levin, 2000). By the early 1980's talk of students' rights and progressive pedagogy became subdued as the narrative of education reform swung toward the more conservative values of standards and accountability in response to the 1983 report, A Nation at Risk (Labaree, 2006; Labaree, 1997).

Attention once again turned to the role of students in schooling in the 1990's as educators and social critics such as Kozol, Fullan, Rudduck and others raised questions about the absence of children's voices in discussions of teaching, learning and school improvement (Cook-Sather, 2006). Other researchers at the time espoused the value of supporting students in finding and developing their individual voices through the writing process (Commeyras, 1995; Dahl, 1995). Oldfather introduced the term "honored voice" to describe the process by which "the community of learners invites, listens to, responds to, and acts upon students' thoughts, feelings, interests, and needs" (Oldfather \& Dahl as cited in Garcia, Kilgore, Rodriguez \& Thomas, 1995, p. 138). Honoring students' voices became a key recommendation of position papers put out by the end of the decade by the American Youth Policy Forum (2000) and the Carnegie Council on Adolescent Development (Jackson \& Davis, 2000) who consider it a vital characteristic of developmentally appropriate practices for adolescents.

Current conceptions of student engagement as articulated by student voice advocates find their origin, definition and justification in multiple perspectives: cognitive psychology, organizational dynamics, citizenship preparation, human rights, and critical 
pedagogy (Lincoln, 1995; Lundy, 2007; Sands, Guzman, Stephens \& Boggs, 2007; Mitra \& Gross, 2009). Applying a systems approach, these conceptions of student voice will be located within the hierarchies of influential systems in which student identity is enveloped. In the process, key characteristics of the student role identity will be clarified. What does it mean? Definitions. The term "student voice" has emerged "to signal a range of efforts that strive to redefine the role of students in educational research and reform" (Cook-Sather 2006 p. 360). "Voice is a metaphor for active student participation in the development and the study of approaches to teaching, learning, and education" through which students partner with adults to make education mutually engaging (Cook-Sather as cited in Bryn Mawr Now, 2011, p. 1). From the perspective of critical pedagogy, voice imparts to students an active role as coauthors with adults in the social production of meaning (Lensmire, 1998).

The term "youth-adult partnership" (YAP) is sometimes used in the research to refer to the redefined student-teacher role that is central to student voice initiatives. Youth-adult partnerships are those in which both youth and adults learn from one another, collaborate in decision-making processes, and work together to effect change (Mitra \& Gross 2009). In the context of education, Fletcher, founder of SoundOut - a student voice advocacy organization, uses the expression "meaningful student involvement" to refer to the actions implied by youth-adult partnerships and student voice work (Fletcher, 2003).

For the purposes of this research I used Fielding 's (2004b) conception of student voice as covering "a range of activities that encourage reflection, discussion, dialogue and 
action on matters that primarily concern students, but also, by implication, the school staff and the communities they serve" (p. 199, italics added).

Student voice applications involve student identity roles that are fundamentally different than traditional student leadership roles such as planning dances, spirit assemblies and fund raising events (Mitra \& Gross, 2009). In its most profound and radical form, student voice "calls for a cultural shift that opens spaces and minds not only to the sound but also to the presence and power of students" (Cook-Sather, 2006, p.363).

What does it look like? Current Topography. The application of student voice reflects a range of reform objectives, strategies and actions (Mitra \& Kirshner, 2011). Mitra and Gross (2009) created a pyramid typology of student voice applications that recognizes three levels of youth engagement: Being heard, Collaborating with adults, and Building capacity for leadership. See Figure 6.

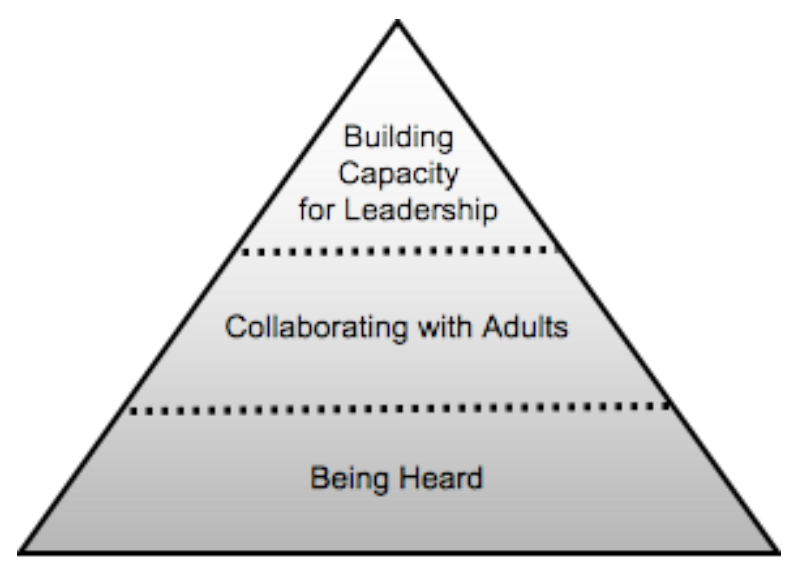

Figure 6. Pyramid of Student Voice (From Mitra and Gross, 2009, p. 523) Reprinted with permission.

The most basic and common of the student voice applications - "being heard" is located at the bottom. At this level students are sought out as sources of information and 
feedback to various scales of educational systems. My review of sixty research studies involving student voice published in peer-viewed journals between 1999 and 2012 revealed that over $70 \%$ used student voice as an information source to evaluate everything from student and teacher performance (Kinchin, 2004; Flutter, 2007; O'Connell Schmakel, 2008), to school curriculum (Wright, 2008; Countryman, 2009), programs (Morgan \& Streb, 2001; Jenkins \& Nelson, 2005) and culture (Doyle \& Feldman, 2006; Rodriguez, 2008). The studies utilized a range of approaches to elicit student perspectives, including surveys (Crick, McCombs, Haddon, Broadfoot \& Tew, 2007; Dillon, 2010), structured or semi-structured interviews (Brooker \& Macdonald, 1999; McIntyre, Pedder \& Rudduck, 2009), as well as other methods, such as engaging students as researchers (Symonds, 2008; Mitra, 2009).

The High School Survey of Student Engagement (HSSE) is one example of a survey instrument that has been in use for several years (Yazzie-Mintz, 2007). It provides both cross-sectional "snapshots" and longitudinal data of ongoing trends in student attitudes with regard to their experiences in participating schools. The HSSE uses a variety of close-ended multiple choice and Likert-scale type questions to explore student engagement and what students themselves say and believe about their school community. Results from the 2006 survey, administered to 81,499 students from 110 schools in 26 states, found that over half of the respondents did not feel they were an important part of their school communities. Perhaps the most significant finding of the 2006 HSSE was in the responses to the single open-ended question on the survey. Most respondents challenged the value of the study since they felt that nothing would be done 
about the issues it raised to make things better for students. Project Director YazzieMintz concludes that there is an engagement gap and suggested future research focus on the nature of the gap and its possible connection to the achievement gap (2007).

Taking a more direct approach to soliciting student voice, the Grant Wood Area Education Agency - an education service district in Iowa, invited students to create short films about what they wanted from schools. The winner in the individual category challenged traditional grading practices, using her experience learning to swivel-ski to advocate for recognition that individuals learn at different rates. At the award ceremony, speaker Superintendent Sarah Pinion stated, "To truly transform our education system, we need everyone's help" (Hogan, 2011). Ironically, a review of Iowa's Blueprint for the Future of Education Reform does not reveal a single reference to student voice (Iowa Department of Education, 2011).

One of the ways that researchers and practitioners have sought to address the engagement gap is by involving students in collaborative efforts to identify and act on school issues (Burton, Smith \& Woods, 2010; Fletcher, 2004). This is represented in level two of the pyramid - Collaborating with adults. At this level, students partner with adults in school reform. Much of the current research on student voice involves this approach (Mitra \& Gross, 2009). Nearly one third of the research studies conducted since 2007 that I reviewed engaged students in the research as participants (Participatory Action Research - PAR) or initiators (Student Action Research - SAR).

A secondary school project carried out in Manitoba exemplifies the PAR/SAR approach. In the context of an English class and in collaboration with teachers and 
university researchers, students were asked to investigate what happens to secondary school graduates. Students defined their own research questions, gathered data, and analyzed it to draw their own conclusions (Levin, 2000). Involving students in such research reshapes the student-teacher relationship, making it more "explicitly and joyfully interdependent" as students and teachers learn from and with each other (Fielding, 2004a, p. 308).

Student participation in research is only one form of collaborating with adults in school reform efforts. Some of the earliest manifestations of student voice work began at the classroom level and continue to have application. Commeyras (1995), expressing a constructivist approach, suggests that student questions guide instruction. Applying a Socratic methodology of questioning that involves ever increasing "reflective, evaluative, and critical answers" can encourage student voices (Lincoln 1995, p. 89). More recently, Thiesen (2006) proposes that students employ negotiation and consultation to play an active role in shaping their learning experiences. Such democratic talk must be part of classroom practices if student voice is to be developed and maintained (Johnston \& Nichols, 1995).

Beyond the classroom, collaboration between youth and adults can occur at any level of educational systems (Fletcher, 2004). Students can participate on school and district committees (Levin, 2000; Schachter, 2010), in teacher education programs (Cook-Sather, 2007b; Thiesen, 2006) and on state commissions (Barton, 2008; Selby, 2011).

"Building capacity for leadership," located at the top of the pyramid of student 
voice, is the least common expression of meaningful student involvement. At this level, student agency and efficacy is enabled toward the critique and transformation of schools and communities (Mitra \& Gross, 2009). Mitra and Gross describe one such example. Youth at an alternative school for at-risk students in the San Francisco Bay area created a documentary over a two-year period entitled Take a Look Around. The video was completed in partnership with adults from a non-profit that had developed a stable relationship with the school over an extended period of twenty years. The student video recorded three critical issues the students identified in their community: the abundance of drugs and alcohol, the high rates of community violence, and the lack of grocery and retail stores. For the youth, the decision to make a video stemmed from a desire to depict their lives. According to one of the students involved, the purpose of the project was "to let everybody know that there's other ways to deal with situations than with violence. Speech is powerful too" (p. 529). On the other hand, the project sponsor wanted "to dispel the negative stereotypes of these teens and change them into activists. Because delinquents do make good activists" (p. 529). The documentary was shown at the high school, other schools in the district and at a community event.

While some organizations focus on social activism as a means to develop youth leadership capabilities, others take a more direct approach (Mitra \& Kirshner, 2011). In a Wisconsin high school, building student leadership capacity has been institutionalized. A Student Advisory Team (SAT) engages the student body in a program called Raising Student Voice and Participation. Through a series of class meetings, issues at the school that need improvement are identified. The SAT then develops action plans to address the 
issues (Anderson, 2011).

The characteristics of school programs and practices that support meaningful student involvement (Fletcher, 2008) as represented in levels two and three of the pyramid of student voice include:

1) A school-wide approach that embeds student voice in the ecology of the school rather than something limited to one specific activity carried out at one specific time.

2) High levels of student authority that move beyond just providing opportunities for students to be heard, toward validation and authorizing students to act.

3) Interrelated strategies that engage students in ongoing school improvement through a variety of access points and approaches at all levels of the system. 4) Sustainable structures of support that maintain meaningful student involvement and reach beyond the student body to include the community. 5) Personal commitment on the part of students and educators arising from internal motivations that are not coerced.

6) Strong learning connections which situate student involvement as a mechanism for personal and organizational learning.

Fletcher (2011) goes on to propose a model for evaluating levels of youth engagement based on Hart's "ladder of participation" which was first presented in 1992 as a model of youth participation toward citizenship (Shier, 2001). See Figure 7.

Hart considered the first three rungs as levels of non-participation where youth are 
powerless and uniformed, while authentic participation begins with "youth informed" at the fourth rung (Shier, 2001). Applied to the pyramid of student voice, activities involving "being heard" might occupy any level between 1 and 5 depending upon the intentions of adults, while "collaborating with adults" and "building capacity for leadership" demonstrate participation at levels 5 to 8 . Hart considered activities at rung 6 to be those directed by adults to which youth have been invited to participate as full equals, in contrast to rung 8 where youth invite adults to participate as partners in projects and activities which they have initiated. For example, Participatory Action Research (PAR) could occur at rung 6, while Student Action Research could occur at either rung 7, if adults were informed but not involved, or rung 8 if adults were invited to participate as consultants or co-researchers.

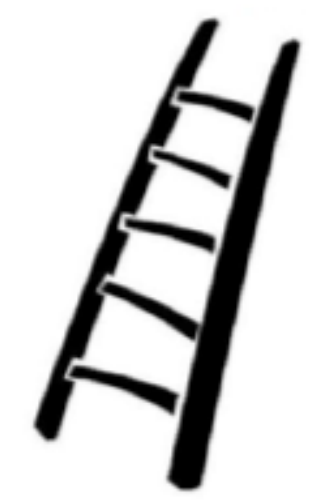

8. Youth-Adult Equity

7. Completely Youth-Driven

6. Youth-Adult Equality

5. Youth Consulted

4. Youth Informed

3. Tokenism

2. Decoration

1. Manipulation

Figure 7. Ladder of Student Voice (Adapted by Fletcher, 2011, from work by Hart et al., 1994) Reprinted with permission.

All higher forms of authentic student participation entail a redefinition of youthadult relationships and the spaces - both physical and conceptual - within which they coconstruct meaning (Fielding, 2007). They require relationships that recognize the agency of both youth and adults in community (Quicke, 2003) as they "communicate with and 
learn from one another" (Cook-Sather, 2006 p. 367). They necessitate a reframing of identity roles on the part of both youth and adults around issues of power and authority (Mitra, 2009; Schultz \& Oyler, 2006). They demand "a transformation of what it means to be a student; what it means to be a teacher" (Fielding, 2004a, p. 296).

Thus far in this section the historic development of student voice as an expression of progressive education and human rights has been traced. An expanded definition of its meanings, examples of its application, and significant implications for the redefinition of role identities for both students and teachers have been documented. Next, the justifications for implementing student voice are considered.

Why do it? Justifications. Student voice advocates find validation within a variety of domains, including psychology, organizational dynamics, citizenship preparation, human rights, and critical theory (Lincoln, 1995; Lundy 2007; Sands, Guzman, Stephens \& Boggs, 2007; Mitra \& Gross, 2009). Considered from a systemic perspective, we can locate these domains within a network of relationships centering on the adolescent as a complex adaptive system, and extending outward to the various spheres of influence within which her identity and roles are co-created. See Figure 8.

The rationales for promoting student voice work are bounded by the limits of the systemic relationships that generate youth roles. These systemic relationships likewise carry implications for the roles students might play in schools.

Psychological Development. Much of what takes place in the classroom can be described in terms of student engagement. To enhance learning, one must first engage the students (Newmann, 1992). Current reform efforts, enacted with little or no 
involvement on the part of students, offer dubious hope for increasing student engagement (Mitra \& Gross 2009). On the other hand, authentic student voice activities are by their nature conceived and implemented as acts of expanded involvement intended to increase engagement.

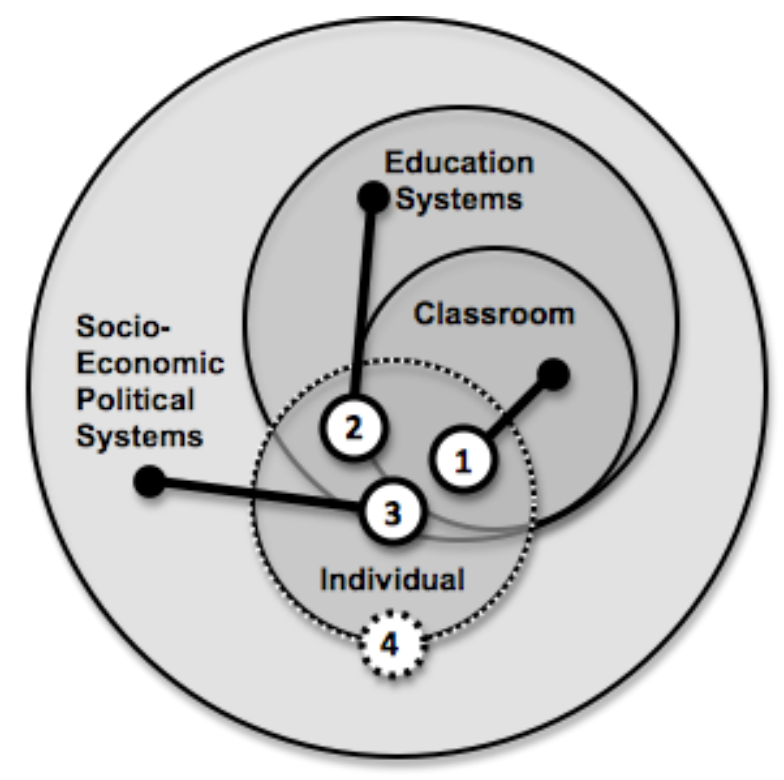

Figure 8. Justification for Student Voice Viewed Systemically

1. Psychological Development

2. Organizational Feedback

3. Citizenship Preparation / Human Rights

4. Critical Theory / Critical Pedagogy

Fredricks, Blumenfeld, and Paris (2004) propose a model of school engagement as a "multi-dimensional construct" involving a combination of behavioral engagement, emotional engagement and cognitive engagement (as cited in Wang \& Eccles, 2011, p. 31). Behavioral engagement is demonstrated by positive and purposeful participation in learning activities. Emotional engagement is experienced through the affective response of belonging to, and identifying with, school. Cognitive engagement refers to a self- 
regulated approach to learning and the use of meta-cognitive strategies such as those advocated by constructivist approaches. All three are recognized as supporting adolescent developmental needs for competency, autonomy, and relatedness (Fredricks et al., 2004, as cited in Wang \& Eccles, 2011) that in turn have been found to be necessary to support student motivation and academic success in school (Mitra, 2004).

Additionally, all three support the student voice model of meaningful student involvement.

Behavioral engagement. The increased participation advocated by student voice requires a more active student presence in the classroom. Teachers cannot be the only ones defining these moments. By definition, purposeful participation suggests a student engaged in managing her own learning. This will in turn raise student questions about curriculum and instruction. Inevitably, students will want a voice in the what, when, where and how of learning (Levin, 2000) - precisely as student voice advocates would have it.

Emotional engagement. At its heart, student voice work is relational - both through its focus on the renegotiation of student-teacher/student-organizational roles, and in its acknowledgement of the integrity of the person. The transformative potential of voice is realized through mutual dialogue, simultaneously supporting a person-centered focus often lacking in the technocratic approaches that can subjugate student needs to the needs of the educational system (Crick et al., 2007). The key is to "bring the system back into balance" by refocusing on the needs of all the people in the system (McCombs, 2003, as cited in Crick et al, 2007, p. 270) and by making students "an integral part of the 
conversation about learning, school culture, and the relevance of school to their lives" (Thiessen, 2006, p. 352). Before a student can choose to engage in learning, she must have a sense of membership in, ownership of, and the value of - the school experience (Angus, 2006).

Cognitive engagement. Student voice grew out of a child-centered progressive movement advocating a constructivist approach to teaching and learning. Reform efforts to raise academic achievement continue to recognize the value of constructivist approaches (Levin, 2000). The central principle of constructivist practice is that learning involves an active process of meaning-making. Knowledge and understanding are not transmitted to passive students, but rather constructed by students actively participating in the process. Cook-Sather (2006) declares that student voice should "build on...centuryold constructivist approaches to education" (p. 365).

And so the student voice agenda supports and is supported by a constructivist approach to curriculum and instruction. Benefits of this kind of meaningful involvement in learning include increases in youth efficacy, agency, belonging, knowledge and competence (Osberg, Pope, \& Galloway, 2006; Mitra, 2009). Field and Braggs (as cited in Noyes, 2005) expand this list of positive youth outcomes to include: developing inquiring minds and learning new skills, reflecting on their own learning, developing social competences and new relationships; and a chance to be active and creative.

Engagement for learning. Schooling is essentially about learning. Psychological perspectives, constructivist learning theory, self-determination theory, and motivation theory all support active student engagement in learning (Sands et al., 2007). "This 
process enables youth to meet their own developmental needs and will strengthen student ownership of the change process" (Mitra \& Kirshner, 2011, p.1). Likewise, student motivation is promoted by meeting developmental needs through meaningful tasks with an appropriate level of autonomy in a setting that provides challenge, support, and respect (Levin, 2000).

In relation to this positioning of meaningful student involvement within the boundaries of psychology, Levin (2000) reminds us that "teachers are not the producers of learning; in the end it is students who must do the learning," reinforcing the idea that school improvement is contingent upon giving learners a greater voice in shaping their learning experiences (p. 162). This echoes Cook-Sather's (2006) assertion of "the centrality of respect for students as knowers and actors" (p. 367). Engaging students as equals is fundamental to this process. "Partnership fosters ownership; ownership sparks motivation; motivation drives learning," declares Beattie (p. 158, 2012). Fielding (2006) adds a moral imperative in the realignment of student and teacher roles and curriculum demanded of student voice work. "The functional ways in which we work together in schools to achieve personal, communal and educational ends should be transformed by the moral and interpersonal character of what we are trying to do" (p. 301).

And what are we trying to do? In this section student voice was justified within a psychology frame in support of engagement and constructivist learning theory. Next, organizational dynamics provide further backing for a student voice agenda.

Organizational Dynamics. The challenges facing school reform efforts to increase student performance and engagement are well documented (Levin, 2000; Smyth, 
2006a; Yassie-Mintz, 2007; Lundy 2007; Sands, Guzman, Stephens \& Boggs, 2007;

Fletcher, 2004). However, in the United States, purposefully including students in the process of reform is rarely considered (Cook-Sather, 2006; Levin, 2000). This represents a glaring oversight if for no other reason than that from a systems perspective, the student experience of schooling - outside of the achievement scores, graduation rates and other data captured on school "report cards" - remains a reservoir of underutilized information on the impacts of school practices (Lincoln, 1995) limiting the insights of both educators and students (Levin, 2000). If reform efforts are to succeed for the benefit of students and schools, establishing systems for soliciting and acting on student feedback is essential (Authentic Education, 2011; Sands et al., 2007). "As a nation, we've wasted what students know about their own classroom experiences instead of using that knowledge to inform school reform efforts" (Ferguson as cited in Dillon, 2010). Levin (2000) suggests that schooling itself become a part of the curriculum, engaging students in gathering data, conducting surveys, debating options, and considering alternatives. Students can evaluate lessons, curriculum, assessment and school processes, providing insight on how to enhance them (Fletcher, 2003). Students are capable of recognizing effective teaching (Dillon, 2010) and the organizational conditions that impact their motivation to learn (Ruddock \& Flutter, 2004: Mitra \& Gross 2009). And student feedback has been found to motivate teachers to take corrective action when information from external research and settings failed to do so (Levin, 2000). "If we are truly interested in understanding what supports or detracts from students putting forth more effort, becoming more engaged in learning experiences, and 
achieving at higher levels, then it only makes sense that we would include them in our inquiry" (Sands et al., 2007, p. 326).

The fact that students lack professionalized knowledge about educational structures and processes should not undermine the legitimacy and value of their experiences, opinions and ideas. On the contrary, this lack of formal enculturation into the business of schooling has the potential to provide fresh perspective and insight into the education process and holds great transformative potential (Rudduck \& Flutter, 2004). "Partnering with students to identify school problems and possible solutions reminds teachers and administrators that students possess unique knowledge and perspectives about their schools that adults cannot fully replicate" (Mitra, 2006 p. 315). In this context, learning and meaning making result as students and adults work together to reframe student participation in school reform (Mitra, 2004).

Levin (2000) summarizes the arguments for greater student participation in education reform as follows:

1. Effective implementation of change requires participation by and buy-in from all those involved, students no less than teachers;

2. Students have unique knowledge and perspectives that can make reform efforts more successful and improve their implementation;

3. Students' views can help mobilize staff and parent opinion in favor of meaningful reform;

4. Constructivist learning, which is increasingly important to high standards reforms, requires a more active student role in schooling;

5. Students are the producers of school outcomes, so their involvement is fundamental to all improvement (p. 156).

Ultimately, effective institutional change around fostering student voice will come down to the specific settings in which students speak and act, and are either listened to or 
ignored. Currently, the common practice in schools is that teachers and administrators, however well intentioned, use their authority to define the boundaries of student roles (von Wright, 2006). There are limits to the efficacy of policy changes to address these institutional barriers. From a systems perspective, Parsons (2007) suggests that significant change is more likely to come from "creative self-organizing" rather than from planned change (p.3). Stone (2002) likewise articulates the limits of rational policy making to achieve intended objectives. This is particularly applicable to the issue of student voice and underlines Freire's recognition of the ultimate impossibility of those with authority and power "liberating" the disenfranchised (Freire, 2003). "To effect change, a social system or organization must be able to make intentional changes in fairly stable aspects of the system and, at the same time, support a zone of activity that is farfrom-equilibrium. In these far-from-equilibrium areas, the subsystems self-organize in creative ways guided by their own learning rather than by predetermined plans or outcomes" (Parsons, 2007, p. 407). What "support zone of activity" might be created in schools and serve as seeds for self-emergent transformation?

Durlak (2007) suggests that meaningful youth engagement could be an overlooked resource to incite systemic change. Beyond using students as passive sources of data about the effects of school policies, practices and procedures, qualitative research approaches, particularly Student Action Research and Participatory Action Research, have the potential to go beyond merely generating data to inform policy, to becoming transformative instruments of policy in and of themselves. These practices have the potential to reshape the relationship between teachers and students, acknowledge and 
support the developmental needs of adolescents, and at the same time develop the agency, competence and sense of belonging of both. "The vital element in this model is the move from reform as being by adults for students to reform by students as well as by adults" (Smith et al., as cited in Levin, 2000, p. 167).

Citizenship Preparation. Another way to justify the importance of increasing meaningful student involvement in the organizational system of schools is to consider it in the context of the adolescent's development toward full citizenship. What are the responsibilities of citizenship? How well are students currently prepared to assume those responsibilities?

According to Kyle and Jenks (2002), while there may be little agreement among educational and democratic theorists about fundamental democratic values and principles, there is a consensus that meaningful participation and freedom be included. Although defining what it means to be free in a democratic society may be difficult, describing participation is less problematic. For their part, Torney-Purta, Lehmann, \& Schulz (2004) describe four basic types of democratic participation: 1) Informed Voting, defined as the expectation that one will vote in national elections and will gain information about candidates before voting; 2) Conventional Participation, defined as the expectation that one will write a letter about a political issue or join a political party; 3) Volunteer/Charity Participation, defined as the expectation that one will volunteer in the community or collect money for a charity or social cause; 4) Activist Participation, defined as the expectation that one will participate in a protest march or collect signatures for a petition.

From a systems perspective, these could be considered as forming a hierarchy of 
increasing levels of engagement with voting as the fundamental mode of political involvement, followed by conventional, volunteer and finally activist participation. This systematizing suggests the increase in personal investment required to move from voting, to political activism, and reflects the resulting tighter couplings between the individual and the greater sociopolitical system. It also suggests the amplification of personal voice as one moves from voting for a political representative of her personal values and beliefs, toward direct expression of those values and beliefs.

The statistics on the most basic level of civic involvement, voting, paint a picture of youth disengagement. Despite the relatively higher voter turnout in the past two presidential elections, a longitudinal review of voting statistics for 18-24 year olds from 1972-2004 in both presidential and midterm elections reveals what some researchers refer to as "dismal" levels of electoral participation (Pasek, Feldman, Romer \& Jamieson, 2008, p. 26).

The fact that 18-24 year old citizens have the lowest voting rates, compared to the other demographic groups represented is not surprising. Plutzer (2002) proposes a developmental model of voter engagement. Connections with the larger political system during this period are weak. Citizens in this age group are more transient than their elders. Few have the constraints of marriage, a mortgage, and a career that would tend to create tighter couplings with the greater sociopolitical community and add value to election participation. Nor have they yet had time to build a self-reinforcing history of political engagement. Participation expands as one explores and gains more knowledge and experience in the sociopolitical environment. As more information and experience is 
gained from this environment, opportunities for other forms of participation and political activism are realized. Following this argument, we would expect to see increased levels of participation as the population ages or from segments of the population that are more highly educated, which is exactly what the research reveals (Center for Information and Research on Civic Learning and Engagement (CIRCLE), 2010). The entire process seems natural and somewhat inevitable - just another emergent system developing utility in response to expanding relationships with its environment.

Then how do we make sense of the voting statistics of the 30 and older segment whose participation ranges from $69.5 \%$ in 1972 to $67.0 \%$ in 2008 in presidential elections, but from only $54.0 \%$ in 1974 to $51.4 \%$ in 2010 in midterm elections (CIRCLE, 2010)? What combination of social and/ or cultural capital deficits might explain a situation in which almost half the post-adolescent population chooses not to engage in the minimum expression of citizen participation? We must at least consider the possibility that the habits of thinking and doing, the relevance of acquired knowledge, and the utility of cognitive "maps", developed through the common experience of public education, all play a role in citizens choosing not to have their voices heard.

Morgan and Streb (2001) in their evaluation of the declining voter turnout suggest that Americans are intolerant, lack trust in their government, and "do not believe that they can effect change" (p. 154). They describe two theoretical models on political learning to help explain how adults develop their political attitudes and behaviors. The Primacy Principle maintains that political attitudes are developed early on and remain relatively consistent throughout life. The Structuring Principle explains this persistence of political 
orientation as new information is "processed and filtered through the political schema that was established as a young adult" (p. 155). They conclude "if young people do not become involved in their community in their youth, they are more likely to remain detached when they are adults" (p. 156). Likewise, Bandura (2005) suggests that the sense of efficacy youth develop early in life has significant outcomes regarding later engagement with the political system.

In their report on the Civic Mission of Schools (Carnegie Corporation of New York and CIRCLE, 2003) the Center for Information and Research on Civic Learning and Engagement has suggested that policy makers "encourage schools to experiment with forms of pedagogy and management that exemplify democracy " and are "reflected in the way a school operates, how it is organized, and how students and staff interact" (p. 31). The report goes on to suggest that increasing student voice is central to this process. Warwick proposes that "Citizenship Education and student voice have much in common" (2008, p. 332). The skills and habits of engagement implicit in enabling student voice support the development of personal power that Bragg (2007) sees as fundamental to effective participation in liberal western democracies.

And yet while it may be accepted that a primary goal of public education is to prepare youth for productive citizenship, "students rarely get to practice political participation as part of the normal school curriculum" (Schultz \& Oyler, 2006, p. 425). Indeed, despite the importance of developing the skills of political participation (Levin, 2000), schools tend to reinforce a passive model of engagement rather than agency (Mitra \& Gross, 2009). Additionally, the current focus on student outcomes and accountability 
have led to a decline in civic education (NCSS, 2010; McMurrer, 2007; Carnegie Corporation of New York and CIRCLE, 2003) and, according to Mitra and Gross (2009), weakened the democratic mission of schools.

In contrast, increasing student voice "promotes the underlying social and political goals we hold as a society" (Sands et al., 2007, p. 337). Involving students in the decisions that affect their lives in school reinforces the belief that political systems are "responsive and influenceable" (Bandura, 2005, p.30). Research supports the idea that such meaningful involvement during adolescence increases the likelihood of participation in organizations and the political process later in life (Verba et al., as cited in Morgan \& Streb, 2001). Lincoln (1995) reinforces the location of both the problem of preparation for citizenship and the solution within the system of public schools:

We are beginning to understand that the support of a democratic, just, and economically viable and prosperous society requires active participation and critical thinking skills far beyond what many of our students experience in school. The "laboratory" where such skills are learned or not learned is the largest public social institution remaining in the United States: the public schools. Exercising "voice" in public affairs or the normal duties of citizenship requires that individuals have found their voices (p. 89).

Human Rights. But do youth have a "right" to have their voices heard and acted upon? That adolescents in western democracies demonstrate a developmental need for increased autonomy is well documented (Mitra, 2004; Eccles \& Roeser, 2011). Student voice advocates Johnston and Nichols, after noting earlier research connecting school practices that disempower students with student disengagement, go on to assert that "most students yearn to have a voice in their own schooling, to be free and to construct 
their own vibrant lives in school" (1995, p. 94). When schools and teachers suppress student voices for the sake of compliance "they repress student engagement and create only a single knowledge, allow only one voice" (Apple \& Beane, as cited in Sands et al., 2007, p. 326). Such assertions, which are ubiquitous in the student voice literature, represent expressions of what Stone (2002) refers to as "normative rights." Normative rights are those that derive their legitimacy from morality, rationality or natural law. "Life, liberty and the pursuit of happiness" are examples of normative rights derived from natural law.

Declarations of youth rights to voice are often framed "within the discourse of human rights" (Bragg, 2007, p. 344). Advocates of positioning student voice as a rights issue often contextualize it within a narrative of civil rights and democratic freedoms (Cook-Sather, 2006; Bragg, 2007; Fielding, 2004b; Mitra \& Gross, 2009). "One might argue, for instance, that attention to the voices of children and teenagers is reflective of a long evolution in the extension of civil rights in this country, a social and legal context issue" (Lincoln, 1995, p. 88). Cook-Sather notes the convergence of arguments around voice as a right of membership in a democratic society and declares that student voice work "acknowledges and argues for students' rights as active participants - as citizens - in school and beyond it" (2006, p. 366).

Locating student voice work within a democratic citizenship framework moves the issue from one of "normative rights" to what Stone (2002) refers to as "positive rights." Positive rights are those encoded in policies and laws and backed by the power of the state (p. 326). 
The systemic marginalization of youth has been addressed through numerous policy actions targeting various levels of the systems within which youth are embedded and are aimed at expanding youth roles and responsibilities. At a macro-level, the United Nations Convention on the Rights of the Child (UNCRC) declares that all children have the right to be heard in relation to decisions affecting them (von Wright, 2006) and represents the most significant policy action yet as it addresses the issue of children's rights on a global scale. The full text of Article 12 reads as follows (Lundy, 2007):

1. States Parties shall assure to the child who is capable of forming his or her own views the right to express those views freely in all matters affecting the child, the views of the child being given due weight in accordance with the age and maturity of the child.

2. For this purpose, the child shall in particular be provided the opportunity to be heard in any judicial and administrative proceedings affecting the child, the views of the child being given due weight in accordance with the age and maturity of the child.

The UNCRC that was passed in 1989, and ratified by all UN members except the United States and Somalia, has created a legal mandate that has generated an increased focus on using student perspectives to inform policy at all levels of society including educational practice. Systemic efforts to promote student engagement and voice can be found in many countries, including England, Australia, and Canada (Cook-Sather, 2007b). The UK has been particularly active in its response, producing literature on student voice, developing students as researchers, and legislating school structures for consulting pupils (Noyes, 2005; Lundy 2007). This is reflected in the publication of student voice literature. An examination of 179 peer-reviewed articles on student voice published between 1981 and 2012 revealed that over 50\% (n91) were generated by 
authors from UK countries, whereas $41 \%$ (n74) were published by US authors. "The reality is that the UK (along with every other established nation in the world bar one) has acknowledged that [youth voice] is a fundamental human right and has made a public commitment to ensuring compliance" (Lundy, 2007, p. 940).

Currently, in the United States there is no similar policy activity at the national level (Cook-Sather, 2006), leaving efforts to foster youth engagement and student voice to be conceived and enacted at state and local levels (Cook-Sather, 2007b).

For its part, the American Youth Policy Forum (2000) suggests an increase in youth voice and engagement from the national level down to the local:

Identify, strengthen, and if need be, create appropriate structures to ensure youth a voice in the creation of policies that impact upon them, and to ensure that they play a central role in implementing the changes called for. Reinforce expectations that youth will contribute to their schools, communities, state and nation, and create clear pathways for them to do so (Strategies to Redesign High Schools section).

And yet this and other declarations of the importance of systematizing student voice have had few broad policy impacts. The Raising Student Voice and Participation program by National Association of Student Councils and endorsed by the National Association of Secondary School Principals (National Association of Student Councils, 2012) is perhaps the only national initiative on student voice. The program involves school-wide summits facilitated by students to listen to and act on issues raised by the student body. However, the program operates within the traditional roles and structures of student leadership groups and school administrators are under no policy obligation to act on the issues raised. The only example of student voice work organized at a state level in the nation occurred in Washington state, which had an Office of Student 
Engagement at the Washington Office of Superintendent of Public Instruction (OSPI) from 2005 until 2007 when it was closed for lack of funding (Barton, 2008).

And so the United States remains on the sidelines of student voice work while other western democracies act on the recognized legal status of youth to have a voice in policies ranging from the local level to the national level (Lundy, 2007). Nevertheless, the call to increase meaningful youth involvement continues to be raised, and student voice continues to be framed as both a normative and legal right of youth (Cook-Sather, 2006; Bragg, 2007; Fielding, 2004b; Mitra \& Gross, 2009). As Arnot and Reay (2007) declared, "The history of egalitarianism points to the need to elicit and act upon pupil voice."

Critical Pedagogy. Critical theory approaches to student voice recognize its location within all the systemic relationships presented thus far: as an expression of identity, social position within organizations, as a right of participation, and as fundamental to a constructivist learning process.

Critical pedagogies see students as active participants in the construction of meaning rather than passive recipients of meanings determined and controlled by authoritative others (Sands et al., 2007). From the perspective of critical pedagogy, schools, as much as everyday life, must provide the skills and resources for students - and teachers - to find their voices, clarify their convictions, and act with civic courage (Freire \& Giroux, as cited in Orner, 1992). "A growing body of research increasingly indicates the effectiveness of schools that incorporate critical pedagogies" (Sands et al., 2007, p. 326). 
The concept of voice within critical pedagogies is a complex one. It is seen not as arising from a unitary "self," but rather as socially constructed and historically located "within an oppressive society that privileges the meanings, values, and stories of some over others" (Lensmire 1998, p. 270). These voices, though inherently incomplete and positional, requiring both affirmation and interrogation, are also fundamental to creating the relationships within which students and teachers can negotiate power and meaning (Freire \& Giroux, as cited in Sands et al., 2007).

Cook-Sather (2006) sees student voice as an expression of critical pedagogy's commitment "to redistribute power not only within the classroom, between teachers and students, but also in society at large" (p. 365). Indeed, Cook-Sather goes on to declare that student voice work is rooted in addressing the imbalances of power between youth and adults with the outcome of enabling students and teachers to "communicate with and learn from one another" (p. 367). Such agentic relationships offer the possibility of "producing a community in which everyone is a participant and everyone is empowered" (Quicke, 2003, p. 52).

Lensmire (1998) adds further clarification to the role of voice within critical pedagogies by declaring that enabling voice is not so much a goal, as it is a vital precondition providing resources and material for the collective work of the classroom community. Within this community, student voices "make available a multiplicity of texts that can be examined, learned from and criticized" (p. 269).

Like critical pedagogy, student voice work "supports the interrogation by the oppressed of their own experiences and sees this interrogation as the means by which to 
come to an understanding of their power as knowers and creators of their own world and, in turn, as potential transformers of their world" (Cook-Sather, 2007a, p. 395). Also, like critical pedagogy, student voice work is founded on a response to the marginalization of particular groups - in this case, students - due to "the traditional exclusion of young people from dialogue and decision-making about issues of schooling" (p. 390).

It is the recognition of and reaction to this exclusion that lies at the heart of this study and has informed the conceptual framework, research questions, literature review, research design and methodology.

Within the ecology of systems inside which students must construct meanings, negotiate identity, navigate power differentials, and make choices of participation, schools are "powerfully positioned to either constrain or nurture their engagement in learning" (Faircloth, 2012, p.187). Bragg (2007) reminds us that, "For years many educators argued in favor of student voice as part of a larger emancipatory project, hoping it would be transformative not just of individuals, but of the oppressive hierarchies within educational institutions and even in society" (p. 344).

Critical pedagogy, by consistently interrogating the complexity of systems within which youth are socially and culturally positioned, and with its insistence on the centrality of voice while simultaneously critiquing it, provides the most systemic justification for student voice work. At the same time, this dynamic and situated conception of student identity cautions against any oversimplification of role identity and reinforces the absolute need to "listen closely" to what students have to say (Cook-Sather, 2006, p. 367). 
This section provided a justification for student voice from a variety of domains within a systems framework. Critical theory emerged as an inclusive approach because it positioned identify as a relational construct at the intersection of all the enveloping systems. This critical conceptualization of voice in particular raised the issue of the complexities that arise from a systemic interrogation of student identity and student voice. In the final section these complexities are further explored.

What complicates it? Polyphony and Positionality. The concept of student voice, efforts to engage it, and investigations researching it, are complicated by several factors: the assumptions informing the voice discourse, the complexities of identity and positionality shaping voice, and the appropriation of student voice work within existing power structures. Many of the claims surrounding student voice are too often uncritically embraced (Bragg, 2007; Orner, 1992).

The risk is in assuming a normative status for student voice and the values it projects. For example, increasing student "agency" is presented as a justification and desirable benefit of meaningful student involvement, but Bandura (2001) informs us that, "Personal control is neither an inherent drive nor universally desired" (p. 13). Does that remove its relevancy as a motivating factor in student voice work? No. The value of agency remains valid when it is positioned within the historical-cultural context of modern western societies that conceptualize identity as autonomous and individualistic.

Other researchers have questioned the binary conception of "sharing power" and "empowering students" that are central to the student voice narrative and argue for replacing it with a more nuanced and systemic concept of power as pervasive, complex 
and contextual (Taylor \& Robinson, 2009). The concern is that binary conceptions of power, as well as binary conceptions of identity ("student" and "teacher") may reinforce the very social conditions and hierarchies of power and domination student voice is meant to challenge (Orner, 1992; Fielding, 2006; Bragg, 2007; Cook-Sather, 2007a; Arnot \& Reay, 2007). Some have raised doubts about even the possibility of giving students an authentic voice within the managerialist institution of schooling (Moran \& Murphy, 2012).

The very expression "student voice" has been criticized for suggesting a collective student experience and identity that simply does not exist (Cook-Sather, 2007a). Unlike the assumption of a "unitary, unfettered individual self" implied in the application of voice in writing, the social "self" is transient and contextual, "created out of the cultural resources at hand" (Lensmire, 1998, p. 267). And just as there can be no single "student," there can be no single "student voice" (Cook-Sather, 2007a; Arnot \& Reay, 2007). As we attend to the plurality of student voices, Bernstein suggests we consider the "acoustic of the school" (as cited in Arnot \& Reay, 2007, p. 321), or perhaps more accurately, "the cacophony of competing voices" (Reay, as cited in Taylor \& Robinson, 2009, p. 170). Additionally, the expectation of "voice" may deny "the potential power of silence and resistance" (Cook-Sather, 2006, p. 369), further marginalizing students who may not find value in engaging in the student voice agenda (Cook-Sather, 2007a; Bragg, 2007).

The issues raised here are important, but do not derail the vision or value of student voice work. Rather, they challenge one to recognize, embrace and critically act 
on the complexities inherent in student voice and student identity. Considered systemically the issues raised are not surprising. Identity and voice arise as relational manifestations within an ecology of social, cultural, political, economic, and biological constructs and therefore represent a temporary convergence of psycho-social attributes unique to a specific historical time and place. While this lends caution regarding the research goal of generalizing student role characteristics in this study, it does not disavow it. Instead, as Cook-Sather advises, "issues of identity and voice are complex and cannot be addressed once and for all. Rather, in each new context and with each new group of participants, we need to revisit these complex issues and rethink why and how we conceptualize and enact student voice work" (2007, p. 396).

\section{Student Voice and the Student Role Identity Standard}

Despite the complexities of generalizing student role characteristics, particularly the possibility for diminishing the range of potential student behaviors, there remains value in identifying common attributes of meaningful student involvement for the purposes of evaluation and critique. A review of the student voice literature reveals a range of observations, assumptions and expectations regarding values and behaviors manifesting student voice principles. Themes identified in the research on meaningful student involvement were organized according to role attributes as described in role theory (Major 2003; Thomas \& Biddle as cited in Brookes, Davidson, Daly, and Halcomb, 2007). The results are summarized in Table 1.

The first set of student role attributes, "Characteristics," answers the question, "What is a student?" Themes in the student voice literature suggest that a student is an 


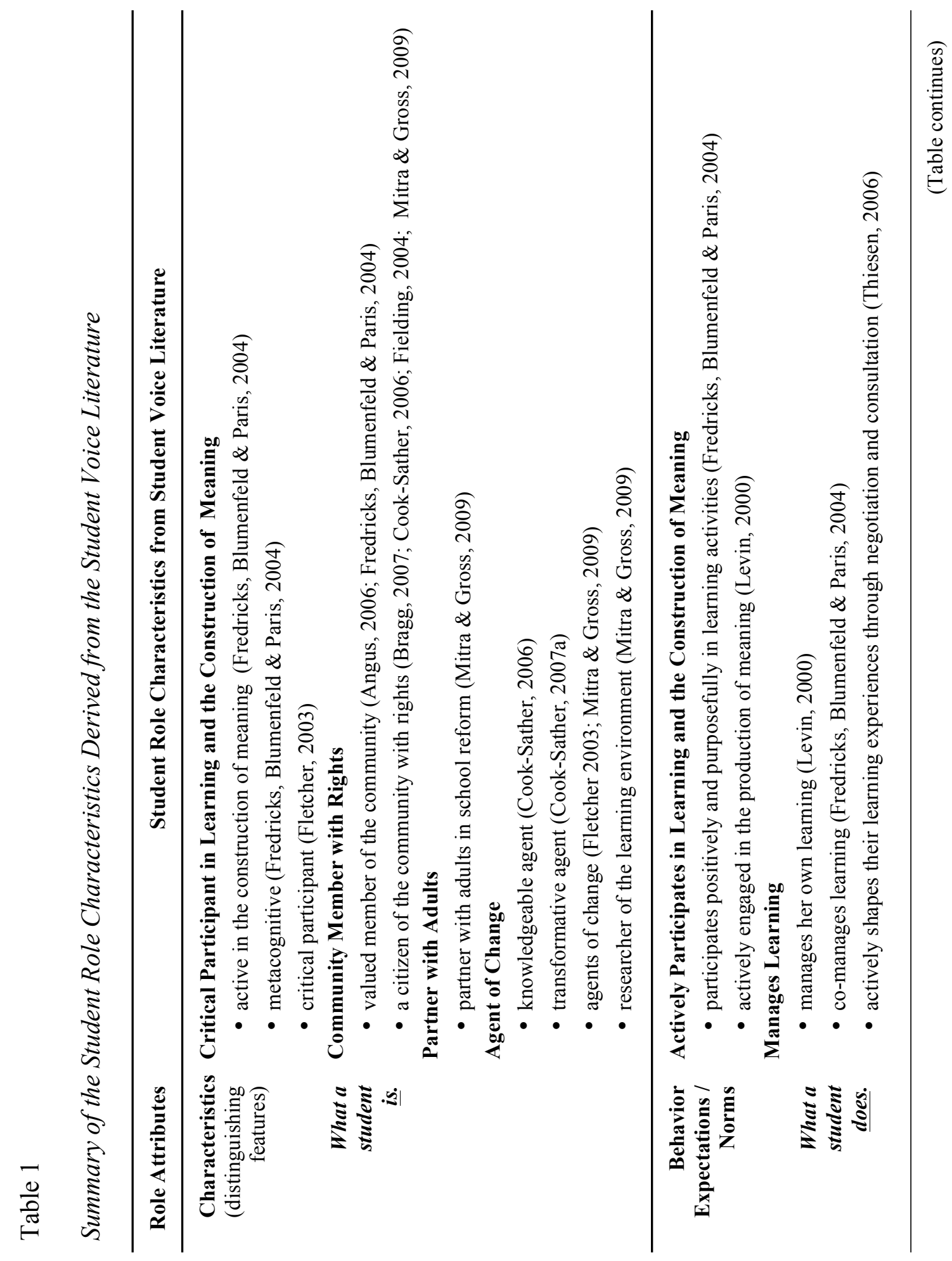




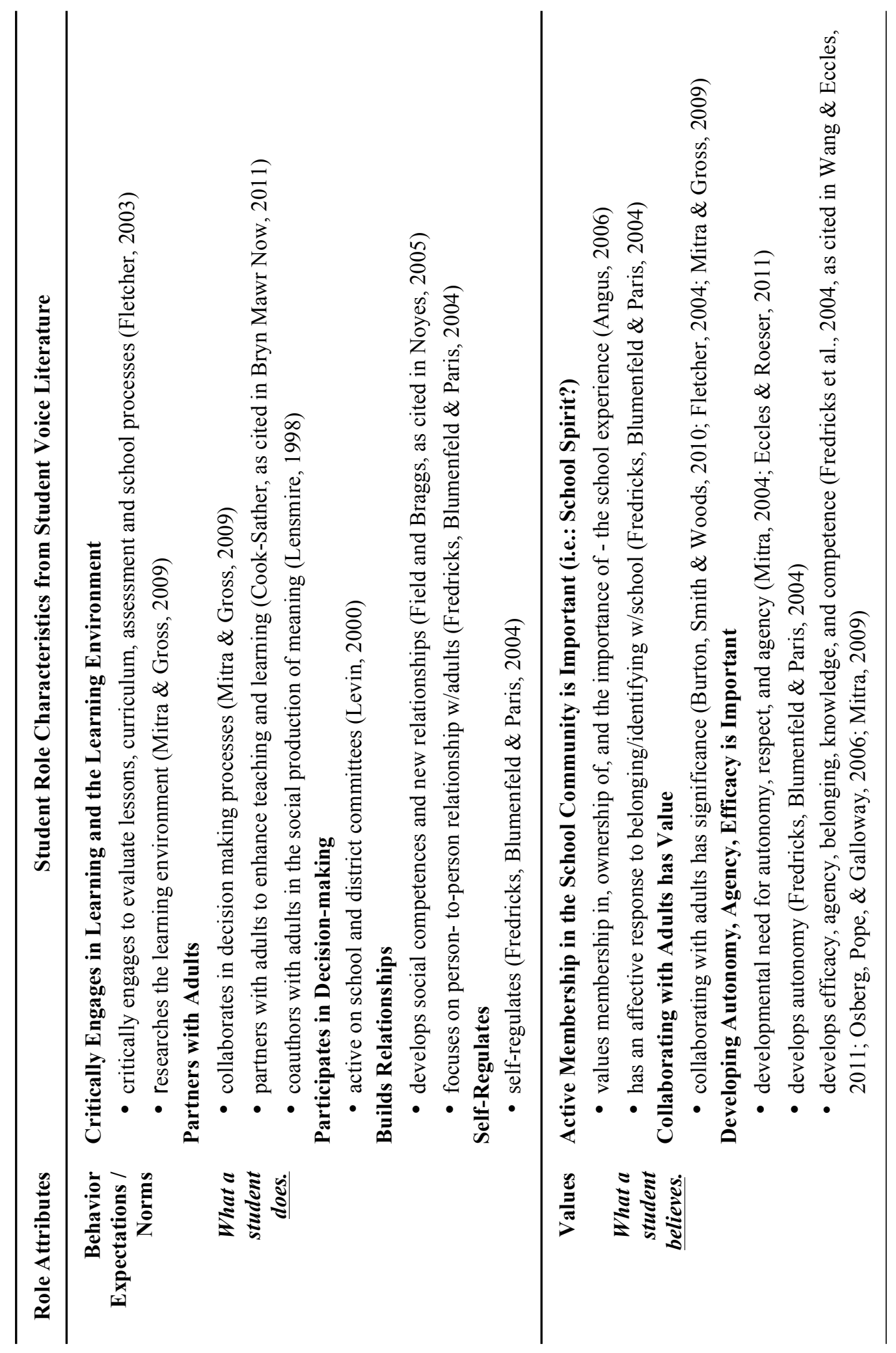


active participant in the learning process, employing critical awareness in the active construction of meaning (Fredricks, Blumenfeld \& Paris, 2004; Fletcher 2003). Such a student is a valued member of the school community with recognized and articulated rights (Angus, 2006; Bragg, 2007; Cook-Sather, 2006; Fielding, 2004; Fredricks, Blumenfeld \& Paris, 2004; Mitra \& Gross, 2009). She is also a partner with adults (Mitra \& Gross 2009) and a knowledgeable agent of change (Cook-Sather, 2006; Cook-Sather, 2007a; Mitra \& Gross, 2009).

The second set of student role attributes, "Behavior Expectations / Norms" answers the question, "What does a student $d o$ ?" Student voice themes associated with this attribute describe a student that is actively participating in and managing their learning (Fredricks, Blumenfeld \& Paris, 2004; Levin, 2000) through negotiation and consultation with other members of the school community, both students and adults (Thiesen, 2006). This active participation includes critically engaging in school to research, evaluate and transform the learning environment (Mitra \& Gross, 2009; Fletcher, 2003). In the process she is building relationships with adults (Field and Braggs as cited in Noyes, 2005; Fredricks, Blumenfeld \& Paris, 2004) and partnering with them to enhance teaching and learning (Mitra \& Gross, 2009; Cook-Sather, as cited in Bryn Mawr Now, 2011). In addition, she may join school and district committees to expand her participation and influence in the decision-making processes that affects her and the school community (Levin, 2000). Throughout she practices and develops self-regulating habits of thinking and doing (Fredricks, Blumenfeld \& Paris, 2004).

The final set of student role identity attributes, "Values," resolves the question, 
"What does a student believe?" The dominant themes from the student voice literature suggest that a student values a sense of belonging and active membership in the school community (Angus, 2006; Fredricks, Blumenfeld \& Paris, 2004), including collaborating with adults (Burton, Smith \& Woods, 2010; Fletcher, 2004; Mitra \& Gross, 2009). Developing autonomy, agency, and efficacy is also an important part of her school experience (Mitra, 2004; Eccles \& Roeser, 2011; Osberg, Pope \& Galloway, 2006; Mitra, 2009).

While this compilation of student role attributes derived from the student voice literature is not intended to be definitive or normative, it does provide a baseline for identifying and evaluating student characteristics, behaviors and attitudes applying student voice principles.

\section{Conclusion}

In this chapter a conceptual framework for investigating the problem of student identity was proposed that utilized systems thinking as a tool to explore the intersection of student role identity and student voice. Role theory was summarized and a model for role identity acquisition offered. Role identity acquisition was described as process of gradual correspondence between role as cultural object - a role standard, and role performance - the perceived meanings of one's behavior in specific situations. In addition, the development of role standard attributes was framed as demonstrating the systemic properties of structure, function and history as a subsystem of the "self". Role acquisition was then considered in relation to adolescent development and the organizational context of school. A model of the adolescent as a complex adaptive 
system engaged in an ongoing cycle of role elaboration within multiple contexts was articulated. Some of the implicit and explicit principles around which schools are organized and the implications for informing student and teacher role standards were pointed out.

Following this, the literature on student voice was reviewed to trace its historic development as an expression of progressive education and human rights. An expanded definition of student voice, examples of its application, and significant implications for the redefinition of role identities for both students and teachers were documented.

Next, justification for implementing student voice was considered from a variety of domains within a systems framework. Critical theory emerged as an inclusive approach that positioned identify as a relational construct at the intersection of all the enveloping and internal systems. Issues arising from a critical interrogation of student identity and student voice were briefly explored.

Finally, the characteristics of the student role identity standard derived from the student voice literature were articulated and presented as a conditional template for identifying and analyzing student attitudes and behaviors in the field that align with student voice principles.

In the next chapter I present a rationale for this study as a critical ethnographic participatory action research design consistent with a conceptual framework applying systems thinking to explore the intersection of student role identity and student voice. The research questions guiding the study and the procedures for data collection and analysis are articulated. Issues regarding participant protection, validity and limitations 
are also addressed. 


\section{Chapter III: Methodology}

The purpose of this study was to develop an understanding of how students and teachers conceptualize the student role within the organizational context of high school and to compare those constructs with each other and the student role identity standards derived from the student voice literature. See Figure 9. This chapter begins with a description of the research design and rationale for its application consistent with a conceptual framework that utilizes systems thinking as a tool to explore the intersection of student role identity and student voice within the context of enveloping systems of influence.

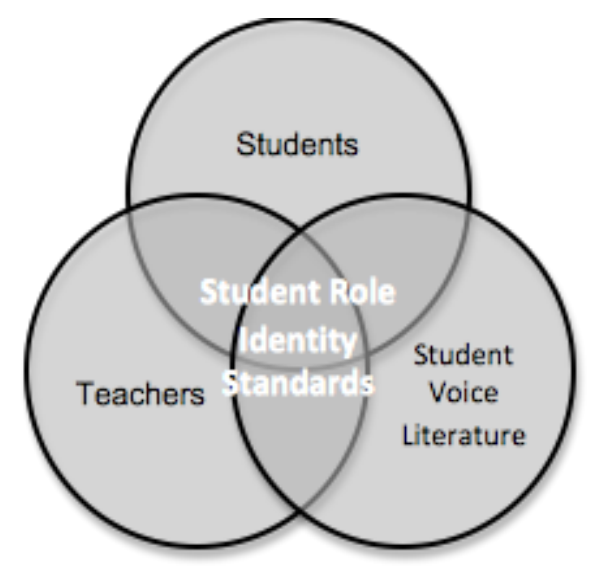

Figure 9. Student Role Identity Standards from Three Perspectives: Students, Teachers and the Student Voice Literature.

\section{Research Design}

This study applied critical ethnography in the context of participatory action research. Keeping with student voice values and participatory action research protocols, students played a vital role in developing and piloting survey questions, assisting in interpreting and organizing responses, and in reviewing and commenting on the 
analyses and conclusions. Engaging students as co-researchers, it employed a structured approach to understand how adolescents and teachers conceptualize the student role through the use of an online software platform called Thoughtstream. Thoughtstream provided a structured collaborative process that enables groups to share, organize and evaluate their responses to open-ended questions through an online environment.

\section{Rationale}

Ethnography is a qualitative research approach for "describing, analyzing and interpreting the shared and learned patterns of values, behaviors, beliefs, and language of 'culture sharing groups' " (Harris, 1968, as cited in Creswell, 2007, p. 68). This approach supported the goal of this inquiry which sought to understand the learned patterns of values, behaviors, and beliefs that comprise the student role identity standard for students and teachers in the context of a rural high school.

Historically, the application of ethnography in the research of role development theory has been preferred over the use of more empirical methodologies (Biddle, 1986; Collier \& Callero, 2005). More recently, Eccles and Roeser (2011), in their study of schools as contexts for adolescent development, concluded that ethnographic studies would continue to be an important inquiry approach in the field.

Examples of ethnographic methods are also found in the research on student voice. For example, Silva (2001) took an ethnographic approach to investigate how students in her high school were responding to school reform efforts. McGregor (2011), looking at the intersection of students and macrosystems, utilized ethnography to explore issues of globalization, technological change and identity formation with students in his 
secondary school History and English classes.

Critical ethnography is a particular type of ethnographic research in which the researcher expands the role of participant information gatherer to becoming an advocate for the empowerment of marginalized groups. Such an approach seeks to explicate and redistribute power and control (Creswell, 2007) that is fundamental to the invocation of student voice (Cook-Sather, 2006). This notion of "voice" as an expression of personal and group efficacy is central in critical research, particularly as it applies to student voice (Arnot \& Reay, 2007).

This study applied a critical approach in a number of ways. Advocating for student voice has become central to my professional practice. A subtext of this research was the idea that the participation of the school community in the study would have an egalitarian influence on school culture by validating the power of student voices - not merely as rich sources of information, but as valuable co-creators of meaning. In addition, the inclusion of students as co-researchers throughout the process had the potential to increase their sense of agency, belonging and competence (Osberg, Pope \& Galloway, 2006; Rubin \& Jones, 2007; Mitra, 2009).

Having students engaged as participants and co-researchers in an inquiry with both explicit and implicit goals around impacting school culture through the creation of shared meanings, aligns this approach with Action Research principles (Reason \& Bradbury, 2006). As a form of action research, Student as Researcher (SAR) addresses the issue of student empowerment directly by fully engaging students as equals in a collaborative process aimed at school transformation (Noyes, 2005). In this way SAR 
reorients the focus of the research from product to process - egalitarian participation and discourse, "where opinions are valued and difference is expected and wrestled with; where power differentials are explicated, critiqued and resisted" (2005, p. 535). Symonds (2008) employed an ethnographic approach in a Student Action Research study into the relationship between early adolescent psychological development and middle and secondary school environments. In Symonds's application, students were educated about a variety of qualitative research approaches, tried them out, and evaluated their experiences. This study also involved educating students about research design, and data collection and interpretation.

Additionally, a critical ethnography in the context of participatory action research aligns with the systems approach that frames this study. This methodology acknowledges the dynamic relationships existing within and between all systemic levels: from role identity standards as cognitive subsystems of the self-system, to the participants as complex adaptive systems, to the school as an organizational system. It further acknowledges the embeddedness of these systems in an ecology of metasystems that include other natural systems, designed physical systems, designed abstract systems and social systems, all engaged in a vibrant process of co-creation.

\section{Research Questions}

The goal of this research was to develop a situated description of student role characteristics - the student role standard - within the organizational context of a rural high school from the perspectives of students and staff. To accomplish this I focused my research on the following research questions: 
1) How do youth from a rural high school conceptualize the role of "student" in the organizational context of the school?

2) How do teachers and administrators within the same high school community conceptualize the role of "student" in the organizational context of the school?

Answers to these questions allowed me to compare and contrast student role conceptions from the perspectives of two dominant stakeholders within the school organization. Importantly, it allowed me to consider how youth and teacher student role conceptions compare with the student role identity standard suggested in the literature on student voice and efforts to increase meaningful student involvement in school and community reform.

\section{Setting}

River High School is located in the town of River, a rural community with a population of around 8,000 on the boundary of the Willamette Valley and the foothills of the Cascades. While the timber industry was once the primary employer of the town, River began evolving from an economically depressed community, caused by mill closures in the mid 1980s, into a bedroom community for Portland commuters looking for rural landscapes and cheaper housing. The economic downturn of the past several years has had a significant impact on the community resulting in several business closures in the historic downtown core.

RHS is a secondary school of approximately 750 students, of which $44 \%$ receive free or reduced-price lunches. The student body ethnicity is approximately $77 \%$ white and 17\% Hispanic, with small numbers of African Americans, American Indians and 
Asians making up another $2.5 \%$. The on-time graduation rate for the senior class has gone up from $69 \%$ in 2009 to $76 \%$ in 2013 . Students articulate to the high school from a single middle school that in turn is fed by four elementary schools scattered in smaller close-knit communities throughout the district. Thirty-five certified staff, 25 classified and support staff, and three administrators make up the school faculty. RHS received an Outstanding rating on the 2012 state report card and was one of only 3 public high schools in Oregon to receive a distinguished Great Schools Rating of 8 out of a possible 10. U.S. News recognized RHS with a Bronze Medal in its rating of Best High Schools in 2012 .

The issue of "student voice" is not new to RHS. As a member of the high school community for fifteen years I have been an outspoken advocate of meaningful student involvement that challenges traditional student roles. Several years ago when I first suggested that students have a more direct role in teacher evaluation, I received anonymous notes of disbelief and condemnation. Since that time, due in part to staff turnover, current administrators and most teachers are familiar with the term and have embraced the idea, if not yet the practices, of engaging student voice. Student inclusion in some decision-making processes has been attempted, but inconsistently. For example, there have been student members on the Site Council on-and-off over the last several years - though no formal orientation or training was ever provided for either the students or the adult council members to facilitate their inclusion. The current principal has sought out student input on several occasions regarding such things as proposed schedule changes and the inclusion of the new Homeroom period. But again, these well-meaning 
attempts to engage students have been sporadic and limited primarily to consultation. Nonetheless, as a result of this growing awareness and advocacy, the RHS School Improvement Plan for 2012 (River High School, 2012) drafted by the Site Council and approved by the staff, includes the following:

\section{Goal 5: Student Voice}

Currently students do not have a recognized voice in the decision making process.

Develop a system that includes students in relevant decision making.

\section{Theory of Action}

If we develop a community that includes students as part of the decision making process, then it will increase student ownership of the school culture.

\section{Intervention 1}

Develop a Student Senate, or like structure, that is composed of student representatives from advisory and leadership classes to be part of the decision making process.

\section{Resources Needed}

Planning time for developing a model.

Despite this inclusion, however, little action has been taken on this goal. A

Student Senate was finally organized in the spring of 2013, but rather than addressing issues of concern to students, it was given the task of organizing a whole-school community service event. The Senate was not reactivated in 2014. Student roles and student voice in the RHS organization have moved little beyond the traditional opportunities afforded by participation in the Leadership class or within the leadership structure of school sports, clubs and organizations. That said, the administrative team has been informed of this study and remains enthusiastic supporters of its implementation.

\section{Study Participants}

Participants in this study consisted of three groups: a selected group of students 
to act as co-researchers with me, a student group, and a teacher group. A fourth group made up of parents was dropped from inclusion in the study due to the extremely low return of Informed Consent forms. The protocol for selecting each group of participants was as follows:

Student Research Team. In order to maximize student voice in this research project, a group of students was selected to join a Student Research Team (SRT) to act as co-researchers with me throughout the study. Through both a personalized and open process, students were invited to attend an informational meeting describing the project and the role of the SRT. Personal invitations were sent to students recommended by their teachers and/or known to the researcher as individuals possessing the critical thinking and communication skills deemed necessary to carry out the co-researcher role effectively. At the same time, an open invitation was sent out to the entire student body via the weekly school announcements, and flyers were posted throughout the building. Eighteen students attended the informational meeting and were provided background on the project, an overview of the methodology, and an explanation of the research role that the SRT would play. Each student was given an application to gauge interest in the project and availability to see it through to completion. Two teacher recommendation forms were included in order to get some perspective on the suitability of the applicant for the research role. From the applicant pool, a group of 8 students were invited to join the SRT, at which point requisite Informed Consent forms were processed according to IRB guidelines. Attention was given to involve a range of students, from those whose attitudes and/or academic performance suggested disengagement from school, to those 
who demonstrated agency and efficacy within the school environment. Five students attended the first meeting of the Student Research Team, and three maintained their participation through the completion of the study, which included co-facilitating the Thoughtstream process. These three students comprised the Student Research Team (SRT).

Student Participation Group. The researcher asked staff to gauge their homeroom students' interest in participating in the research project with the goal of identifying two classes from each year, freshmen through seniors. The homeroom structure at River High School is alphabetical by year with approximately 23 students per class, thus potentially providing a random sample of the RHS student body. Two homerooms at each grade level were identified and Informed Consent forms were distributed. Homeroom teachers assumed the responsibility for following up on collecting paperwork and turning it over to me. In all, forty-four students returned the required consent forms: 10 freshmen, 15 sophomores, 7 juniors, and 12 seniors, comprising the Student Participation Group (SPG).

Teacher Participation Group. The two administrators at River high school were oriented to the essential questions and research methodology to gain support for the study. The certified teaching staff was given a similar orientation during a staff meeting. Both administrators and teachers were invited to join in the study. Staff members not present were contacted through email with additional invitations announced during later staff meetings. Informed Consent forms were distributed to all and processed according to IRB guidelines. Thirty-three returned the forms and comprised the Teacher 
Participation Group (TPG).

Parent Participation Group. The Informed Consent paperwork for the Student Participation Group contained an invitation to the parents to also participate in the research project. Two of these forms were returned. This was followed by a direct mailing to the forty-three parents whose students were participating in the study. Only four additional Informed Consent forms were returned. While some data was captured from these few participants, it was not enough to retain the Parent Participation Group (PPG), which was consequently dropped from formal inclusion in the study.

\section{Role of Researcher}

Consistent with a critical ethnography employing a participatory action research approach framed by systems thinking, my role in this study involved a complex interplay of being, behaving and becoming.

Being. The subjective identity (self-system) that I brought into this encounter is informed by several dominant self-relevant meanings (role standard attributes). My role identity as a teacher is dynamic, but well established, developed over a professional career spanning 27 years of working with adolescents. During this time how I conceptualize this role within the organizational context of school has changed. I have come to see myself as a critical activist, seeking to collaboratively shape the learning environment to ever more closely align with the core values that comprise the fundamental role attributes of my "self." These attributes include an unflinching critical self-honesty, an acute sense of personal responsibility, the affirmation of the centrality of relationship, and profound respect for the equality of personhood of each individual I 
encounter.

My role identity as researcher, while much less developed, is equally informed by these core attributes and integrated through them into the superlative identity role of my "self." These values inform my encounters with staff and students, many of whom I have established meaningful personal relationships with. Thus, I anticipated my membership position and reputation within the community would serve as a positive resource toward the effective implementation of the study.

Behaving. These same role attributes of being inform my actions in the world. This research study is an expression of this. As a critical activist I see my teacherresearcher role as an opportunity to learn from, for, and with, the members of the school community towards our mutual and ongoing transformation into a community that recognizes, values and supports the voices of all for the benefit of all. At the same time that I act on these values, I recognize competing identity standards that see the utility in exercising the power of my position and reputation to "objectify" others to meet personal ends. Therefore the incorporation in this study of transparency in implementation, constant solicitation of feedback and ongoing critical reflection were intended to address this.

Becoming. The process of role identity development and systemic integration of identity roles is dynamic and ongoing. Through participation in this research I expected to expand my researcher role identity while continuing the life-long process of selfsystem integration of my various role standards such that my role identity and role behavior align ever more closely. The process of becoming was documented through 
weekly field notes that included reflective writing.

Flowing out of this socially constructed and historically situated subjective self were several assumptions and biases.

1) I assumed that the motivation for agency, efficacy and meaningful participation in community that I value is normative for most individuals - particularly in the socialpolitical-historical context of this study.

2) I believed that the knowledge, identity, and relationships I had developed over my 15 year history in the RHS community were resources that would benefit both the implementation of this study - by evoking student and staff buy-in, and the interpretation of the results - by providing an informed perspective of the context.

3) I believed that working cooperatively, the SRT students and I would be able to adequately reorient the power differential embodied in the student-teacher binary, to enable a truly collaborative research team.

Therefore my role as participant researcher in this study was to work collaboratively with student researchers and participants, as well as with teachers, and administrators in the completion of this study. In so doing, my role was to embody the core values, assumptions and beliefs that imbue this study as I engaged opportunities to inform and educate the community toward our mutual transformation into a community that recognizes, values and supports the voices of all for the benefit of all.

\section{Data Collection Strategies}

The study primarily utilized the data collection methods of the Thoughtstream (Ts) online software platform. Secondary data was gathered through weekly field notes, 
the reflective writing and group interview of the Student Research Team, and comments submitted by participant groups.

Thoughtstream. Thoughtstream (Ts) is an online software platform that provides a structured collaborative process that enables groups to share, organize and evaluate their responses to open-ended questions. The Ts protocol is summarized in Figure 10.

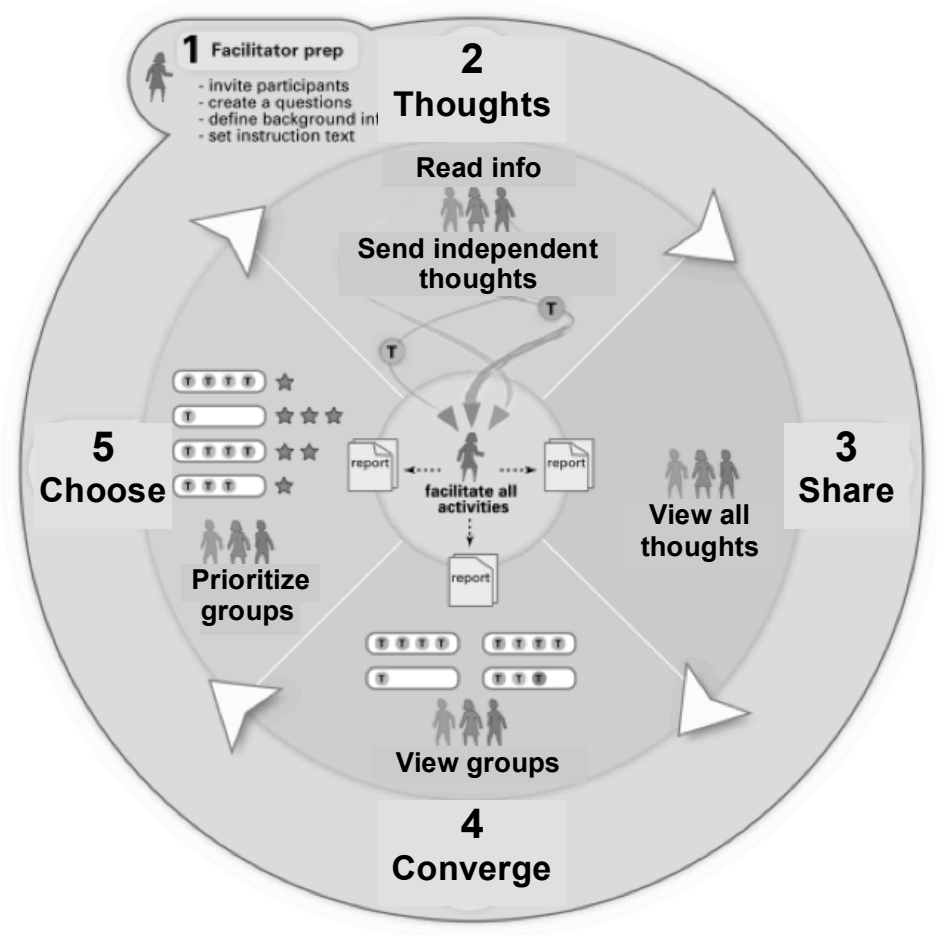

Figure 10. The Thoughtstream Process

(International Fulcrum Management Solutions, 2012)

Reprinted with Permission.

Ts uses a five step process. 1) Facilitator Prep: First the facilitators develop one or more open-ended questions - known as a Thought Stream (TS) - for participants to consider. Background information and materials are also developed to help participants understand and respond to the question(s). 2) Thoughts Activity: In step two, invited participants respond to the TS questions via an online portal. The format for 
responding has two parts: a concise "thought summary" of no more than 75 characters, and an optional explanation to elaborate on the thought summary. Participants may submit as many "thoughts" in response to a question as they wish. The "thought summary" serves to facilitate the process of organizing responses and identifying themes. 3) Share Activity: In this optional step, the facilitators can allow participants to review all the responses before any of the information has been summarized and organized. This procedure was not included in this study due to time constraints. 4) Converge Activity: In step four, the facilitators organize common ideas in the responses into themes. 5) Choose Activity: In the final step, participants go back online to prioritize the thematic categories created in the Converge Activity. This ranking is accomplished by assigning a number of stars to selected categories.

The Thoughtstream platform was utilized to collect, converge and prioritize thoughts from students and teachers around their conceptions of the student role within the organizational context of high school. While I assumed the role of administrating the online Ts software, the members of the Student Research Team acted as co-facilitators throughout the Ts process.

Data Collection Process and Timeline. The timeline and application of the Thoughtstream process along with associated acronyms are summarized in Table 2 and Table 3, followed by an expanded description of the key steps of implementation.

Student Research Team (SRT) Activities: The SRT partnered with me to facilitate the Thoughtstream process throughout the study. Meeting times and places were negotiated with the group and took place after school in my classroom for 2-3 hours 
Table 2

Thoughtstream(Ts) Implementation Timeline and Activity Summary

\begin{tabular}{|c|c|c|c|c|}
\hline Timeline & Ts Stage & SRT Actions & SPG Actions & TPG Actions \\
\hline Week 1 & & $\begin{array}{l}\text { - Recruitment of } \\
\text { students initiated } \\
\text { via announcements, } \\
\text { classroom visits } \\
\text { and flyers }\end{array}$ & $\begin{array}{l}\text { - Recruitment of } \\
\text { Homeroom teachers } \\
\text { initiated at staff } \\
\text { meeting }\end{array}$ & $\begin{array}{l}\text { - Staff intro and } \\
\text { recruitment initiated at } \\
\text { staff meeting } \\
\text { - Informed Consent } \\
\text { (IC) forms distributed }\end{array}$ \\
\hline Week 2 & & $\begin{array}{l}\text { - Recruitment } \\
\text { meeting } \\
\text { - Applications } \\
\text { distributed }\end{array}$ & $\begin{array}{l}\text { - Recruitment } \\
\text { continued via email } \\
\text { and staff meeting }\end{array}$ & $\begin{array}{l}\text { - Recruitment } \\
\text { continued via email } \\
\text { and staff meeting } \\
\text { - IC forms collected }\end{array}$ \\
\hline Week 3 & & $\begin{array}{l}\text { - Applications } \\
\text { reviewed } \\
\text { - Participants } \\
\text { selected }\end{array}$ & $\begin{array}{l}\text { - Six Homerooms } \\
\text { recruited } \\
\text { - Informed Consent } \\
\text { (IC) forms distributed }\end{array}$ & - IC forms collected \\
\hline Week 4 & & $\begin{array}{l}\text { - Informed Consent } \\
\text { (IC) forms distributed } \\
\text { to eight students }\end{array}$ & - IC forms collected & - IC form reminder \\
\hline Week 5 & & $\begin{array}{l}\text { - Team building } \\
\text { - Study overview } \\
\text { - IC forms collected }\end{array}$ & - IC forms collected & - IC form reminder \\
\hline Week 6 & $\begin{array}{l}\text { - Facilitator } \\
\text { Prep (SRT) }\end{array}$ & - Intro to Ts & $\begin{array}{l}\text { - IC forms } \\
\text { redistributed }\end{array}$ & - IC form reminder \\
\hline Week 7 & $\begin{array}{l}\text { - Facilitator } \\
\text { Prep (SRT) }\end{array}$ & $\begin{array}{l}\text { - Brainstorming } \\
\text { survey questions }\end{array}$ & - IC forms collected & - No Action \\
\hline Week 8 & $\begin{array}{l}\text { - Facilitator } \\
\text { Prep (SRT) }\end{array}$ & $\begin{array}{l}\text { - Initial survey } \\
\text { questions developed } \\
\text { and field tested }\end{array}$ & $\begin{array}{l}\text { - Visited participating } \\
\text { homerooms to push } \\
\text { for return of IC forms }\end{array}$ & - IC form reminder \\
\hline Week 9 & $\begin{array}{l}\text { - Facilitator } \\
\text { Prep (SRT) } \\
\text { - Thoughts } \\
\text { Activity (SPG) }\end{array}$ & $\begin{array}{l}\text { - SRQ TS set up for } \\
\text { student response }\end{array}$ & $\begin{array}{l}\text { - TS open for student } \\
\text { responses }\end{array}$ & - IC form reminder \\
\hline Week 10 & $\begin{array}{l}\text { - Facilitator } \\
\text { Prep (SRT) } \\
\text { - Thoughts } \\
\text { Activity } \\
\text { (TPG/SPG) }\end{array}$ & $\begin{array}{l}\text { - SRQ TS set up for } \\
\text { teacher response }\end{array}$ & $\begin{array}{l}\text { - Students respond } \\
\text { to TS }\end{array}$ & $\begin{array}{l}\text { - TS open for teacher } \\
\text { responses }\end{array}$ \\
\hline
\end{tabular}

(Table continues) 


\begin{tabular}{|c|c|c|c|c|}
\hline Timeline & Ts Stage & SRT Actions & SPG Actions & TPG Actions \\
\hline Week 11 & $\begin{array}{l}\text { - Thoughts } \\
\text { Activity } \\
\text { (TPG/SPG) } \\
\text { - Converge } \\
\text { Activity (SRT) }\end{array}$ & $\begin{array}{l}\text { - SRT reviewed } \\
\text { responses, began } \\
\text { identifying themes and } \\
\text { grouping responses }\end{array}$ & $\begin{array}{l}\text { - Students respond } \\
\text { to TS }\end{array}$ & $\begin{array}{l}\text { - Teachers respond } \\
\text { to TS }\end{array}$ \\
\hline Week 12 & $\begin{array}{l}\text { - Converge } \\
\text { Activity (SRT) }\end{array}$ & $\begin{array}{l}- \text { Continued TS } \\
\text { grouping for SPG }\end{array}$ & $\begin{array}{l}\text { - TS Thoughts } \\
\text { Activity closed }\end{array}$ & $\begin{array}{l}\text { - Teachers respond } \\
\text { to TS }\end{array}$ \\
\hline Week 13 & $\begin{array}{l}\text { - Thoughts } \\
\text { Activity (PPG) } \\
\text { - Choose Activity } \\
\text { (SPG) }\end{array}$ & $\begin{array}{l}\text { - Completed TS } \\
\text { grouping for SPG }\end{array}$ & $\begin{array}{l}\text { - TS Choose } \\
\text { Activity opened }\end{array}$ & $\begin{array}{l}\text { - TS Thoughts } \\
\text { Activity closed }\end{array}$ \\
\hline Week 14 & $\begin{array}{l}\text { - Choose Activity } \\
\text { (SPG) }\end{array}$ & $\begin{array}{l}\text { - Reviewed TPG } \\
\text { responses, began } \\
\text { identifying themes and } \\
\text { grouping responses }\end{array}$ & - TS Choose Activity & - No Action \\
\hline Week 15 & $\begin{array}{l}\text { - Converge } \\
\text { Activity (SRT) } \\
\text { - Choose } \\
\text { Activity (TPG) }\end{array}$ & $\begin{array}{l}- \text { Completed TS } \\
\text { grouping for TPG }\end{array}$ & $\begin{array}{l}\text { - TS Choose Activity } \\
\text { closed }\end{array}$ & $\begin{array}{l}\text { - TS Choose Activity } \\
\text { opened }\end{array}$ \\
\hline Week 16 & $\begin{array}{l}\text { - Choose Activity } \\
\text { (TPG) }\end{array}$ & & & $\begin{array}{l}\text { - TS Choose Activity } \\
\text { closed }\end{array}$ \\
\hline Follow Up & - All TSs Closed & $\begin{array}{l}\text { - Reviewed Data } \\
\text { - Planned } \\
\text { Presentations }\end{array}$ & $\begin{array}{l}- \text { Presented key } \\
\text { findings to RHS } \\
\text { students } \\
\text { - Reactivated } \\
\text { Student Senate }\end{array}$ & $\begin{array}{l}\text { - Presented key } \\
\text { findings to RHS } \\
\text { staff } \\
\text { - Presented key } \\
\text { findings to School } \\
\text { Board }\end{array}$ \\
\hline
\end{tabular}

Table 3

Study Acronyms

Ts - Thoughtstream: The application

TS - Thought Stream: A specific set of one or more questions in Ts

SRT - Student Research Team: The group of three students that acted as co-researchers

SRQ - Student Role Questions: The set of questions developed by the SRT to get at students and staff conceptions of the role of students in the organizational context of high school

(Table continues) 


\begin{tabular}{|rl|}
\hline SRQTS - & The Student Role Questions posted as a Thought Stream for participant response \\
\hline SPG - & $\begin{array}{l}\text { Student Participation Group: The representative group of students who chose to } \\
\text { participate in the SRQ Thought Stream }\end{array}$ \\
\hline PPG - & $\begin{array}{l}\text { Parent Participation Group: The parents or guardians of the members of the SPG } \\
\text { who chose to participate in the SRQ Thought Stream }\end{array}$ \\
\hline TPG - & $\begin{array}{l}\text { Teacher Participation Group: The teachers and administrators who chose to } \\
\text { participate in the SRQ Thought Stream }\end{array}$ \\
\hline
\end{tabular}

once a week over a period of eleven weeks. My role in the meetings was to maintain transparency of intent, provide clarity and focus to the process, share my own thoughts and ideas, and bring the snacks! Central to my role was supporting the SRT students' developing understanding of the research goals, research methodology - including issues of confidentiality - and the use of the Thoughtstream process. For their part, student researchers used the opportunity to meet personal goals and graduation requirements by earning mandatory Career Related Learning Experience (CRLE) hours.

Facilitator Prep. After initial team-building activities and the development of team agreements to guide how we would work together over the course of the study, the selected SRT members were given an overview of the research goals including a presentation of role theory and a discussion of student roles. This was followed by a summary of the Thoughtstream process focusing on the development of effective questions in the Facilitator Prep stage. Ts suggests that effective questions are those that are open ended, simply constructed, and that are designed to generate responses that support categorization and prioritization (Fulcrum Management Solutions, 2012). The SRT brainstormed an initial list of four questions that they felt would get at the kind of information that would meet the research goals:

1. What differences do you see between middle school and high school students? 
List 3-5 you think are most significant.

2. What are some essential characteristics that one needs to be a successful high school student? List 3-5 you think are most significant.

3. What does it mean to be actively involved in school? List 3-5 examples of what it means for a high school student to be actively involved in school.

4. What opportunities should high school students have to influence the school community? List 3 you think are most significant.

These were put into a Thought Stream for the SRT members themselves to field

test. After reviewing their experience with the TS and their responses, the SRT

eliminated the first two questions and decided to add a third that directly addressed the

research goals: "What are the characteristics of the role of a student in high school? List

3-5 traits that describe the role students play in the high school and community." The

three questions were then field tested in one class for comprehension and clarity. A final

review and edit generated the three Student Role Questions used to create the student and

teacher Thought Streams:

1. What does it mean to be actively involved in high school? List 3-5 examples of what it means for a high school student to be actively involved in school.

2. What opportunities should high school students have to have their voices heard in order to influence classroom and/or school policies and practices? List 3-5

examples of ways students can or should be able to influence what goes on in the classroom or school.

3. How would you describe the role of a student in high school? List 3-5 traits that describe the role students play in the high school and community.

Each participating group - the student SPG and teacher TPG - had their own

Thought Stream made up of the same three questions. This allowed the data to be

aggregated by group for analysis, interpretation, and comparison.

Thoughts Activity. Once the Thought Stream had been set up, students in the

Student Participation Group (SPG) were invited to a computer lab during three

Homeroom periods and provided with an introduction to the Thoughtstream process and 
instructions for logging into the Ts portal to respond to the Student Role Questions. Members of the SRT were on hand to provide assistance as needed. Students who were absent, unable to attend, and/or unable to complete the questions during the scheduled periods were provided the Ts link and encouraged to visit the Ts portal on their own time.

During this same time, members of the Teacher Participation Group (TPG) were sent an email containing a link to the Ts portal and an invitation to begin the Thoughts Activity process. Follow up emails were sent to reinforce and encourage participation. The Thoughts Activity remained open for both groups for three weeks.

Converge Activity. Even before the Thoughts Activity was closed to further responses, the SRT met and conducted a preliminary review of the postings looking for themes in the responses. The Ts software allows facilitators to create groups from identified themes in the responses and then to easily move responses to the appropriate thematic category through a drag-and-drop process.

When the Thoughts Activity was closed, the SRT completed the Converge Activity over a period of two weeks through a process of creating, reviewing and confirming thematic categories of responses to each question for both the student and teacher Thought Streams. In cases where a response seemed to reflect more than one thematic category, the SRT assigned it to a category based on which theme in the response the SRT judged dominant.

Choose Activity. In the Choose Activity participants prioritized the thematic categories of responses by assigning different numbers of stars to each group. The SRT set up the TS to give each participant six (6) to seven (7) stars, depending on the number 
of thematic categories developed from the responses to the question. The TS was also set up to accept no more than three (3) stars per response group.

Members of the SPG were once again invited to a computer lab during Homeroom period to participate in the Choose Activity. Once again members of the SRT were available to provide assistance as necessary. Likewise, students who were absent, unable to attend, and/or unable to complete the prioritizing during the scheduled periods were provided the Ts link and encouraged to do the Choose Activity on their own time. The Choose Activity for students was left open for three weeks.

Members of the Teacher Participation Group (TPG) were again sent an email containing instructions and a link to the Ts portal to access the Choose Activity. A follow up email was sent to reinforce and encourage participation. The Choose Activity for teachers remained open for two weeks.

After I had compiled and organized the results of the two Thought Streams, the SRT met to review and discuss the data. The SRT members agreed to present a summary of the results they considered most significant to the staff and students of RHS during a staff meeting and a Homeroom period. In addition, the SRT members agreed to accompany me in presenting the study results at a District School Board meeting, once the study was completed. The results of the study will also be posted on the school website. Participants at these meetings were invited to share their reactions to the information presented as well as any other thoughts, observations and/or reflections on the study itself, either immediately following the presentation or later via written comment, email, or online posting. 
In addition to the data captured through the process described above, two other forms of data collection to support the research agenda were employed: my field notes and SRT participant notes, and a closing interview with the SRT members.

Field Notes. Weekly throughout the data collection phase of the study I noted down observations and reflections using the questions below to structure my responses. This log provided a method for analyzing progress, critiquing the methodology, and maintaining critical awareness. Subsequent to the completion of the Ts process, it provided a rich resource for deriving meaning from the research experience. After completion of the formal research process, these notes provided a record for evaluating the procedures and identifying next steps.

I also requested that members of the SRT respond to the same questions at the midpoint and close of their involvement in the research process. This was accomplished by setting up a Thought Stream for the SRT members to use to record their responses. The guiding questions for both the student researchers and myself were:

1. Overall, how has your experience been working with the Student Research Team on the Student Role Study?

2. What do you like most about your participation in this study? List 2-3 experiences you had this week that you like most or believe are the most important.

3. What do you like least about your participation in this study? List the things you dislike, want changed or find the least value in.

4. What impacts is your participation in this study having on you, what you understand, think, and/or believe about yourself and others?

5. What are your thoughts about the study itself - the goals and the methods we are using? Share 3-5 ideas.

6. Is there anything else you would like to add or is there anything we should do differently?

Student Research Team Participant Interviews. At the end of the research 
study I conducted and recorded a semi-structured interview with the members of the Student Research Team. In keeping with the collaborative nature of the study, I inquired whether there was a preference for individual interviews, group interviews with size and makeup to be determined by the group, or some combination of the two. The SRT members chose to have the interview conducted as a group. The student researchers were invited to share their thoughts, observations and reflections on the study and their experiences in it in response to the same guiding questions used for the field notes.

In addition to the applications already mentioned, the field notes and interview data were used to reflect on the larger goals of the study as a critical ethnography engaging students as researchers in participatory action research. These goals included, first, increasing the sense of agency, belonging and competence of the students participating on the SRT; and second, inducing the SRT and RHS community toward a broader vision of the student role and the potential of student voice to both inform and transform classroom and school practices and policies.

\section{Data Management}

One of the challenges of ethnographic research can be data management (Maxwell, 2005). The utilization of the Ts platform eliminated this issue for the most part as the core data was collected and stored online. Additional data, such as field notes, and the student journals were also stored online, the former as a Google Doc and the latter as another Thought Stream. Interview recordings were stored on site in my office and later transcribed to an online document. Hard copies of IC forms were kept in binders and secured in my school office and later at home. 


\section{Data Analysis}

The primary goal of this research was to develop a situated description of the student role identity standard within the organizational context of a rural high school from the perspectives of students and teachers. Analysis of the data first sought answers to the two research questions:

1) How do youth from a rural high school conceptualize the role of "student" in the organizational context of the school?

2) How do teachers and administrators within the same high school community conceptualize the role of "student" in the organizational context of the school?

Creswell (2007, p. 162) suggests that identifying themes and "patterned regularities" is a common approach for analyzing data in an ethnographic study. Data analysis of this kind first occurred in the Thoughtstream process at step four, during the Converge Activity.

During the Converge Activity, the Student Research Team developed categories from the responses by organizing each participant group's submissions to the individual questions around common themes. When a particular response included more than one possible theme, the theme assessed by the research team to be dominant determined its category placement, as the Ts software did not allow assigning responses to more than one category.

Following this, the student and teacher participants prioritized these thematic categories in the Choose Activity. Through this operation, the student and teacher 
participant groups each engaged in a process of self-definition of the student role by submitting thoughts, and evaluating the student role attributes by ranking them.

At this point the Thoughtstream process was concluded as well as the immediate involvement of the Student Research Team, and I assumed responsibility for analysis and interpretation of the data. Later, the Student Research Team members were given the opportunity to review the SRQ Thought Stream data and my interpretations, and were invited to add their own comments as well as participate in disseminating the results of the study.

The next step of analysis involved organizing the results generated in the Converge Activity and the Choose Activity. The thematic categories developed from the responses of students and teachers to each of the TS Student Role Questions were ordered, first by the number and percentage of thoughts assigned to each group, and second, by how many stars had been assigned to each by the participants. Results were then reviewed to identify general patterns in each of the student and teacher response sets. During this phase, thematic categories and thoughts identified as aligning with student voice principles were identified and labeled. Significant similarities and differences in the student and teacher responses were also articulated.

The thematic categories generated in response to question three, "How would you describe the role of a student in high school?" were analyzed next. Two data sets for each thematic category - the number of thoughts and the number of assigned stars - were combined in order to provide a more complete summary of how the participants conceptualized and valued each characteristic of the student role. The role characteristics 
for each participant group were then organized by arranging them around larger themes revealed in the data to produce an initial profile of the student role. These initial profiles of the student role were then used to compare and contrast students and teachers conceptions of the student role.

Subsequently, these student and teacher profiles of the student role were expanded by incorporating the thematic categories generated in response to the other two Thought Stream questions. These elaborated profiles were again used to compare and contrast student role conceptions from the perspectives of the students and teachers.

In the final stage of the Ts data analysis, the elaborated student and teacher profiles of student role characteristics were compared with the student identity role standard derived from the student voice literature, and against the typologies of student engagement developed by Mitra and Gross (2009) and Fletcher (2011).

Later, highlights of the research results were shared with the school community for their consideration and comment at two meetings: a staff meeting, and a homeroom meeting. A third presentation to the RHS School Board has been scheduled for later this spring. Comments of participants were noted during and after each presentation and also underwent categorizing analysis to identify key issues and themes.

My field notes, the SRT participant notes, and the closing interview with the SRT members, also underwent a categorizing analysis to identify key issues and themes. Data from my field notes was used primarily to evaluate the research design and to help identify next steps. Data from the SRT was also used to evaluate the research design and to determine the degree to which participation in the study achieved the secondary goal of 
increasing the sense of agency, belonging and competence of the students participating on the SRT.

Finally, data from all sources was reviewed to look for evidence that the study had induced the SRT participants and RHS community toward a broader vision of the student role and the potential of student voice to both inform and transform classroom and school practices and policies.

\section{Participant Protection}

The centrality of relationships in a participatory ethnographic study raises important issues of researcher integrity and respect of participant rights (Maxwell, 2005). These issues may be compounded by the hierarchical power structures embedded within youth-adult relationships as well as youth-institution relationships (Arnot \& Reay, 2007; Bragg, 2007; Cook-Sather, 2007b). It is therefore implicit that a participatory critical ethnography such as this place the highest priority on ensuring ongoing transparency of intent, methodology, participant roles and use of data. Following the Institutional Review Board (IRB) guidelines on human subject research protocols was the beginning of addressing these issues.

All participants invited to participate in the study received a written description of the proposed research that included a rationale, the study objectives, a summary of how data would be collected and handled, and an assurance of the right to withdraw from participation at any time. Complete, signed Informed Consent forms were required of all participants - students, teachers and parents.

Data collection through the Thoughtstream process was done anonymously for 
members of the student, teacher and parent participant groups. No email addresses or IP addresses were collected. The use of field notes and interview data were also explained including assurances of confidentiality in their use.

Students in the role of co-researchers and their parents received additional information defining their unique role in the study and the expectations regarding issues of confidentiality. In addition, the student researchers received instruction on the standards and rationale guiding human subject research.

\section{Validity}

Maxwell (2005) identifies two significant validity threats, researcher bias and reactivity - the influence of the researcher on the study participants. Maxwell goes on to suggest several practices and strategies for addressing these validity threats, some of which are particularly applicable to this study: explicating personal biases, intensive long-term involvement, triangulation, quasi-statistics, and respondent validation.

Personal Bias. The personal values, assumptions and beliefs that infused this study have already been articulated. Some of the most significant included the assumption that: 1) the motivation for agency, efficacy and meaningful participation in community is normative for most individuals; 2) the knowledge, identity, and relationships I have developed over my 17 year history in the RHS community are resources that would benefit both the implementation of this study and the interpretation of the results; and 3) working cooperatively, the SRT students and I would be able to adequately restructure the power differential embodied in the student-teacher binary, to enable a truly collaborative research team. 
An additional assumption that could have influenced the selection and interpretation of data was my hypothesis that the student role identity standard suggested by the responses of the students would reflect a disempowered, disengaged orientation.

Maxwell (2005) suggests that declaring my assumptions is the beginning of moderating their threat to the validity of the study.

Immersion. While the Thoughtstream process itself is relatively indirect and short-lived, my membership in the RHS community, as stated earlier, has been both long and involved, providing a potentially rich resource for both implementing the study and interpreting the results.

Triangulation. Cook-Sather (2007) cautions the education researcher that "any interpretation of identity must be informed by multiple sources and undertaken from various angles" (p. 393). Both Creswell (2007, p. 208) and Maxwell (2005, p. 112) discuss the value of collecting data from multiple sources to substantiate interpretations and explanations. Triangulation was built into the structure of this study in several ways. First, the student role was described from two unique perspectives: student and teacher. The student participant group included representatives from all grade levels at RHS. The teacher participant group included over $85 \%$ of the certified staff representing a range of subject areas and years in the profession. Role definitions generated by each group were compared and contrasted with each other and with the student role identity standards derived from the student voice literature. The research results were shared with the RHS community for additional comment and critique. Finally, the members of the Student Research Team provided a critical perspective throughout the process on my 
understandings and explanations. Combined, these elements provided a complex of checks and balances to inform my interpretations and conclusions.

Quasi-statistics. Quantitative applications can have a valid role in qualitative studies (Maxwell, 2005) and are part of the Thoughtstream process. This applied to two areas of the study. The number of thoughts generated around a particular theme provided an initial quantitative measure of the significance of that theme to the participants. Then, during the Choose activity, participants prioritized the themes extracted by the researchers from their individual responses to the Student Role Questions. This ranking was achieved by assigning different numbers of stars to thematic categories of responses and thus provides a quantitative measure of the groups' evaluation of the themes. Combined, these two pieces of quantitative data were applied to interpreting and evaluating the respondents' submissions.

Respondent Validation. Perhaps the most important validation strategy in this participatory critical ethnography is respondent validation. Cook-Sather (2007), Fielding (2004), Mitra (2007) and others warn about researchers "translating student responses into language that adults would understand" (Mitra, 2007, as cited in Cook-Sather, 2007a, p. 400) and then into analytic themes from which they draw conclusions based on adults' assumptions and worldviews. This critical issue was addressed from the beginning of the study by establishing a group of students to participate as co-researchers. Through the Student Research Team (SRT), students had a voice in developing the Thoughtstream questions and interpreting the responses. They were also involved in an ongoing process of critically evaluating my interpretations and explanations of student responses. 


\section{Limitations}

The following limitations to this study are worth noting:

1) The age-specific abilities of student researchers may have impacted the construction of survey questions and background information, the interpretation of responses, and evaluation of results (Symunds, 2008).

2) The use of an online platform to present background information, and questions requiring typed responses, may have impeded the full participation and quality of responses of some participants.

3) Though initially intended as a random sampling based on alphabetized homeroom assignments, the student participation group became self-selected based upon which students were motivated and/or organized enough to return the Informed Consent forms and thus may not adequately represent the thoughts and feelings of the general student population.

4) The number of student respondents who submitted the required Informed Consent forms (n44) and participated (n47) was lower than anticipated. This smaller sample size could impact the validity of their responses to represent the thoughts and feelings of the general student population. Note: The reason the number of participants exceeds the number of students returning IC forms could be because students participated more than once employing a different user name, and/or shared the Ts link with students who had not submitted IC forms.

5) The number of student and teacher participants that completed both steps of the Thoughtstream process was minimal making up essentially two distinct subgroups of 
participants. This further diminished the sample size for each step.

6) As a critical ethnography, the data generated is too limited in focus, duration and sample size, as well as too site specific, to be generalizable to other individuals, groups and contexts beyond RHS.

\section{Conclusion}

In this chapter I presented a rationale for this study as a critical ethnographic participatory action research design consistent with a conceptual framework applying systems thinking to explore the intersection of student role identity and student voice within the context of enveloping systems of influence. The research questions guiding the study and the procedures for data collection and analysis were articulated and issues regarding participant protection, validity and limitations were addressed.

How this research study, as a "designed abstract system" actually functioned in interactions with the designed abstract systems (school curriculum and policies) and social systems (student, teacher and community) within which it was implemented - and

how those interactions influenced the structure, function and history of these systems, and the study itself - are the subject of Chapters IV, V, and VI. 


\section{Findings}

The goal of this research was to develop a situated description of the student role within the organizational context of a rural high school from the perspective of students and teachers toward identifying barriers and abetments to the facilitation of student voice. Data were collected through the use of an online software platform, Thoughtstream, which supports the gathering, organizing and evaluation of community responses to open-ended questions. Forty-three students and thirty-three teachers, including two administrators, participated in the Thoughtstream process over a period of eight weeks, generating four hundred "thoughts" in response to three questions:

1. What does it mean to be actively involved in high school?

2. What opportunities should high school students have to have their voices heard in order to influence classroom and/or school policies and practices?

3. How would you describe the role of a student in high school?

The Student Research Team developed categories from the responses by organizing each participant group's postings to the individual questions around common themes. When a particular response included more than one possible theme, the theme assessed by the research team to be dominant determined its category placement. Students and teachers were then given the opportunity to prioritize the thematic categories.

In this chapter, the results of the Thoughtstream process are presented with a focus on thoughts and themes relating to student voice. For each category, sample responses will be provided to support the theme identified by the research team. Spelling and grammar in individual postings have been edited for clarity. 


\section{Question 1: What does it mean to be actively involved in high school?}

The first question asked student and teacher participants to consider what it means for a student to be actively involved in high school. A total of 166 thoughts were generated, 98 posted by 37 students, 58 posted by 20 teachers. The submissions were organized by theme and categorized as summarized in Table 4. Categories of those thoughts relating to student voice are shaded in the table.

Table 4

Question 1: Summary of Student and Teacher Categorized Responses

\begin{tabular}{|c|c|c|c|}
\hline \multicolumn{4}{|c|}{$\begin{array}{l}\text { Q1: What does it mean to be actively involved in high school? } \\
\text { - List 3-5 examples of what it means for a high school student to be actively involved in school. }\end{array}$} \\
\hline Q.1 Student Response Categories & Thoughts & Q.1 Teacher Response Categories & Thoughts \\
\hline $\begin{array}{l}\text { Participate in Clubs and } \\
\text { Activities: } \\
\text { To be actively involved in school } \\
\text { means to participate in clubs or } \\
\text { other activities including sports. }\end{array}$ & $\begin{array}{c}36 \\
(37 \%)\end{array}$ & $\begin{array}{l}\text { Participating in clubs, sports, } \\
\text { activities and/or events: } \\
\text { To be actively involved in school } \\
\text { means to participate in clubs, sports, } \\
\text { activities and/or events outside of the } \\
\text { classroom. }\end{array}$ & $\begin{array}{c}21 \\
(36 \%)\end{array}$ \\
\hline $\begin{array}{l}\text { Academic Involvement: } \\
\text { To be actively involved in school } \\
\text { means you are focused on learning } \\
\text { and being academically successful. }\end{array}$ & $\begin{array}{c}20 \\
(20 \%)\end{array}$ & $\begin{array}{l}\text { Academic Involvement: } \\
\text { To be actively involved in high school } \\
\text { means to take ownership and } \\
\text { responsibility for one's engagement in } \\
\text { learning and academic success. }\end{array}$ & $\begin{array}{c}16 \\
(28 \%)\end{array}$ \\
\hline $\begin{array}{l}\text { Participate in Sports: } \\
\text { To be actively involved in school } \\
\text { means to participate in a sport. }\end{array}$ & $\begin{array}{c}11 \\
(11 \%)\end{array}$ & $\begin{array}{l}\text { Establishing Relationships: } \\
\text { To be actively involved in school } \\
\text { means developing supportive } \\
\text { relationships with peers, teachers, and } \\
\text { the community in general. }\end{array}$ & $\begin{array}{c}9 \\
(16 \%)\end{array}$ \\
\hline $\begin{array}{l}\text { Establish Relationships: } \\
\text { To be actively involved in school } \\
\text { means developing supportive } \\
\text { relationships with peers, teachers, } \\
\text { and the community in general. }\end{array}$ & $\begin{array}{c}11 \\
(11 \%)\end{array}$ & $\begin{array}{l}\text { Making school a better place: } \\
\text { To be actively involved in school } \\
\text { means to be actively engaged in } \\
\text { making the school a better place. }\end{array}$ & $\begin{array}{c}5 \\
(9 \%)\end{array}$ \\
\hline
\end{tabular}

(Table continues) 


\begin{tabular}{|c|c|c|c|}
\hline Q.1 Student Response Categories & Thoughts & Q.1 Teacher Response Categories & Thoughts \\
\hline $\begin{array}{l}\text { Lead and/or Voice Opinions: } \\
\text { To be actively involved in school } \\
\text { means to find opportunities to be a } \\
\text { leader and/or to voice opinions. }\end{array}$ & $\begin{array}{c}7 \\
(7 \%)\end{array}$ & $\begin{array}{l}\text { Being Active in Student Leadership } \\
\text { Organizations: } \\
\text { To be actively involved in high } \\
\text { school means to become active in } \\
\text { student leadership organizations. }\end{array}$ & $\begin{array}{c}2 \\
(3 \%)\end{array}$ \\
\hline $\begin{array}{l}\text { Show School Spirit: } \\
\text { To be actively involved in school } \\
\text { means taking pride in your school, } \\
\text { showing your school spirit, and } \\
\text { trying to make school better. }\end{array}$ & $\begin{array}{c}6 \\
(6 \%)\end{array}$ & $\begin{array}{l}\text { X: Other: } \\
\text { These responses were not easily } \\
\text { categorized within the other } \\
\text { categories or did not answer the } \\
\text { question. }\end{array}$ & $\begin{array}{c}5 \\
(9 \%)\end{array}$ \\
\hline $\begin{array}{l}\text { Right Attitude: } \\
\text { To be actively involved in school } \\
\text { means to have the right attitude } \\
\text { toward success. }\end{array}$ & $\begin{array}{c}4 \\
(4 \%)\end{array}$ & & \\
\hline $\begin{array}{l}\text { X: Other: } \\
\text { These responses did not answer the } \\
\text { question. }\end{array}$ & $\begin{array}{c}3 \\
(3 \%)\end{array}$ & & \\
\hline Total Thoughts & $98(100 \%)$ & Total Thoughts & $58(100 \%)$ \\
\hline Total Student Voice Thoughts & $7(7 \%)$ & Total Student Voice Thoughts & $7(12 \%)$ \\
\hline Number of Participants ( /47) & $37(79 \%)$ & Number of Participants ( /32) & $20(63 \%)$ \\
\hline
\end{tabular}

The majority of student thoughts (n67, 68\%), as well as teacher thoughts (n37, $64 \%$ ), referred to academic involvement or participating in clubs, sports or school activities. "To be actively involved in high school means to work hard on grades," posted Student 24. "Students who are actively involved put their academics first," submitted Teacher 4. "Participate in clubs, sports, school events, and student government," stated Student 47. "Students should involve themselves in activities outside the classroom," suggested Teacher 7.

Both groups identified "establishing relationships" within the school community as a manifestation of active involvement (students: $\mathrm{n} 11,11 \%$; and teachers: $\mathrm{n} 9,16 \%$ ). 
"You have to be social enough to interact with fellow students and teachers. That means talking to everyone," posted Student 11. "I believe education is primarily relational," offered Teacher 22. In addition, 7\% (n7) of student responses and 12\% (n7) of staff responses were identified as embodying student voice principles of engagement.

For the student group, thoughts expressing student voice principles of engagement and influence were grouped in the category "Lead and/or voice opinions." For example, Student 29 posted, “As young adults, it is important for high school students to take on leadership roles so that they have the opportunity to change the world to better suit them and future generations." And Student 17 proposed that, "In order for a student to be actively involved, a student needs their opinion to be heard."

Within the teacher submissions, two categories, "making school a better place" and "being active in student leadership organizations" include responses manifesting student voice principles of engagement and influence. Teachers responded that a student could be involved by participating in "leadership, school government, and student councils" (Teacher 5) and "taking an active role in the governing body of the school" (Teacher 21). Teacher 3 submitted that, "As an active member of the school community who owns their own learning, a student would be in a position to evaluate that community for ways it could be improved. If the school can be improved, it only follows that the student would be involved in causing those improvements to come about."

Students and teacher participants then had the opportunity to prioritize their respective categories by assigning 1-3 stars of an allotted six stars to the categories of their choice. Nineteen students (40\%) and fifteen teachers (47\%) participated in this 
phase of the data collection. Results of this ranking are summarized in Table 5.

For the teachers, "academic involvement" ranked first, receiving 30\% (n24) of the total assigned stars for an average rating of 1.60 stars. Students also ranked "academic involvement" first, as well as "lead and/or voice opinions," each receiving 18\% (n20) of the total assigned stars for an average rating of 1.54. In contrast, teachers ranked the categories representative of student voice, "making school a better place" and "being active in student leadership organizations," relatively low, assigning 8\% (n6, average $1.20)$ and $6 \%(\mathrm{n} 5$, average 1.25$)$ of total assigned stars respectively. Meanwhile, “establishing relationships" was ranked third by both teachers $(18 \%, \mathrm{n} 18)$ and students $(13 \%, \mathrm{n} 14,1.40)$, but received the highest average rating by teachers $(1.80)$ of any category of question one.

Overall, the thematic categories representing student voice principles received $18 \%(\mathrm{n} 20)$ of the assigned stars of students, and 14\% (n11) of the assigned stars of teachers.

The first question we reviewed addressed the idea of active involvement. The next question considers opportunities student should have to impact the school environment.

\section{Question 2: What opportunities should high school students have to have their voices heard in order to influence classroom and/or school policies and practices?}

The second question asked student and teacher participants to consider what opportunities high school student have, or should have, to influence classroom and school policies and practices. A total of 128 thoughts were generated, 82 postings by 36 students and 46 by 16 teachers. The submissions were categorized by theme as 
Table 5

Question 1: Summary of Student and Teacher Category Rankings

\begin{tabular}{|c|c|c|c|c|c|c|c|}
\hline \multicolumn{8}{|c|}{ Q1: What does it mean to be actively involved in high school? } \\
\hline $\begin{array}{l}\text { Student } \\
\text { Response } \\
\text { Categories }\end{array}$ & $\begin{array}{l}\text { Overall } \\
\text { Rating }\end{array}$ & $\begin{array}{c}\text { Partici } \\
\text { pant } \\
\text { Count }\end{array}$ & $\begin{array}{l}\text { Average } \\
\text { Rating }\end{array}$ & $\begin{array}{l}\text { Teacher } \\
\text { Response } \\
\text { Categories }\end{array}$ & $\begin{array}{l}\text { Overall } \\
\text { Rating }\end{array}$ & $\begin{array}{c}\text { Partici } \\
\text { pant } \\
\text { Count }\end{array}$ & $\begin{array}{c}\text { Average } \\
\text { Rating }\end{array}$ \\
\hline $\begin{array}{l}\text { Academic } \\
\text { Involvement }\end{array}$ & $\begin{array}{c}20 \\
(18 \%)\end{array}$ & 13 & 1.54 & $\begin{array}{l}\text { Academic } \\
\text { Involvement }\end{array}$ & $\begin{array}{c}24 \\
(30 \%)\end{array}$ & 15 & 1.60 \\
\hline $\begin{array}{l}\text { Lead and/or Voice } \\
\text { Opinions }\end{array}$ & $\begin{array}{c}20 \\
(18 \%)\end{array}$ & 13 & 1.54 & $\begin{array}{l}\text { Participating in } \\
\text { clubs, sports, } \\
\text { activities and/or } \\
\text { events }\end{array}$ & $\begin{array}{c}23 \\
(29 \%)\end{array}$ & 13 & 1.77 \\
\hline Right Attitude & $\begin{array}{c}18 \\
(16 \%)\end{array}$ & 12 & 1.50 & $\begin{array}{l}\text { Establishing } \\
\text { Relationships }\end{array}$ & $\begin{array}{c}18 \\
(23 \%)\end{array}$ & 10 & 1.80 \\
\hline $\begin{array}{l}\text { Establish } \\
\text { Relationships }\end{array}$ & $\begin{array}{c}14 \\
(13 \%)\end{array}$ & 10 & 1.40 & $\begin{array}{l}\text { Making school a } \\
\text { better place }\end{array}$ & $\begin{array}{c}6 \\
(8 \%)\end{array}$ & 5 & 1.20 \\
\hline $\begin{array}{l}\text { Participate in } \\
\text { Sports }\end{array}$ & $\begin{array}{c}14 \\
(13 \%)\end{array}$ & 9 & 1.56 & $\begin{array}{l}\text { Being Active in } \\
\text { Student } \\
\text { Leadership } \\
\text { Organizations }\end{array}$ & $\begin{array}{c}5 \\
(6 \%)\end{array}$ & 4 & 1.25 \\
\hline $\begin{array}{l}\text { Participate in } \\
\text { Clubs and } \\
\text { Activities }\end{array}$ & $\begin{array}{c}12 \\
(11 \%)\end{array}$ & 9 & 1.33 & $\mathrm{X}$ : Other & $\begin{array}{c}3 \\
(4 \%)\end{array}$ & 3 & 1.00 \\
\hline $\begin{array}{l}\text { Show School } \\
\text { Spirit }\end{array}$ & $\begin{array}{c}12 \\
(11 \%)\end{array}$ & 11 & 1.09 & & & & \\
\hline X: Other & 0 & 0 & 0.00 & & & & \\
\hline Total Stars Used & $\begin{array}{l}110 \\
(100 \%)\end{array}$ & & & Total Stars Used & $\begin{array}{l}79 \\
(100 \%)\end{array}$ & & \\
\hline $\begin{array}{r}\text { Student Voice } \\
\text { Summary }\end{array}$ & $\begin{array}{l}20 \\
(18 \%)\end{array}$ & & & $\begin{array}{r}\text { Student Voice } \\
\text { Summary }\end{array}$ & $\begin{array}{l}11 \\
(14 \%)\end{array}$ & & \\
\hline $\begin{array}{r}\text { Total Number of } \\
\text { Participants ( /47) }\end{array}$ & & $\begin{array}{l}19 \\
(40 \%)\end{array}$ & & $\begin{array}{l}\text { Total Number of } \\
\text { Participants (/32) }\end{array}$ & & $\begin{array}{l}15 \\
(47 \%)\end{array}$ & \\
\hline \multicolumn{8}{|c|}{$\begin{array}{l}\text { Note. Six (6) stars allotted per participant; maximum three (3) stars may be assigned per response group } \\
\text { Overall rating: total number of stars assigned to that group of thoughts } \\
\text { Participant count: the number of people that assigned stars to that group of thoughts } \\
\text { Average rating: the average number of stars that was given to that group of thoughts }\end{array}$} \\
\hline
\end{tabular}


summarized in Table 6. Categories of those thoughts relating to student voice are shaded in the table.

The majority of student thoughts, 63\% (n52), as well as teachers', 73\% (n34), embody student voice principles of engagement. The three categories containing the highest number of student voice related posts for each group include 57\% (n47) of all student submissions and 58\% (n 27) of all teacher submissions for this question.

The student category, "Voicing opinions and voting on policies," had the highest number of responses to this question (n32-39\%). The two themes were grouped together because the research team considered voting as a means of voicing opinion. Of the submissions in this category, several addressed the right of students to speak their minds. Student 39 posted, "Students should be able to speak freely without punishment." Student 10 submitted, "Let us use our right for freedom of speech. Using our right for freedom of speech makes us feel like we can make a change in the community and talk about and debate about local issues that we are facing now.” Other students suggested that student influence include being able to vote on school issues. "Students should have the opportunity to vote not only on class presidents, but on school policies and events. Voting for everything they have gives students a responsibility for the thing they voted for," stated Student 17. Several students proposed specific mechanisms for getting their voices heard. For example, Student 26 suggested, "Utilize homeroom. Ask us if we like the decisions made on our behalf. Listen to us if we have an alternative solution." And Student 37 submitted, "Every Friday there should be a meeting that allows students to be heard with ideas they have." 
Table 6

\section{Question 2: Summary of Student and Teacher Categorized Responses}

Q2: What opportunities should high school students have to influence classroom and/or school policies and practices? • List 3-5 examples of ways students can or should be able to influence what goes on in the classroom or school.

\begin{tabular}{|llll|}
\hline Q.2 Student Response Categories & Thoughts & Q.2 Teacher Response Categories & Thoughts \\
\hline $\begin{array}{l}\text { Voice Opinions / Vote on Policies: } \\
\begin{array}{l}\text { Students should have real } \\
\text { opportunities to voice ideas and }\end{array}\end{array}$ & $32(39 \%)$ & $\begin{array}{l}\text { Influence Classroom Policies: } \\
\text { Students should have opportunities } \\
\text { influence some classroom policies. }\end{array}$ & $11(24 \%)$ \\
ophen
\end{tabular}

opinions without censorship.

Students should have opportunities to

influence policy, and vote on policy

decisions that affect them.

$\begin{array}{lll}\text { Influence Teaching Style, as well as } & 9(11 \%) & \text { Voice Opinions: } \\ \text { Classroom Content and } & & \text { Students should have real } \\ \text { Approaches: } & & \text { opportunities to voice ideas and } \\ \text { Students should have opportunities to } & & \text { opinions. Students should have } \\ \text { have their interests and learning } & & \text { opportunities to influence policy, } \\ \text { styles taken into account in the } & \text { and vote on policy decisions that } \\ \text { classroom. } & \text { affect them. }\end{array}$

Student Government: $\quad 6(7 \%) \quad$ Student Government: $\quad 8(17 \%)$

Students should be able to use Students should be able to use student government to represent their opinions and influence school policies. student government and other leadership roles to voice their ideas.

\section{Follow Rules and Policies:}

These responses suggest that students should follow rules and policies instead of influencing them.
Student Choice:

Students should be able to make their own decisions about things that affect them - like the dress code.

\section{$5(6 \%) \quad$ Extra curricular opportunities:}

Students should have opportunities to form and be involved in clubs, sports and school activities.

\section{$5(6 \%)$}

Work with Administration: $6(13 \%)$ Ask/Survey student for what they would like to see more of or less of in the school climate. Then determine what can be done to accommodate the requests.

\section{Involvement in Clubs, Sports and $4(5 \%)$} Activities:

Students should have opportunities to be involved in clubs, sports and school activities.
Follow Rules and Policies:

These responses suggest that students should follow rules and policies instead of influencing them.
$8(17 \%)$

\section{$8(17 \%)$} s. 


\begin{tabular}{|lllll|}
\hline Q.2 Student Response Categories & Thoughts & Q.2 Teacher Response Categories & Thoughts \\
\hline $\begin{array}{l}\text { X: Other: Academic Suggestions: } \\
\text { These responses offered suggestions } \\
\text { without answering the question. }\end{array}$ & $12(15 \%)$ & $\begin{array}{l}\text { They Should Run It: } \\
\text { Students should have as many } \\
\text { opportunities as is feasible. }\end{array}$ & $1(2 \%)$ \\
\hline $\begin{array}{l}\text { X: Other: These responses were not } \\
\text { easily categorized or did not directly } \\
\text { answer the question. }\end{array}$ & $9(11 \%)$ & $\begin{array}{l}\text { X: Other: These responses were not } \\
\text { easily categorized. }\end{array}$ & $2(4 \%)$ \\
\hline Total Thoughts & $82(100 \%)$ & & Total Thoughts & $46(100 \%)$ \\
\hline Total Student Voice Thoughts & $52(63 \%)$ & Total Student Voice Thoughts & $34(73 \%)$ \\
\hline Number of Participants ( /47) & $36(77 \%)$ & Number of Participants ( /32) & $16(50 \%)$ \\
\hline Note. Shaded cells reference Student Voice Thoughts and Categories. & \\
\hline
\end{tabular}

Students also proposed that they have opportunities to influence classroom policies and practices (n9-11\%). For example, "Teachers could ask what kind of style the students prefer for them to teach, or what types of rules there should be in a classroom," stated Student 13. Student 19 suggested, "We should get to help our teachers create their agendas. Teachers should give us the option for what we are going to be doing that day or the order we will be doing different activities in."

Teacher responses also included that students be given opportunities to voice opinions (n8-17\%) and influence classroom policies (n11-24\%). "Student voice is important," stated Teacher 32, "students should be able to provide feedback to the staff on school policies or classroom lessons." And Teacher 20 posted, "Students should have a say in some of the policies they have to follow, because they do know what is best in certain situations, and if they help create something, they will have more of a reason to respect it." With regard to the classroom, Teacher 29 submitted that students be able to 
"engage in classroom discussion regarding procedures, routine and rules." Teacher 5 suggested that students "participate with the instructor to come up with a set of norms for various activities and functions in the classroom." And Teacher 7 posted, "Give students ways to give feedback on classroom activities. Give surveys or questionnaires to get feedback about what could be improved."

Both student and teachers suggested student government as a vehicle for facilitating student influence on school policies and practices (students: n6-7\%; and teachers: $\mathrm{n} 8-17 \%)$. "Student government, class representatives, and talking to adults," stated Student 47, "all of these things allow students to influence what goes on in the school." Teacher 16 posted, "Through participation in the student senate, kids should have influence over the activities they participate in, projects they pursue, etc." Several teacher comments focused specifically on students working with administrators (n613\%). "A chance to work closely with administration. Having adult guidance while seeing how school policy or practice works," commented Teacher 21. And Teacher 15 suggested that students participate on Site council, leadership teams and the school board.

One thematic category of student responses (n5 - 6\%) advocated that students be able to make their own decisions about things that affect them, like the school dress code (Students 2 and 44). Student 10 posted, "Let us make decisions based on our well being since we are all trying to succeed." Student 44 submitted that students "should be able to choose what they want to do," explaining that, "We are supposed to have freedom of choice in society."

In contrast to influencing classroom and school policies and practices, several 
postings by students (n5-6\%) and teachers (n3-7\%) suggested that students should follow rules and policies instead of influencing them. Student 2 commented, "In most of my classrooms the teachers know what they want us to accomplish and they will work around the way we learn things in order to accomplish their goal for us. I think that is a very good thing and students shouldn't have a say in the way a class is run." Student 25 and Student 41 posted that students should "obey the policies." Teacher 30 submitted, "I hate to have kids 'voice their opinion' but it can't make a real difference.” Teacher 6 commented, "They should not be allowed to choose school policies and best practices," adding, "Please don't get me wrong, as young adults they simply do not have the knowledge of best practices yet. Knowing about policies and procedures and deciding are totally different."

In support of maximizing student engagement, one teacher concluded, "Rules, policies, assemblies, dances, books to read, practical application, community involvement, relevancy of curriculum, what to write about...all of this should be opportunities for students [to] influence their environment. Really, they should run it" (Teacher 19). Although there is only one comment in this category, the SRT felt that the extreme position taken deserved its own group.

Students and teacher participants then prioritized the thematic categories by assigning 1-3 stars of an allotted six stars to the categories of their choice. Nineteen students (40\%) and fifteen teachers (47\%) participated. Results of this ranking are summarized in Table 7.

Students ranked the thematic category "Voicing opinions/voting on policies" first, 
Table 7

Question 2. Summary of Student and Teacher Category Rankings

\begin{tabular}{|c|c|c|c|c|c|c|c|}
\hline $\begin{array}{l}\text { Q.2 Student } \\
\text { Response } \\
\text { Categories }\end{array}$ & $\begin{array}{l}\text { Overall } \\
\text { Rating }\end{array}$ & $\begin{array}{l}\text { Partici } \\
\text { pant } \\
\text { Count }\end{array}$ & Average & $\begin{array}{l}\text { Q.2 Teacher } \\
\text { Response } \\
\text { Categories }\end{array}$ & $\begin{array}{l}\text { Overall } \\
\text { Rating }\end{array}$ & $\begin{array}{c}\text { Partici } \\
\text { pant } \\
\text { Count }\end{array}$ & Average \\
\hline $\begin{array}{l}\text { Voice Opinions / } \\
\text { Vote on Policies }\end{array}$ & $\begin{array}{c}21 \\
(19 \%)\end{array}$ & 12 & 1.75 & Voice Opinions & $\begin{array}{c}30 \\
(32 \%)\end{array}$ & 14 & 2.14 \\
\hline $\begin{array}{l}\text { Follow Rules and } \\
\text { Policies }\end{array}$ & $\begin{array}{c}19 \\
(17 \%)\end{array}$ & 11 & 1.73 & $\begin{array}{l}\text { Student } \\
\text { Government }\end{array}$ & $\begin{array}{c}26 \\
(28 \%)\end{array}$ & 13 & 2.00 \\
\hline $\begin{array}{l}\text { Involvement in } \\
\text { Clubs, Sports and } \\
\text { Activities }\end{array}$ & $\begin{array}{c}19 \\
(17 \%)\end{array}$ & 12 & 1.58 & $\begin{array}{l}\text { Work with } \\
\text { Administration }\end{array}$ & $\begin{array}{c}13 \\
(14 \%)\end{array}$ & 10 & 1.30 \\
\hline Student Choice & $\begin{array}{c}19 \\
(17 \%)\end{array}$ & 10 & 1.90 & $\begin{array}{l}\text { Extra curricular } \\
\text { opportunities }\end{array}$ & $\begin{array}{c}10 \\
(11 \%)\end{array}$ & 6 & 1.67 \\
\hline $\begin{array}{l}\text { Influence } \\
\text { Teaching Style, as } \\
\text { well as Classroom } \\
\text { Content and } \\
\text { Approaches }\end{array}$ & $\begin{array}{c}17 \\
(14 \%)\end{array}$ & 13 & 1.31 & $\begin{array}{l}\text { Follow Rules and } \\
\text { Policies }\end{array}$ & $\begin{array}{c}10 \\
(11 \%)\end{array}$ & 6 & 1.67 \\
\hline $\begin{array}{l}\text { Student } \\
\text { Government }\end{array}$ & $\begin{array}{c}8 \\
(7 \%)\end{array}$ & 6 & 1.33 & $\begin{array}{l}\text { Influence } \\
\text { Classroom } \\
\text { Policies }\end{array}$ & $\begin{array}{c}5 \\
(5 \%)\end{array}$ & 5 & 1.00 \\
\hline $\begin{array}{l}\text { X: Other: } \\
\text { Academic } \\
\text { Suggestions }\end{array}$ & $\begin{array}{c}7 \\
(6 \%)\end{array}$ & 5 & 1.40 & $\begin{array}{l}\text { They Should Run } \\
\text { It }\end{array}$ & 0 & 0 & 0.00 \\
\hline X: Other: Misc. & $\begin{array}{c}2 \\
(2 \%)\end{array}$ & 2 & 1.00 & $\mathrm{X}$ : Other & 0 & 0 & 0.00 \\
\hline Total Stars Used & $\begin{array}{l}112 \\
(100 \%)\end{array}$ & & & Total Stars Used & $\begin{array}{l}94 \\
(100 \%)\end{array}$ & & \\
\hline $\begin{array}{r}\text { Student Voice } \\
\text { Summary }\end{array}$ & $\begin{array}{l}65 \\
(58 \%)\end{array}$ & & & $\begin{array}{r}\text { Student Voice } \\
\text { Summary }\end{array}$ & $\begin{array}{l}74 \\
(79 \%)\end{array}$ & & \\
\hline $\begin{array}{l}\text { Total Number of } \\
\text { Participants ( /47) }\end{array}$ & & $\begin{array}{l}19 \\
(40 \%)\end{array}$ & & $\begin{array}{l}\text { Total Number of } \\
\text { Participants ( /32) }\end{array}$ & & $\begin{array}{l}15 \\
(47 \%)\end{array}$ & \\
\hline \multicolumn{8}{|c|}{$\begin{array}{l}\text { Note. Six(6) stars allotted per participant; maximum three( } 3 \text { stars may be assigned per response group } \\
\text { Overall rating: total number of stars assigned to that group of thoughts } \\
\text { Participant count: the number of people that assigned stars to that group of thoughts } \\
\text { Average rating: the average number of stars that was given to that group of thoughts }\end{array}$} \\
\hline
\end{tabular}


appointing 19\% (n21) of the total assigned stars to it. This was followed closely by "Following rules and policies," "Involvement in clubs, sports and activities," and "Student choice," each receiving 17\% (n19). Third, "Influencing teaching style, classroom content and approaches" received 14\% (n17) of assigned stars. Of these top ranked categories, "Student choice" had the highest average rating at 1.90 stars per participant, followed by "Voicing opinions/voting on policies" (1.75), "Following rules and policies" (1.73), "Involvement in clubs, sports and activities" (1.58) and "Influencing teaching style, classroom content and approaches" (1.31).

Similar to the student rankings, "Voicing opinions" was also ranked first by teachers receiving $32 \%$ (n30) of the total assigned stars. "Student government" ranked second for the teachers receiving $28 \%$ (n26) for an average of 2.00 stars. In contrast, students ranked "Student government" fourth assigning it only eight stars, (7\%) for an average of 1.33 stars. The third ranked teacher category "Working with administrators," received $14 \%$ (n13) of assigned stars. The only other category representative of student voice that ranked, "Influence classroom policies," received 5\% (n5). The one-thoughtcategory, "They should run it," did not receive any stars.

Overall, the thematic categories representing student voice principles received $58 \%(\mathrm{n} 65)$ of the assigned stars of students, and $79 \%(\mathrm{n} 74)$ of the assigned stars of teachers.

Having considered what students and teachers think about student involvement and influence within the school community, attention turns to how the participants responded to a direct question regarding their conceptions of the student role. 


\section{Question 3: How would you describe the role of a student in high school?}

The last question asked student and teacher participants to describe the role high school students play in the high school and community. A total of 116 thoughts were generated by 32 student and 18 teacher participants. Only three (4\%) of the 78 student submissions, and three ( $8 \%$ ) of the 38 teacher submissions reflected student voice

principles of engagement. Again, the submissions were categorized by theme as summarized in Table 8. Categories of those thoughts relating to student voice are shaded in the table.

The majority of student thoughts, $(23 \%$ - n18), as well as teacher thoughts $(29 \%$ n11), identified actively participating in the learning process as one role of a high school student. "Students are here to learn," posted Student 26. "Get good grades," submitted Students 41 and 45. "You have to get good grades so you can graduate," stated Student 11. "Students need to be actively engaged in their own education," suggested Teacher 32. The role of a student is "to actively participate and do it with effort," offered Teacher 16.

In a related theme, several teacher submissions proposed that the role of the student is to recognize that doing school is their job $(11 \%-n 4)$. "I feel like students should act like school is their job - they should try hard, get involved and be on time," posted Teacher 30. "This is the student's job. They should be professionals as if they are at a job and they should expect to be treated professionally by the school staff as if they were a valued employee," submitted Teacher 7.

The three student submissions reflecting a student voice orientation were placed 
Table 8

\section{Question 3: Summary of Student and Teacher Categorized Responses}

Q3: How would you describe the role of a student in high school? $\bullet$ List 3-5 traits that describe the role students play in the high school and community.

\begin{tabular}{|c|c|c|c|}
\hline Q.3 Student Response Categories & Thoughts & Q.3 Teacher Response Categories & Thoughts \\
\hline $\begin{array}{l}\text { To Participate in the Learning / } \\
\text { Academic Success: } \\
\text { The role of students is to participate in } \\
\text { class, learn what is taught, pass their }\end{array}$ & $\begin{array}{c}18 \\
(23 \%)\end{array}$ & $\begin{array}{l}\text { Actively Participate in Learning: } \\
\text { The role of students is to be } \\
\text { actively engaged in the learning } \\
\text { process. }\end{array}$ & $\begin{array}{c}11 \\
(29 \%)\end{array}$ \\
\hline
\end{tabular}

\section{Develop / Discover Personal}

Character:

The role of students is develop personal characteristics such as caring, confidence, commitment, respect, maturity and having a positive attitude.

\section{Current Role is Not Satisfactory:}

These responses reveal dissatisfaction with the role students feel they are currently given.

$\begin{array}{llc}16 & \text { Community Member: } & 5 \\ (21 \%) & \begin{array}{l}\text { The role of the student is to act as a } \\ \text { citizen / member of a community. }\end{array} & (13 \%)\end{array}$

\section{Prepare for College/Adulthood:}

The role of students is to prepare for college, career and life.

$\begin{array}{cl}10 & \text { Self Exploration: } \\ (13 \%) & \text { The role of students is to explore } \\ & \text { interests and grow as a person. }\end{array}$

\section{School is the job:}

$(12 \%) \quad$ The role of the student is to recognize that doing school is their job.

\section{Be Involved in Sports/Clubs/Activities: \\ The role of students is to be INVOLVED - whether it is clubs, sports, activities or academics.}

A Representative and Role
Model:
The role of students is to represent
their families well and be a role
model for other students.

\section{Leadership / Be Role Model*:}

The role of students is to be a leader, impact school policy, and be a role model for other students.

\section{Be Respectful / Responsible:}

The role of students is to be respectful to others and responsible for themselves and their work.

$\begin{array}{lc}\text { Be Respectful: } & 3 \\ & (8 \%)\end{array}$

(8\%) The role of students is to represent $\quad(8 \%)$ their families well and be a role model for other students. inputs to the system to make it more effective. 


\begin{tabular}{|c|c|c|c|}
\hline Q.3 Student Response Categories & Thoughts & Q.3 Teacher Response Categories & Thoughts \\
\hline $\begin{array}{l}\text { Accept the situation and just get the } \\
\text { work done*: } \\
\text { The role of students is to accept the } \\
\text { limits of the situation and do their } \\
\text { work. }\end{array}$ & $\begin{array}{c}4 \\
(5 \%)\end{array}$ & $\begin{array}{l}\text { X: Other*: These responses were } \\
\text { not easily categorized. }\end{array}$ & $\begin{array}{c}5 \\
(13 \%)\end{array}$ \\
\hline $\begin{array}{l}\text { X: Other: These responses did not } \\
\text { answer the question. }\end{array}$ & $\begin{array}{c}2 \\
(3 \%)\end{array}$ & & \\
\hline Total Thoughts & $\begin{array}{l}78 \\
(100 \%)\end{array}$ & Total Thoughts & $\begin{array}{l}38 \\
(100 \%)\end{array}$ \\
\hline $\begin{array}{l}\text { Total Student Voice Thoughts } \\
\text { (*Across these two categories) }\end{array}$ & $\begin{array}{l}3 \\
(4 \%)\end{array}$ & $\begin{array}{l}\text { Total Student Voice Thoughts } \\
\text { (*Includes one in this category) }\end{array}$ & $\begin{array}{l}3 \\
(8 \%)\end{array}$ \\
\hline Number of Participants ( /47) & $32(68 \%)$ & Number of Participants ( /32) & $18(56 \%)$ \\
\hline
\end{tabular}

in different categories. Within the "Leadership" category is Student 42's post that the role of a student is "Leadership. Some students have a voice in school policy." And within the category "Accept the situation and just get the work done," is Student 29's comment, "Students must be able to influence decisions in the school, but once those decisions have been made, they need to accept them or contest them in an orderly manner." Finally, within the category "Prepare for College / Adulthood," is Student 37's submission that the role of students is "To take charge. Students should be able to choose classes and lead their own path through school to best fit their priorities to the career they will choose after high school."

There were several student submissions suggesting dissatisfaction with the role students feel they are currently given (n10, 13\%). The role of students is "Follower" (Student 13), “Test subject" (Student 16), and "Prisoner" (Student 2), adding, "We have to do the same thing everyday...if we don't we get punished." Student 5 concluded, 
"The role just needs to be more expanded."

Two of the three teacher submissions reflecting a student voice orientation with regard to the role of a high school student are found in the category "Provide feedback." Teacher 22 posted, "Students frequently provide insights and ideas that never occurred to me as a teacher. When teachers are open to those insights, learning can really take off." And Teacher 3 elaborated,

In truly high functioning systems, the school community would be structured so that the system side would seek and receive continuous feedback from the "students-as-product" side. Students would provide teachers with feedback that would inform their instruction and management. This would be a part of the way schools work, and would seem normal and reasonable to both teachers and students.

The only other teacher post in the responses to question three that was somewhat aligned with student voice principles is found in the "Other" category. Teacher 31 suggested that teachers offer students a choice between a proficiency model of grading and the more traditional banking model. "If a student chooses banking, a teacher should offer that as an option."

One teacher found the idea of defining student role restricting. "The role of a student should vary drastically," submitted Teacher 19. "If one tries to 'describe the role' of a student, it limits that role. There should be such a variety of roles that there should be no such description."

Finally, students and teacher participants prioritized the thematic categories by assigning 1-3 stars to the categories of their choice. Participants were each allotted seven stars because of the greater number of categories. Nineteen students $(40 \%)$ and fourteen teachers (44\%) participated. Results of this ranking are summarized in Table 9. 
Table 9

Question 3: Summary of Student and Teacher Category Rankings

\begin{tabular}{|c|c|c|c|c|c|c|c|}
\hline \multicolumn{8}{|c|}{ Q3: How would you describe the role of a student in high school? } \\
\hline $\begin{array}{l}\text { Q.3 Student } \\
\text { Response } \\
\text { Categories }\end{array}$ & $\begin{array}{l}\text { Overall } \\
\text { Rating }\end{array}$ & $\begin{array}{l}\text { Partici } \\
\text { pant } \\
\text { Count }\end{array}$ & $\begin{array}{l}\text { Average } \\
\text { Rating }\end{array}$ & $\begin{array}{l}\text { Q.3 Teacher } \\
\text { Response } \\
\text { Categories }\end{array}$ & $\begin{array}{l}\text { Overall } \\
\text { Rating }\end{array}$ & $\begin{array}{l}\text { Partici } \\
\text { pant } \\
\text { Count }\end{array}$ & $\begin{array}{c}\text { Average } \\
\text { Rating }\end{array}$ \\
\hline $\begin{array}{l}\text { Prepare for } \\
\text { College/Adulthood }\end{array}$ & $\begin{array}{c}22 \\
(17 \%)\end{array}$ & 14 & 1.57 & $\begin{array}{l}\text { Actively } \\
\text { Participate in } \\
\text { Learning }\end{array}$ & $\begin{array}{c}27 \\
(29 \%)\end{array}$ & 13 & 2.08 \\
\hline $\begin{array}{l}\text { Be Respectful / } \\
\text { Responsible }\end{array}$ & $\begin{array}{c}19 \\
(15 \%)\end{array}$ & 11 & 1.73 & $\begin{array}{l}\text { School is the } \\
\text { job }\end{array}$ & $\begin{array}{c}18 \\
(19 \%)\end{array}$ & 9 & 2.00 \\
\hline $\begin{array}{l}\text { Accept the situation } \\
\text { and just get the work } \\
\text { done }\end{array}$ & $\begin{array}{c}18 \\
(14 \%)\end{array}$ & 12 & 1.50 & $\begin{array}{l}\text { Community } \\
\text { Member }\end{array}$ & $\begin{array}{c}13 \\
(14 \%)\end{array}$ & 9 & 1.44 \\
\hline $\begin{array}{l}\text { Leadership / Be Role } \\
\text { Model }\end{array}$ & $\begin{array}{c}17 \\
(13 \%)\end{array}$ & 11 & 1.55 & $\begin{array}{l}\text { Self } \\
\text { Exploration }\end{array}$ & $\begin{array}{c}13 \\
(14 \%)\end{array}$ & 7 & 1.86 \\
\hline $\begin{array}{l}\text { Develop / Discover } \\
\text { Personal Character }\end{array}$ & $\begin{array}{c}16 \\
(12 \%)\end{array}$ & 11 & 1.45 & $\begin{array}{l}\text { A } \\
\text { Representative } \\
\text { and Role } \\
\text { Model }\end{array}$ & $\begin{array}{c}9 \\
(10 \%)\end{array}$ & 7 & 1.29 \\
\hline $\begin{array}{l}\text { Be Involved in } \\
\text { Sports/Clubs/ } \\
\text { Activities }\end{array}$ & $\begin{array}{c}14 \\
(11 \%)\end{array}$ & 11 & 1.27 & Be Respectful & $\begin{array}{c}7 \\
(8 \%)\end{array}$ & 6 & 1.17 \\
\hline $\begin{array}{l}\text { To Participate in the } \\
\text { Learning / Academic } \\
\text { Success }\end{array}$ & $\begin{array}{c}13 \\
(10 \%)\end{array}$ & 11 & 1.18 & $\begin{array}{l}\text { Provide } \\
\text { Feedback }\end{array}$ & $\begin{array}{c}6 \\
(6 \%)\end{array}$ & 5 & 1.20 \\
\hline $\begin{array}{l}\text { Current Role is Not } \\
\text { Satisfactory }\end{array}$ & $\begin{array}{c}9 \\
(7 \%)\end{array}$ & 3 & 3.00 & $\mathrm{X}$ : Other & 0 & 0 & 0.00 \\
\hline $\mathrm{X}$ : Other & $\begin{array}{c}3 \\
(2 \%)\end{array}$ & 3 & 1.00 & & & & \\
\hline $\begin{array}{r}\text { Total Stars } \\
\text { Used }\end{array}$ & $\begin{array}{l}131 \\
(100 \%)\end{array}$ & & & $\begin{array}{r}\text { Total Stars } \\
\text { Used }\end{array}$ & $\begin{array}{l}93 \\
(100 \%)\end{array}$ & & \\
\hline $\begin{array}{r}\text { Student Voice } \\
\text { Summary }\end{array}$ & 0 & & & $\begin{array}{r}\text { Student Voice } \\
\text { Summary }\end{array}$ & $\begin{array}{l}6 \\
(100 \%)\end{array}$ & & \\
\hline
\end{tabular}

(Table continues) 


\begin{tabular}{|c|c|c|c|}
\hline $\begin{array}{l}\text { Q.3 Student } \\
\text { Response } \\
\text { Categories }\end{array}$ & $\begin{array}{lc}\text { Partici } & \text { Average } \\
\text { pant } & \text { Rating } \\
\text { Count } & \text { Rating }\end{array}$ & $\begin{array}{c}\text { Q.3 Teacher } \\
\text { Response } \\
\text { Categories }\end{array}$ & $\begin{array}{l}\text { Partici } \\
\text { pant } \\
\text { Count }\end{array}$ \\
\hline $\begin{array}{l}\text { Total Number of } \\
\text { Participants ( /47) }\end{array}$ & $\begin{array}{l}19 \\
(40 \%)\end{array}$ & $\begin{array}{l}\text { Total Number } \\
\text { of Participants } \\
\text { (/32) }\end{array}$ & $\begin{array}{l}14 \\
(44 \%)\end{array}$ \\
\hline \multicolumn{4}{|c|}{$\begin{array}{l}\text { Note. Seven(7) stars allotted per participant; maximum three }(3) \text { stars may be assigned per response group } \\
\text { Overall rating: total number of stars assigned to that group of thoughts } \\
\text { Participant count: the number of people that assigned stars to that group of thoughts } \\
\text { Average rating: the average number of stars that was given to that group of thoughts }\end{array}$} \\
\hline
\end{tabular}

When ranking their student role categories, students rated "Prepare for college and/or adulthood" first, assigning 17\% (n22) of the total assigned stars for an average of 1.57 stars. This was followed closely by "Be respectful and/or responsible" (15\%, n19), "Accept the situation and just get the work done" (14\%, n18), "Leadership and/or be a role model" (13\%, n17), and "Develop and/or discover personal character" $(12 \%, \mathrm{n} 16)$. Of this set, "Be respectful and/or responsible" had the highest average rating at 1.73. "To participate in the learning and/or academic success" ranked near the bottom with $10 \%,(\mathrm{n} 13)$ and a 1.18 average rating.

In contrast, for the teachers, "Actively participate in learning” ranked first, receiving $29 \%$ (n27) of the total assigned stars for an average rating of 2.08 stars. "School is the job" ranked second, receiving 18 stars (19\%, average 2.00). Tied for third were "Community member" and "Self exploration" garnering 13 stars (14\%) each, with "Self exploration" receiving the higher average rating of 1.86 compared to 1.44 for "Community member." In contrast to the second place rating by students (15\%, n19), "Be respectful" was ranked second to last by teachers, receiving 7 stars (8\%).

The one teacher category representing student voice principles ranked last, 
receiving $6 \%(\mathrm{n} 6)$ of the assigned stars for an average of 1.20 . Interestingly, the student category "Current role is not satisfactory" also ranked near the bottom (n9, 7\%) but received the highest average rating (3.00) of any category in any of the three questions. This indicates that the three participants (16\%) that ranked it felt very strongly about it assigning it all of their allotted stars.

In this chapter the results of the Thoughtstream process were presented with a focus on thoughts and themes relating to student voice. The categorized responses of students and teachers to each of the three online questions were summarized. The ranked categories were then presented. Throughout, particular attention was given to those thoughts and categories identified as aligning with student voice principles. In the next chapter these results will be analyzed to develop a description of student role identity as communicated by the RHS participants. 


\section{Analysis}

The goal of this research was to develop a situated description of the student role within the organizational context of high school from the perspectives of students and staff. The research questions guiding this inquiry included:

1) How do youth from a rural high school conceptualize the role of "student" in the organizational context of the school?

2) How do teachers and administrators within the same high school community conceptualize the role of "student" in the organizational context of the school?

Data was collected, categorized, and ranked through the use of an online software platform from the responses of students and teachers to three questions developed by the Student Research Team:

1. What does it mean to be actively involved in high school?

2. What opportunities should high school students have to have their voices heard in order to influence classroom and/or school policies and practices?

3. How would you describe the role of a student in high school?

In this chapter answers to the two research questions are proposed based on what the responses, categories and rankings reveal about how participant students and teachers conceptualize the student role, what these conceptions reveal about the participants' thinking, and how these conceptions compare with one another.

Responses to the third online question are considered first, as it addressed the issue of student role directly, asking participant to answer: "How would you describe the role of a student in high school?" 


\section{Student Perspectives}

Figure 11 summarizes how student participants responded to and later ranked the categorized responses to the online question, "How would you describe the role of a student in high school?" In graphing the results, the thought data and category rankings summarized separately in Chapter IV have been combined in order to better capture the thinking of the participants. The rankings, depicted in the dark area of the bar, reveal how each particular category of responses was valued by the respondents. The light grey area of the bar, representing the percentage of total submissions assigned to each category, provides an initial snapshot of how significant that aspect of the student role was for respondents. Combined, the thought data and rankings provide a more complete summary of how the participants viewed the various aspects of the student role.

For example, for the students, the category "Participate in the learning / academic success" initially garnered the highest number of thoughts, but later received the second lowest ranking. But when the number of thoughts and the ranking are considered together, they more completely express the significance of this category to the respondents. This combining procedure is further justified by the fact that for both students and teachers, there was limited crossover between the participants contributing thoughts, and those ranking the categories. For this student role question, only $25 \%$ (n8) of the 32 students contributing thoughts also participated in the ranking process, in essence providing two distinct viewpoints on the question. For questions one and two, the crossover rate was $24 \%$ and $22 \%$ respectively. For the teachers, the crossover rate was even lower, with $15 \%$ of those ranking the categories having contributed to the 
responses of question one, $0 \%$ for question two, and $5 \%$ for question three. The implications of this limitation will be discussed further in Chapter VI.

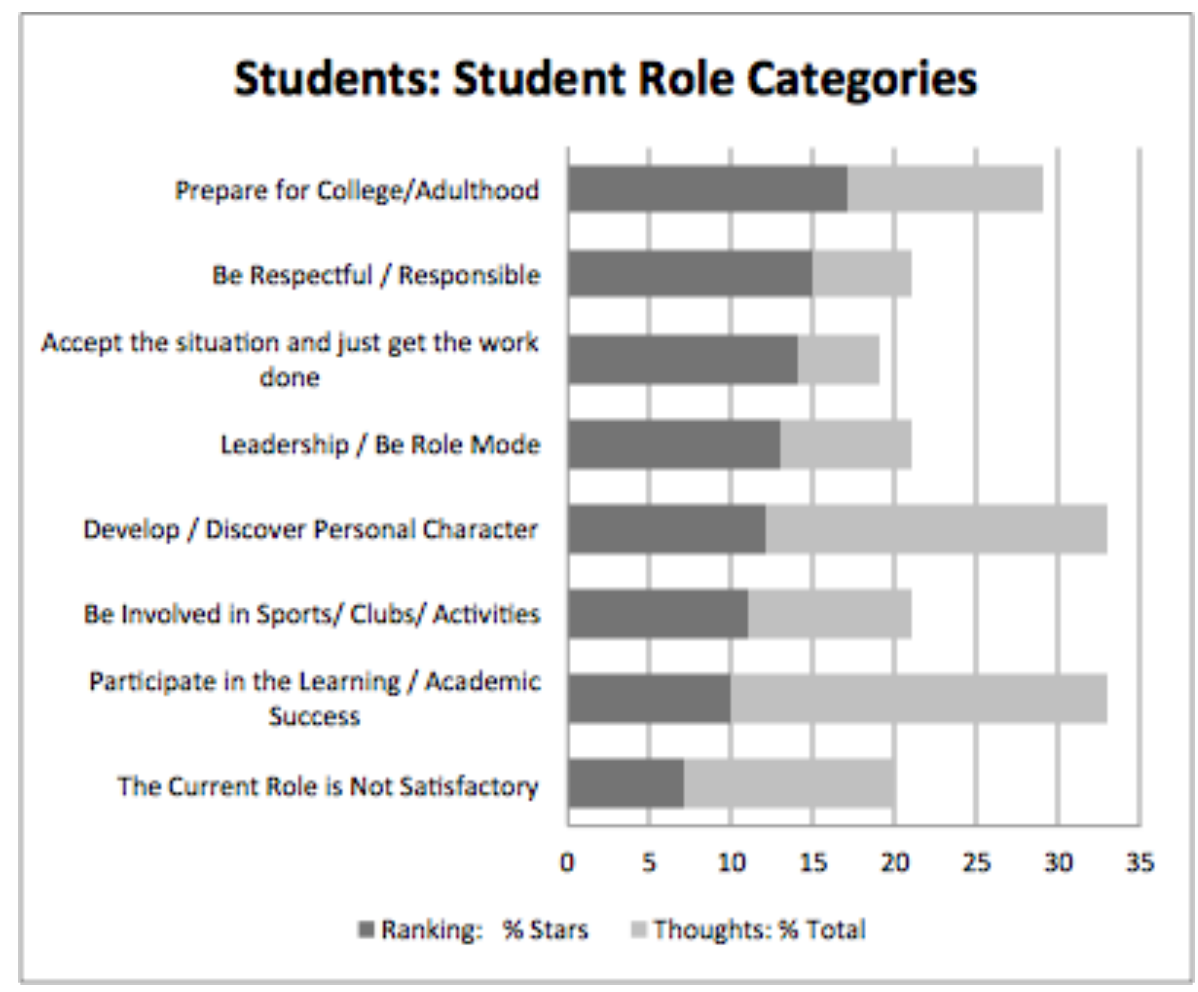

Figure 11. Summary of Student Role Categories' Thoughts and Rankings by Student Participants.

Following this method, three student role categories stand out: "Preparing for College/Adulthood," "Developing / Discovering Character," and "Participating in the Learning / Academic Success." These categories reveal three distinct loci of the student role identity: an internal psychological dimension - character development; an external behavioral dimension - participation in academics; and a temporal dimension - preparing for the future. Considered within a systems framework, these role identity categories manifest the fundamental systemic qualities (Zwick, 2006) of structure (being - what a 
student is), function (behaving- what a student does) and history (becoming -

contextualizing being and behaving in time - in this case, what a student will become).

The other categories, relatively equivalent in their combined scores despite differences in numbers of thoughts and rankings, can be loosely placed within this typology of being,

behaving, and becoming. See Table 10.

Table 10

Systemic Typology of Student Response Categories

System Qualities (Adapted from Zwick, 2006)

Student Response Categories

Temporal: Focused on the future

Prepare for College/Adulthood: The role of

(history/becoming/what a student will become)

students is to prepare for college, career and life.

Behavioral: Focused on present actions (function/behaving/what a student does)

To Participate in the Learning / Academic

Success. The role of students is to participate in

class, learn what is taught, pass their classes and graduate.

Accept the situation and just get the work done: The role of students is to accept the limits of the situation and do their work.

Be Involved in Sports/ Clubs/ Activities: The role of students is to be INVOLVED - whether it is clubs, sports, activities or academics.

Leadership / Be a Role Model: The role of students is to be a leader, impact school policy, and be a role model for other students.

Be Respectful / Responsible: The role of students is to be respectful to others and responsible for themselves and their work.

Psychological: Focused on internal conditions (structure/being/what a student is)

Develop / Discover Personal Characteristics:

The role of students is to develop personal characteristics such as caring, confidence, commitment, respect, maturity and having a positive attitude.

Other: Current Role is Not Satisfactory: These responses reveal dissatisfaction with the role students feel they currently have.

Within the behavioral group, the categories have been ordered to represent a 
gradual transition from direct engagement in the academic "work" of schooling, through involvement in the extracurricular offerings of school, transitioning toward more psychological states of "being" - a leader, a role model, respectful and responsible.

The placement of thematic categories is not meant to suggest that every response within each category conforms completely with the typology, but rather that the overall theme suggested by the category of responses is accurately reflected by its placement along the three dimensions. Many comments, while placed within one category, include other dimensions. For example, Student 39 submitted that the role of a high school student is to "Learn life lessons. Students should learn what's right from wrong. Students should learn important tasks and career choices so they get a better understanding of how life will work once out of school." This response includes both a psychological dimension, learning right from wrong, and a temporal one, focusing on future application, but was considered as generally reflecting the characteristics of the "Prepare for College / Adulthood" thematic category.

Similarly, within the thematic category "Develop/Discover Personal Characteristics," was placed this response from Student 26: "Learning isn't strictly academic. High school is a time for us to learn who we are (for the most part), what we like, what we want to do, and how to be an adult." This comment, while contextualizing learning within a temporal dimension oriented to the future, focuses on discovering personal characteristics and so was grouped with that theme.

Considered as a whole, there is nothing particularly surprising about the students' conceptions of the student role. Each dimension and the comments it contains seems to 
fall within traditional ideas of what it means to be a high school student, as exemplified by the following submissions representative of each thematic category.

Prepare for College/Adulthood: "Students must realize that high school IS their future," submitted Student 29, adding, "High school is a crucial point where landmark decisions are made. These decisions will follow students for the rest of their lives and they need to realize that each day of high school shapes their future."

Participate in the Learning / Academic Success: "Graduate on time," posted Student 45, "So you can go to college and be able to get a good job." Accept the situation and just get the work done: "It very much is just finish this," stated Student 5. "For the basic student its just get done with work, go home." Be Involved in Sports/Clubs/Activities: Student 9 submitted, "Being involved in school is always very important, whether it's in sports, clubs, or school activities. Being involved gives students motivation towards achieving higher goals."

Leadership/Be a Role Model: "When younger students look up to us it is crucial that we set a good [example]," suggested Student 8.

Be Respectful/Responsible: "The role a student plays in high school is being responsible," stated Student 27. "Being a student who has their goals all ready to graduate, has a great personality, and gets good grades.”

Develop/Discover Personal Characteristics: "Be mature," posted Student 41. "This is the period of your life when you are a teenager and you need to learn how to act like an adult."

Even responses in the thematic category Current Role is Not Satisfactory, 
depicting the student role as "Follower" (Student 13), "Test subject" (Student 16), or "Prisoner" (Student 2), seem to reflect familiar student opinions.

What is surprising in the responses to the student role question, is the lack of any significant inclusion of the kind of student agency suggested in the responses to the other two Thoughtstream questions.

When asked what opportunities high school students should have to influence classroom and/or school policies and practices, $63 \%$ of the submissions suggested an expanded student role that included multiple opportunities to have their voices heard at all levels of the school system. During the ranking stage, the thematic categories of these submissions expressing student voice principles received $58 \%$ of the allotted stars. And in response to the question about what it means to be involved in school, $7 \%$ of the submissions included student voice principles and garnered $18 \%$ of the ranking stars. And yet when asked to describe the student role, only three of the submissions, just $4 \%$ of the total, even obliquely manifested student voice ideas. In other words, while the students expressed a strong desire for meaningful involvement at all levels of the school organization in responses to the other questions, they did not see this active participation as a fundamental part of their role as members of the school community. A similar pattern of disconnect also appears in the teacher data.

\section{Teacher Perspectives}

Figure 12 summarizes how teacher participants responded to and ranked the categorized responses to the student role question. In comparison to the student submissions, a review of the teacher responses reveals both similarities and differences. 


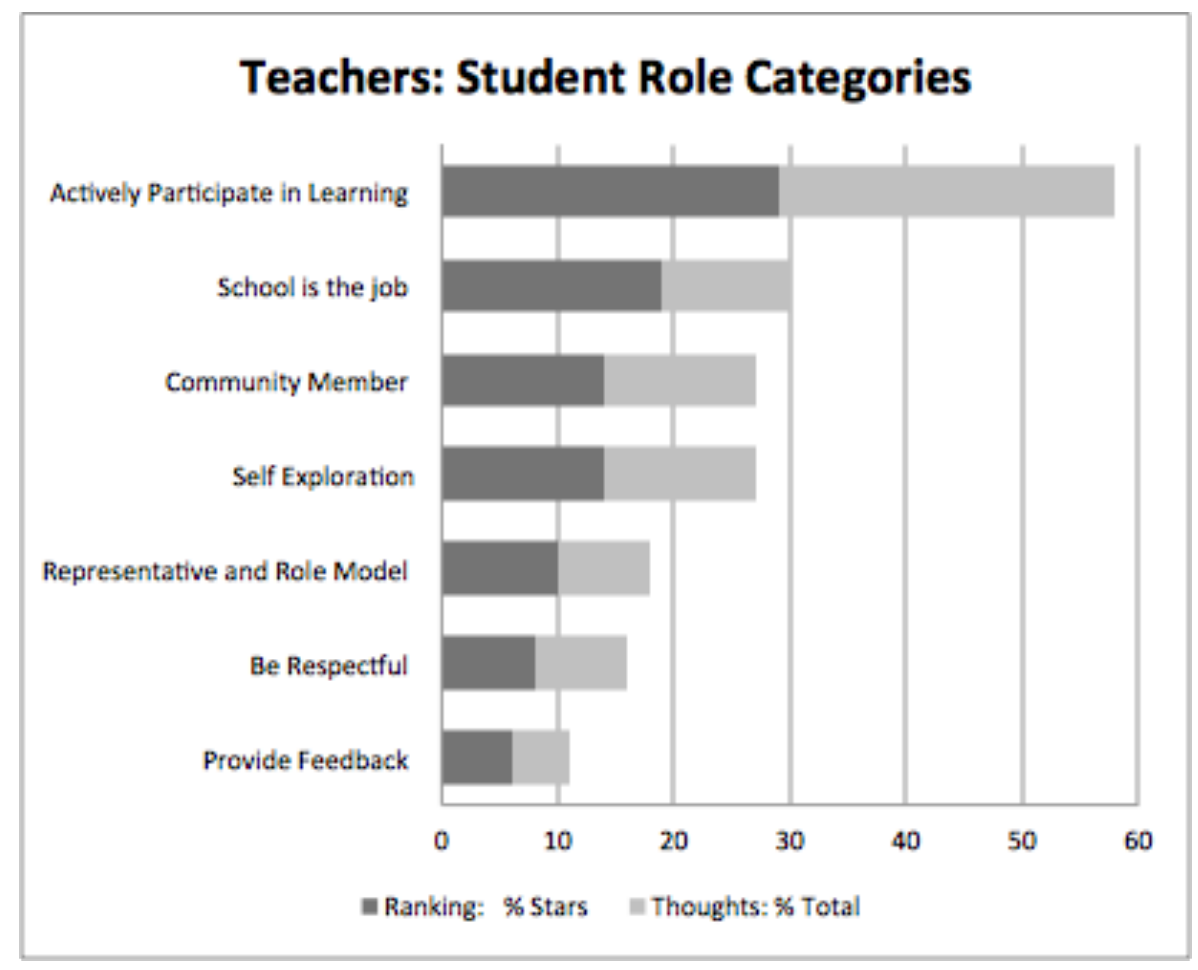

Figure 12. Summary of Student Role Categories' Thoughts and Rankings by Teacher Participants.

Two significant aspects of the teacher responses are apparent in the graph. First is the clear dominance of the category "Actively Participate in Learning." When considered with the related second ranked category, "School is the Job," it becomes apparent that the most important aspect of the student role for teachers is an academic one. This focus on the academic aspect of the student role could be expected as it aligns with the traditional educational mission of schools and the professional responsibility teachers have to ensure student learning. However, this focus on the academic mission of schools, although appropriate and understandable, could cause teachers to see other areas of expanded student involvement as a distraction from the assessed outcomes for which they are held accountable. 
The second significant result revealed in the teacher data is the relative consistency between the percentage of total thoughts in each thematic category and its ranking, despite the lack of crossover between participants of the thought and ranking processes described earlier. Contrast this with the student results displayed in Figure 11. In only one category of student data does the percentage of thoughts and the ranking align, "Be involved in Sports/Clubs/Activities." In every other category the number of thoughts and the ranking are disjointed, one being higher or lower than the other - some, like "Be Respectful/Responsible” and "Current Role is Not Satisfactory," significantly so. The same general pattern was found in the responses to the other questions, with the teachers being more consistent than the students in their rankings of response categories in relation to the percentage of total thoughts assigned to each of the categories. This consistency by the staff hints at the relative stability of the teachers' cognitive models of the student role in comparison to the students' developing understandings, and could also have consequences regarding the acceptance of an expanded definition of student role.

When the typology developed from the student responses is applied to the teacher groups, additional areas of divergence are revealed. See Table 11.

While both the student and teacher thematic categories include Psychological and Behavioral dimensions, the Temporal theme did not dominate enough of the teacher responses to warrant a category explicitly addressing this aspect. A search through both the teacher and student submissions using the terms "future," "career," "college," and “job,” followed by a review of associated responses, identified just five teacher comments (13\%) including references to the future, compared with fifteen postings 
Table 11

Systemic Typology of Teacher Response Categories

\begin{tabular}{|c|c|}
\hline System Qualities (Adapted from Zwick, 2006) & Teacher Response Categories \\
\hline $\begin{array}{l}\text { Temporal: Focused on the future } \\
\text { (history/becoming/what a student will become) }\end{array}$ & No Categories. \\
\hline $\begin{array}{l}\text { Behavioral: Focused on present actions } \\
\text { (function/behaving/what a student does) }\end{array}$ & $\begin{array}{l}\text { Actively Participate in Learning: The role of } \\
\text { students is to be actively engaged in the learning } \\
\text { process. } \\
\text { School is the job: The role of the student is to } \\
\text { recognize that doing school is their job. } \\
\text { Community Member: The role of the student is } \\
\text { to act as a citizen / member of a community. } \\
\text { Representative and Role Model: The role of } \\
\text { students is to represent their families well and be a } \\
\text { role model for other students. } \\
\text { Be Respectful: The role of students is to be } \\
\text { respectful to others and responsible for themselves } \\
\text { and their work. }\end{array}$ \\
\hline $\begin{array}{l}\text { Psychological: Focused on internal conditions } \\
\text { (structure/being/what a student } i s \text { ) }\end{array}$ & $\begin{array}{l}\text { Self Exploration: The role of students is to } \\
\text { explore interests and grow as a person. }\end{array}$ \\
\hline Other: & $\begin{array}{l}\text { Provide Feedback: The role of students is to } \\
\text { provide inputs to the system to make it more } \\
\text { effective. }\end{array}$ \\
\hline
\end{tabular}

(19\%) from students that included a future orientation. And all five teacher submissions included other themes that led to their placement within other categories. For example, Teacher 15 described the role of the student as a "Learner preparing for the future," then added, "They are learning who they are - that's why it is so important to provide lots of activities and opportunities." The orientation toward personal development led to its placement in that category. Ironically, Teacher 15 , in response to an earlier question, posted, "The issue is that most teens, as I see it, are too busy and too concerned about the current moment. They are not developed enough to think into the future or to care about 
how their actions will affect others."

While I have no doubt that teachers at RHS do indeed frame their work as preparing students for the future, the absence of a stronger presence of this sentiment in the responses is noteworthy, especially considering the "college and career ready" sloganing that currently imbues the adult narrative on youth education. This general lack of expressed forward thinking in the teacher responses reinforces the conclusion that the students' concepts of the student role is more strongly oriented toward the future than the one articulated by the adult respondents. Also, this apparent lack of temporal contextualization of the student role by teachers represents a potential blind spot in considering membership in the school community as a precursor to citizenship in the body politic. This oversight is amplified given the inclusion of a description of the student role as that of a "citizen or community member" as one theme in the teacher responses. Again, this disconnect could have consequences regarding the acceptance of an expanded definition of the student role that recognizes the rights of citizenship inherent in membership in the school community.

\section{Comparison of Student and Teacher Perspectives}

Other differences and similarities can be found between the student and teacher conceptions of the student role when organized as in Table 12. In the table, similar response categories of the students and teachers have been aligned, leaving blanks when no similar theme exists between the two.

If anything, the table reveals more congruence than difference in how student and teacher participants defined the student role. Both identified academic engagement as a 
Table 12

\section{Comparison of Student and Teacher Student Role Categories}

Student Categories Describing Student Role

Prepare for College/Adulthood: The role of - - -

students is to prepare for college, career and life.

To Participate in the Learning / Academic Success. The role of students is to participate in class, learn what is taught, pass their classes and graduate.

Accept the situation and just get the work done: The role of students is to accept the limits of the situation and do their work.

Be Involved in Sports/ Clubs/ Activities: The role of students is to be INVOLVED - whether it is clubs, sports, activities or academics.

- - Community Member: The role of the student is

Leadership / Be Role Model: The role of students is to be a leader, impact school policy, and be a role model for other students.

Be Respectful / Responsible: The role of students is to be respectful to others and responsible for themselves and their work.

Develop / Discover Personal Characteristics: The role of students is to develop personal characteristics such as caring, confidence, commitment, respect, maturity and having a positive attitude. to act as a citizen / member of a community.

Teacher Categories Describing Student Role

Actively Participate in Learning: The role of students is to be actively engaged in the learning process.

School is the job: The role of the student is to recognize that doing school is their job.

$--$

$-\cdot-$

Representative and Role Model: The role of students is to represent their families well and be a role model for other students.

Be Respectful: The role of students is to be respectful to others and responsible for themselves and their work.

Self Exploration: The role of students is to explore interests and grow as a person.

- - - Provide Feedback: The role of students is to provide inputs to the system to make it more effective.

Current Role is Not Satisfactory: These responses reveal dissatisfaction with the role students feel they currently have. 
significant aspect of the student role. Likewise, being a role model, and being respectful and responsible, were themes in the responses of both groups. And both student and teacher respondents recognized an internal, psychological dimension of the student role as depicted in the student thematic category, "Develop / Discover Personal Characteristics," and the teacher thematic category, "Self Exploration."

There were, however, also significant points of difference between each group's conception of the student role. Involvement in sports, clubs and activities was included as a dimension of the student role by students, but was not a theme in the teacher responses to this question. This omission by the teachers, like the omission of a future orientation, reinforces the primacy of academics in the teacher perspective. Perhaps in response to a lack of empowerment to engage the system on their own terms, the student category, "Accept the situation and just get the work done" received the third highest ranking, while the number of submissions expressing dissatisfaction with the current student role included the third highest number of thoughts (Refer to Figure 11). As Student 5 posted, "The role just needs to be more expanded, not just get done and go."

Finally, the smallest and lowest ranked teacher category, "Provide Feedback: The role of students is to provide inputs to the system to make it more effective," is the only student role category in either group's responses to the question of student role that specifically advocates for student voice, though importantly, not for student empowerment. Rather the vision of student engagement captured in this category is a passive, utilitarian one, which sees students as a source of information for adults to act on, rather than agents of change themselves. 
The diminished consideration of student voice and the conventional aspects of the student role depicted in both the student and teacher responses to defining the student role, stand in stark contrast to conceptions of the student role revealed in responses to the other two questions. The range of student voice themes revealed in the student and teacher responses to questions one and two, which asked respondents to consider what it means to be actively involved in high school and what opportunities students should have to influence policies and practices, are aligned and summarized in Table 13.

Similar themes appear in the responses of both students and teachers and include: being able to voice opinions and vote on policies; influence classroom practices and policies; and using student government and leadership organizations to represent student ideas. In addition, teachers saw students working with administrators and specifically working to make school a better place. Meanwhile, some students felt they should just be able to make their own decisions about things that affect them, at least in certain areas like the dress code, an idea not included in the teacher responses.

As mentioned previously, these declarations of meaningful student involvement and influence at all levels of the system first appeared in the submissions to question one regarding what it means to be actively involved in high school, and then dominated the thoughts and rankings of question two, which asked what opportunities students should have to influence classroom and/or school policies and practices. For comparison, the percentage of submissions to all three questions expressing a student voice orientation is depicted in Figure 13. 
Table 13

Summary of Student Voice Themes in Student and Teacher Responses

to Questions 1 and 2.

Q.1: What does it mean to be actively involved in high school?

Q.2: What opportunities should high school students have to have their voices heard in order to influence classroom and/or school policies and practices?

Student Responses $\quad$ Teacher Responses

Q.2: Student Choice: Students should be able to make their own decisions about things that affect them - like the dress code.

Q.2: Voice Opinions/Vote on Policies: Students should have real opportunities to voice ideas and opinions without censorship. Students should have opportunities to influence policy, and vote on policy decisions that affect them.

Q.2: Influence Teaching Style, Classroom Content and Approaches: Students should have opportunities to have their interests and learning styles taken into account in the classroom.

Q.2: Student Government: Students should be able to use student government to represent their opinions and influence school policies.

\section{Q.1: Lead and/or Voice Opinions: To be} actively involved in school means to find opportunities to be a leader and/or to voice your opinions
Q.2: Voice Opinions: Students should have real opportunities to voice ideas and opinions. Students should have opportunities to influence policy, and vote on policy decisions that affect them.

Q.2:Influence Classroom Policies: Students should have opportunities influence some classroom policies.

Q.2: Student Government: Students should be able to use student government and other leadership roles to voice their ideas.

\section{Q.1: Active in Student Leadership}

Organizations: To be actively involved in high school means to become active in student leadership organizations.

- - Q.2: Work with Administration: Ask/Survey student for what they would like to see more of or less of in the school climate. Then determine what can be done to accommodate the requests.

- - Q.1: Making school a better place: To be actively involved in school means to be actively engaged in making the school a better place. 


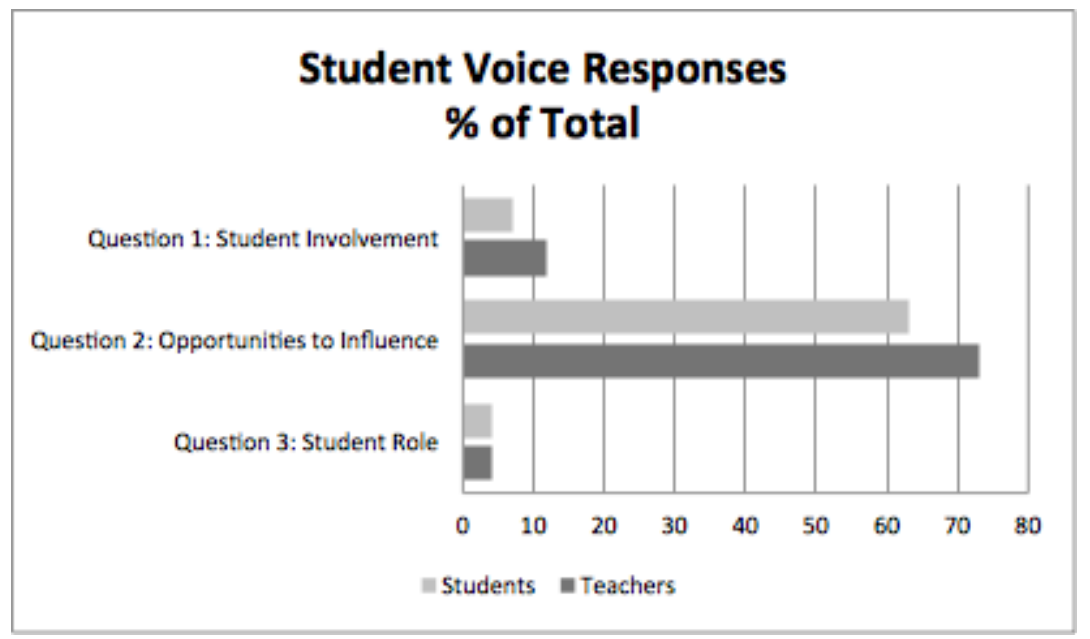

Figure 13. Summary of Student Voice Submissions

The graph reveals that in response to Questions 1 and 2, a total of nearly $70 \%$ of student submissions, and over $80 \%$ of teacher submissions, were identified as expressing student voice principles. Once categorized by theme, the rankings of the categories reinforce the significance of the student voice principals revealed in the number of thoughts. See Figure 14.

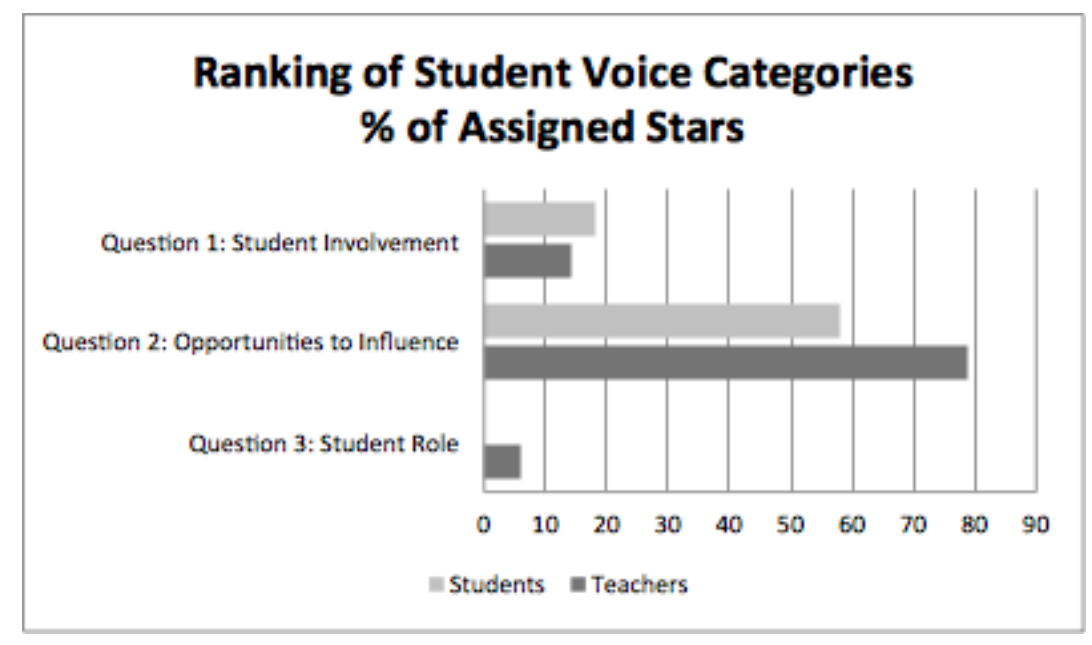

Figure 14. Summary of Student Voice Category Rankings 
When ranking the categories of responses to Questions 1 and 2, students assigned a total of $76 \%$ of their allotted stars to categories aligned with student voice principles, while teachers assigned nearly all of theirs at 93\%. These rankings of the student voice categories and the number of thoughts submitted expressing student voice ideas indicate an overwhelming orientation among students and staff toward meaningful student involvement and influence both within and beyond traditional avenues. Both students and teachers expressed a variety of ways that students could engage and influence decisions, policies and practices from the classroom to the school level, including participating on site council and the school board. And yet essentially none of these expressions of student agency carried over to inform conceptions of the student role as described in response to question three.

One possible explanation for this situation is how the participants interpreted the question, "How would you describe the role of a student in high school?" And yet the variety of responses to the question as indicated by the range of thematic categories revealed in the submissions suggests that the question was understood broadly enough to have allowed inclusion of more agentic notions of the student role. Another possibility is that the conceptions of the student role expressed in the responses of both students and teachers reveals the depth of the RHS community's enculturation into societal norms, beliefs and customs that define the boundaries of appropriate student involvement, including relations of power and authority (Apple \& Beane 1995; Stone 2002; Jenks, 2004), that inform this research. Thus although expressing an expansive view of meaningful student involvement and influence in response to the first two questions, the 
students and teachers have yet to challenge deeper, possibly unexamined assumptions that would permit integration of their notions of student agency into a systemic definition of what a student is, does, and becomes.

Up to now we have considered the conceptions of the student role identified in response to question three from both the student and teacher perspectives pointing out the lack of inclusion of the student voice principles articulated in response to the other online questions. We now turn our attention to a fuller elaboration of the student role that incorporates the responses to all three questions.

\section{A Synthesis of Characteristics of the Student Role Identity Standard}

In order to more fully represent the student and teacher conceptions of the student role so that they might be compared with each other and with student role characteristics depicted in the student voice literature, the responses to all three online questions were synthesized. Common themes in the respondents' submissions across questions were identified, combined, and edited for clarity as necessary. Duplicate themes were eliminated and in the case of categories where the Student Research Team had paired related themes, some were separated in order to detail distinct characteristics of the student role. For example, the category "Be respectful and responsible" contains two ideas - the outwardly directed relational concept of "respect," and the more inward, personal attitude of "responsibility" - and so were articulated separately. The resulting themes were organized according to role attributes identified in role theory (Major 2003; Thomas \& Biddle as cited in Brookes, Davidson, Daly, and Halcomb, 2007) without consideration to the original participant rankings or number of thoughts submitted. 
Categories such as "Current Role is Not Satisfactory" that did not contribute features to the student role identity standard were not included in the synthesis.

\section{Student Conceptions}

The summary of this process of integration and organization applied to the student response categories is summarized in Table 14 and answers the first research question: How do youth from a rural high school conceptualize the role of "student" in the organizational context of the school?

The first set of student role attributes, "Characteristics," answers the question, "What is a student?" Student response categories assigned to this group include traditional notions of the student as a role model, and one who is respectful and responsible. These traits are exemplified in the following comments. As Student 15 responded to the question regarding the role of high school students, "Leaders." Student 19 posted, "The role of upper classmen is to be a good example for the underclassmen." And Student 33 submitted, "You have to be very responsible to be a successful student in high school." This group also included the more agentic conception of the student as a leader impacting the learning environment.

The second set of student role attributes, "Behavior Expectations / Norms" answers the question, "What does a student $d o$ ?" Student response categories assigned to this attribute include both traditional student norms of behavior and belief, and those representing a more agentic view of the student role and were sub-grouped accordingly. Associated with more traditional definitions of the student role were expectations of involvement in all aspects of conventional school life: academics, athletics, clubs 
Table 14

\section{A Summary of the Student Role Characteristics according to Students}

\begin{tabular}{|c|c|}
\hline Role Attributes & Student Response Categories \\
\hline $\begin{array}{r}\text { Characteristics } \\
\text { (distinguishing } \\
\text { features) } \\
\text { What a student } \underline{\text { is. }}\end{array}$ & $\begin{array}{l}\text { Leader: The role of students is to be a leader, voicing opinions and impacting } \\
\text { school policy. } \\
\text { Role model: The role of students is to be a role model for other students. } \\
\text { Respectful: The role of students is to be respectful to others. } \\
\text { Responsible: The role of students is to be responsible for themselves and their } \\
\text { work. }\end{array}$ \\
\hline $\begin{array}{r}\text { Behavior } \\
\text { Expectations / } \\
\text { Norms } \\
\text { (expected patterns } \\
\text { of behavior and } \\
\text { belief) } \\
\text { What a } \\
\text { student does. } \\
\text { (Traditional } \\
\text { Themes) }\end{array}$ & $\begin{array}{l}\text { Be involved: The role of students is to be INVOLVED - whether it is clubs, sports, } \\
\text { activities or academics. } \\
\text { Participate in the learning toward academic success: The role of students is to } \\
\text { participate in class, learn what is taught, pass their classes, and graduate. } \\
\text { Show school spirit: To be actively involved in school means taking pride in your } \\
\text { school, showing your school spirit. } \\
\text { Participate in sports/ clubs/ activities: The role of students is to participate in } \\
\text { clubs, sports, and school activities. } \\
\text { Prepare for college/adulthood: The role of students is to prepare for college, } \\
\text { career and life. } \\
\text { Develop / Discover personal character: The role of students is to develop } \\
\text { personal characteristics such as caring, confidence, commitment, respect, maturity } \\
\text { and having a positive attitude. } \\
\text { Follow rules and policies: These responses suggest that students should follow } \\
\text { rules and policies instead of influencing them. }\end{array}$ \\
\hline $\begin{array}{r}\text { What a } \\
\text { student does. } \\
\text { (Agentic Themes) }\end{array}$ & $\begin{array}{l}\text { Voice opinions: Students should have real opportunities to voice ideas and } \\
\text { opinions without censorship. } \\
\text { Use student government: Students should be able to use student government to } \\
\text { represent their opinions and influence school policies. } \\
\text { Influence policies: Students should have opportunities to influence policy } \\
\text { Vote on policies: Students should have opportunities to vote on policy decisions } \\
\text { that affect them. } \\
\text { Influence teaching style, classroom content and approaches: Students should } \\
\text { have opportunities to have their interests and learning styles taken into account in } \\
\text { the classroom. } \\
\text { Student choice: Students should be able to make their own decisions about things } \\
\text { that affect them - like the dress code. }\end{array}$ \\
\hline $\begin{array}{r}\text { What a } \\
\text { student does. } \\
\text { (Other themes) }\end{array}$ & $\begin{array}{l}\text { Establish relationships: To be actively involved in school means developing } \\
\text { supportive relationships with peers, teachers, and the community in general. }\end{array}$ \\
\hline $\begin{array}{r}\text { Values } \\
\text { (attitudes, beliefs) } \\
\text { What a } \\
\text { student believes. }\end{array}$ & $\begin{array}{l}\text { Have the right attitude: To be actively involved in school means to have the right } \\
\text { attitude toward success. } \\
\text { Accept the situation: The role of students is to accept the limits of the situation } \\
\text { and do their work. } \\
\text { Other Inferred Values: education is important for future success; involvement in } \\
\text { all aspects of school life is important; relationships with students and staff are } \\
\text { important; voicing opinions and influencing policies and practices are important; } \\
\text { personal character is important. }\end{array}$ \\
\hline
\end{tabular}


and other extracurricular school activities. As Student 6 summarized, “A student's role in high school is to be involved."

This group also includes: "Prepare for college / adulthood," and "Discover / Develop personal characteristics," as well as "Follow rules and policies."

Incorporating a more expansive view of the student role included categories describing opportunities to influence policies and practices at all levels by voicing opinions, voting, making decisions, and using student government as an instrument of influence. As Student 37 submitted, "The leaders of this school should listen to some of the ideas we have."

The last category in the group, "Establish relationships," was listed separately because of its unique focus on the relational nature of schooling, and because the appearance of this theme in the student responses was both unexpected and gratifying: gratifying because it aligns with my most fundamental beliefs about the nature of teaching and learning, and surprising because I did not expect the students to articulate its significance. "And being connected to a community makes things less awful," Student 26 elaborated, "It gives you something to strive for and care about."

The final set of attributes, "Values," resolves the question, "What does a student believe?" The student categories of "Have the right attitude" and "Accept the situation" seemed best suited to this group. Student 4 explained it this way, "Children to young adults need to have a good attitude so as to not pressure or foul up another kid's day." And Student 4 submitted, "If you're a positive person then not only you but people around you will be happy." 
In addition, attitudes and beliefs inferred from the other response categories and the thoughts and rankings presented earlier were added. These inferences include that students believe: education is important for future success; involvement in all aspects of school life is important; relationships with students and staff are important; student opportunities to voice opinions and influence policy and practices are important; and personal character is important. Justification for this inclusion can be found in the articulated themes present in the Behavior Category, and the ratings these themes received as described previously.

\section{Teacher Conceptions}

The same process of integration and organization applied to the student response categories was also applied to the teacher response categories and is summarized in Table 15 and answers the second research question:

How do teachers and administrators within the same high school community conceptualize the role of "student" in the organizational context of the school?

Teacher response categories assigned to the first set of student role attributes, "Characteristics," include conceptions of the student as a community member, active in student leadership organizations; also a role model and family representative, and one who is respectful and responsible.

Teacher response categories assigned to the second set of student role attributes, "Behavior Expectations / Norms" also include both traditional student norms of behavior and belief, and those representing a more agentic view of the student role. Included in the more traditional definitions of the student role were expectations of actively 
Table 15

\section{A Summary of the Student Role Characteristics According to Teachers}

\begin{tabular}{|c|c|}
\hline Role Attributes & Teacher Response Categories \\
\hline $\begin{array}{r}\text { Characteristics } \\
\text { (distinguishing } \\
\text { features) } \\
\text { What a } \\
\text { student is. }\end{array}$ & $\begin{array}{l}\text { Community member: The role of the student is to act as a citizen/member of a } \\
\text { community } \\
\text { Role model: The role of students is to be a role model for other students. } \\
\text { Representative: The role of students is to represent their families well. } \\
\text { Respectful: The role of students is to be respectful to others. } \\
\text { Responsible: The role of students is to be responsible for themselves and their work. }\end{array}$ \\
\hline $\begin{array}{r}\text { Behavior } \\
\text { Expectations / } \\
\text { Norms } \\
\text { (expected } \\
\text { patterns of } \\
\text { behavior and } \\
\text { belief) } \\
\text { What a } \\
\text { student does. } \\
\text { (Traditional } \\
\text { Themes) }\end{array}$ & $\begin{array}{l}\text { Actively participate in learning: The role of students is to be actively engaged in the } \\
\text { learning process, to take ownership and responsibility for one's engagement in } \\
\text { learning and academic success. } \\
\text { Recognize school is the job: The role of the student is to recognize that doing school } \\
\text { is their job. } \\
\text { Participate in sports/ clubs/ activities: Students should have opportunities to form } \\
\text { clubs and be involved in clubs, sports and school activities and events. } \\
\text { Self exploration: The role of students is to explore interests and grow as a person. } \\
\text { Follow rules and policies: These responses suggest that students should follow rules } \\
\text { and policies instead of influencing them. }\end{array}$ \\
\hline $\begin{array}{r}\text { What a } \\
\text { student does. } \\
\text { (Agentic } \\
\text { Themes) }\end{array}$ & $\begin{array}{l}\text { Voice opinions: Students should have real opportunities to voice ideas and opinions. } \\
\text { Use Student Government and Leadership: Students should be able to use student } \\
\text { government and other leadership roles to voice their ideas. } \\
\text { Influence policies: Students should have opportunities to influence policy } \\
\text { Vote on policies: Students should have opportunities to vote on policy decisions that } \\
\text { affect them } \\
\text { Influence classroom policies: Students should have opportunities influence some } \\
\text { classroom policies. } \\
\text { Work with administration: Ask/Survey student for what they would like to see } \\
\text { more of or less of in the school climate. Then determine what can be done to } \\
\text { accommodate the requests. } \\
\text { Make school a better place: To be actively involved in school means to be actively } \\
\text { engaged in making the school a better place. } \\
\text { Provide feedback: The role of students is to provide inputs to the system to make it } \\
\text { more effective. }\end{array}$ \\
\hline $\begin{array}{r}\text { What a } \\
\text { student } \underline{\text { does. }} \text {. } \\
\text { (Other themes) }\end{array}$ & $\begin{array}{l}\text { Establish relationships: To be actively involved in school means developing } \\
\text { supportive relationships with peers, teachers, and the community in general. }\end{array}$ \\
\hline $\begin{array}{r}\text { Values } \\
\text { (attitudes, } \\
\text { beliefs) } \\
\text { What a } \\
\text { student } \\
\text { believes. }\end{array}$ & $\begin{array}{l}\text { NONE } \\
\text { Inferred Values: active engagement in academics is important; involvement in } \\
\text { aspects of school life other than academics is important; developing relationships } \\
\text { with students and staff is important; voicing opinions and influencing policies and } \\
\text { practices is important; personal character is important. }\end{array}$ \\
\hline
\end{tabular}


participating in the learning and considering school the "job," as well as participating in sports, clubs and other school activities and events. Also included in this group were self exploration and following rules and policies.

Many thematic categories in this set of attributes expressed a more agentic view of the student role. These included opportunities to influence policies and practices from inside the classroom to the entire school by voicing opinions, voting, using student government and leadership to voice ideas, working with administration and providing feedback.

The teacher response categories assigned to this set of attributes also included "Establish relationships" which was again listed separately because of its unique focus on the relational nature of schooling.

There were no thematic categories from among the teacher responses to the three online questions that explicitly corresponded to the final set of attributes, "Values." However, attitudes and beliefs inferred from the other response categories and the thoughts and rankings presented earlier suggest several assumptions regarding what attitudes teachers feel students should embrace. These inferences include that students should believe that, active engagement in academics is important; involvement in aspects of school life other than academics is important; developing relationships with students and staff is important; voicing opinions and influencing policy and practices is important; and personal character is important." And again, justification for these themes can be found in the articulated themes present in the Behavior Category, and the ratings these themes received as described previously. 


\section{Comparing Student and Teacher Student Role Attributes}

To compare and contrast features of the student role identity standard disclosed by compiling the student and teacher responses to all three questions, thematic categories from both groups were aligned. Categories in bold are those that had no corresponding theme in the other group. See Table 16.

Similar to trends described previously, this alignment of student and teacher responses reveals many similarities in how student and teacher participants defined the student role. When describing what a student is, both groups identified role model, respectful and responsible as student role characteristics. Both groups saw active participation in academics and extracurriculars, personal exploration and development, and following rules and policies, as behavior norms. Voicing opinions, voting, influencing policies and an influential student government were likewise identified as student role expectations. And accordingly, the values inferred from these norms are similar for both groups.

However, the table also clarifies points of difference between student and teacher conceptions of the student role, some of which have been described previously, such as the student future orientation toward college and adulthood. While both students and teachers recognized the role of student government organizations, student responses included the idea of the student as a leader, "voicing opinions and impacting school policy," either within or outside traditional school government structures. As Student 23 submitted, "to be actively involved in high school one would need to step up and be a leader. This doesn't mean being in ASB or the Leadership class, but just being a good 
Table 16

Alignment of the Student Role Characteristics in Student and Teacher Responses

\begin{tabular}{|c|c|c|}
\hline Role Attributes & Student Response Categories & Teacher Response Categories \\
\hline $\begin{array}{r}\text { Characteristics } \\
\text { (distinguishing } \\
\text { features) } \\
\text { What a } \\
\text { student is. }\end{array}$ & $\begin{array}{r}\text { Leader } \\
--- \\
--- \\
\text { Role model } \\
\text { Respectful } \\
\text { Responsible }\end{array}$ & $\begin{array}{l}\text { Citizen / Community member } \\
\text { Family representative } \\
\text { Role model } \\
\text { Respectful } \\
\text { Responsible }\end{array}$ \\
\hline $\begin{array}{r}\text { Behavior } \\
\text { Expectations / } \\
\text { Norms } \\
\text { What a } \\
\text { student does. } \\
\text { (Traditional } \\
\text { Themes) }\end{array}$ & $\begin{array}{r}\text { Be involved } \\
\text { Show school spirit } \\
\text { Prepare for college/adulthood } \\
\text { Participate in the learning toward } \\
\text { academic success } \\
\text { Participate in sports/ clubs/ activities } \\
\text { Develop / Discover personal character } \\
\text { Follow rules and policies }\end{array}$ & $\begin{array}{l}-- \\
\text { Actively participate in learning } \\
\text { Recognize school is the job } \\
\text { Participate in sports/clubs/ activities } \\
\text { Self exploration } \\
\text { Follow rules and policies }\end{array}$ \\
\hline $\begin{array}{r}\text { What a } \\
\text { student does. } \\
\text { (Agentic } \\
\text { Themes) }\end{array}$ & $\begin{array}{r}\text { Student choice } \\
\text { Voice opinions } \\
\text { Student government } \\
\text { Influence policies } \\
\text { Vote on policies } \\
\text { Influence teaching style, classroom } \\
\text { content and approaches }\end{array}$ & $\begin{array}{l}\text { Make school a better place } \\
\text { Provide feedback } \\
\text { Voice opinions } \\
\text { Student government } \\
\text { Influence policies; Work with } \\
\text { administration } \\
\text { Vote on policies } \\
\text { Influence classroom policies }\end{array}$ \\
\hline $\begin{array}{r}\text { What a } \\
\text { student } \underline{\text { does. }} \text {. } \\
\text { (Other themes) }\end{array}$ & Establish Relationships & Establish Relationships \\
\hline $\begin{array}{r}\text { Values } \\
\text { (attitudes, } \\
\text { beliefs) } \\
\text { What a } \\
\text { student } \\
\text { believes. }\end{array}$ & $\begin{array}{r}\text { Have the Right Attitude } \\
\text { Accept the situation } \\
\text { - Inferred Values: } \\
\text { - involvement in all aspects of school } \\
\text { life is important } \\
\text { - active engagement in academics is } \\
\text { important for future success } \\
\text { - developing relationships with students } \\
\text { and staff are important; } \\
\text { • voicing opinions and influencing } \\
\text { policies and practices are important; } \\
\text { • personal character is important }\end{array}$ & $\begin{array}{l}-- \\
- \text { Inferred Values: } \\
\text { - involvement in aspects of school life } \\
\text { other than academics is important } \\
\text { - active engagement in academics is } \\
\text { important } \\
\text { - developing relationships with students } \\
\text { and staff is important; } \\
\text { - voicing opinions and influencing policies } \\
\text { and practices is important } \\
\text { - personal character is important }\end{array}$ \\
\hline
\end{tabular}


role model." And Student 11 posted, "You need to take charge and not just do what everyone tells you to do." Such expressions exemplify a sense of personal agency that aligns with student voice principles.

Teachers described students as citizens and community members, a conception nowhere articulated in the student responses, but defined narrowly in ways designed to reinforce student responsibility rather than student rights. "A high schooler is both a citizen of a community and a student," submitted Teacher 17, adding, "A school is a small city. Kids must be good citizens within the city to make it a healthy place. Schools are to educate kids, both as citizen and as a scholar. Each student must make positive contributions." Teacher 32 posted, "Students need to be a citizen in their own community and support their community and school." The emphasis in these comments, as in many similar teacher postings, is on having students accept and step into a community role that adults have imagined for them, rather than seeing them acting as cocreators of the role.

Another student role characteristic unique to the teacher perspective was the idea of the student as a representative of family and community. Teacher 11 submitted, "The students are their parents' legacy and the younger kids' role models. They need to understand that the community is riding on their shoulders into the future. They interact with other communities and help create a reputation that must be lived up or down to." While the student responses also included the "role model" theme, none of the student comments contextualized the student role within the larger community in the same way. Considered systemically and developmentally, this could represent a stage during which 
the adolescent, whose identity is at a critical period of expanded development (Steinberg, 2005), has not yet articulated the relationship between who she is and the social, cultural, historical context within which her identity is realized.

For the students, the awareness of contextualized identity is perhaps best represented by the school-spirit theme that appeared only within their responses. As Student 22 declared, "Show school spirit, wear school colors, cheer in games, and have fun at school while learning." And Student 15 submitted, "Students show pride in their school by participating in spirit week, assemblies, class competitions and even doing something as simple as wearing a River HS Shirt." This theme is also echoed in the student Behavior expectation to "Be involved," an expression that occurs 19 times in student submissions. "A student's role in high school is to be involved," stated Student 6, adding, "To pay attention and get the work that has to be done to pass and finish high school. A student's role in the community is to help with fundraisers and make the community a better place to live in." This identification with school and community exemplifies the process of role identity development as a manifestation of the expanding relationships between the individual and the macro-systems- social, political, economic in which her identity and roles are co-created.

The teacher category "Make school a better place" contained thoughts that represent two recurring themes regarding the student role that appear in the teacher submissions - one recognizing and supporting the developing autonomy and agency of students, and another that seeks to control and direct this expanding role toward adult ends. The submission by Teacher 9 in response to the question "What does it mean to be 
involved in high school?" exemplifies this tension. "Pride. Someone with pride of ownership. Ownership and pride shows in respect to the building, oneself, the materials, teachers, and work done. Pride breeds confidence and ambition. Pride means to constantly question how to make the place you are in better." The submission frames the student role first as one of ownership - suggesting a position of power. And how is the student to use this power but to respect the institution of schooling, represented in the list of school artifacts, the institution which provides minimal opportunities for the student to exercise real power and influence.

The post ends just as ambivalently, "Pride breeds confidence and ambition. Pride means to constantly question how to make the place you are in better." Again, the teacher assigns the student role to a position of power to question and act "to make the place you are in better." Does the institution provide systemic opportunities for students to question and act? And better for whom? The assumption in this and other teacher comments seems to be that enlightened student activism will necessarily align with adult goals rather than challenge them. Meanwhile the post of Student 29 perhaps better captures the reality of the student position within the school organization: "Students must know that they are subordinate to school staff. Even though high school students [should?] be allowed some autonomy, they must accept that they are subordinate to school staff and should not behave with insolence when asked to do something they disapprove of."

\section{Conclusion}

The goal of this research was to develop a situated description of the student role 
within the organizational context of a rural high school from the perspective of students and teachers toward identifying barriers and abetments to the facilitation of student voice. The research questions guiding this inquiry were:

1) How do youth from a rural high school conceptualize the role of "student" in the organizational context of the school?

2) How do teachers and administrators within the same high school community conceptualize the role of "student" in the organizational context of the school?

In this chapter the student and teacher responses to the three online questions about student involvement, influence and role, were evaluated to reveal how the participants conceptualize the student role, what these conceptions reveal about the participants' thinking, and how these conceptions compare with one another.

Responses to the third online question were considered first, as it addressed the issue of student role directly, asking participant to answer: "How would you describe the role of a student in high school?"

Student submissions revealed three distinct orientations of the student role identity characteristics that aligned with the systemic qualities of structure (being - what a student is), function (behaving- what a student does), and history (becoming contextualizing being and behaving in time - what a student will become). A comparison of student and teacher responses organized along this typology revealed more similarities than differences in how each conceptualize the student role. What was noteworthy, however, was the lack of any significant inclusion of the thematic categories aligned with student voice principles identified in the responses to the other two online questions. 
These examples of student agency and efficacy were organized and evaluated to emphasize the similarities in student and teacher submissions as well as the disconnect between conceptions of the student role articulated in the responses the first two online questions, and the role depicted in responses to the third. It was posited that this disconnect revealed the unexamined enculturation of the participants into traditional notions of appropriate student engagement and power.

An expanded description of the student role from both the student and teacher perspectives was then elaborated by consolidating the thematic categories generated in response to all three of the Thought Stream questions. The categories were organized according to the three role attributes identified in role theory (Major 2003; Thomas \& Biddle as cited in Brookes, Davidson, Daly, and Halcomb, 2007). The elaborated profiles thus derived from aggregating all the respective respondents' submissions provided an answer to the two guiding research questions.

Finally, the consolidated student and teacher student role profiles were compared and contrasted revealing a list of characteristics expressing traditional ideas of what it means to be a high school student, as well as an alignment in most student identity characteristics between the student and teacher conceptions.

Exceptions in the students' thematic categories of the student profile not found in the teacher themes included: an explicit temporal orientation toward college and careers; the idea of the student as a leader, "voicing opinions and impacting school policy" both from within and from outside traditional student leadership structures; a focus on school spirit as an expression of community belonging and involvement; the notion that students 
should be able to exercise unfettered freedom of choice on some issues such as the dress code; and that students should just accept the limits inherent in their position and get the work done.

Within the teachers' student profile, thematic categories that diverged from the student conceptions included: defining the student as a citizen/community member and family representative; the expectation of providing feedback to the system; and taking action to make the school a better place. It was pointed out that some of the teacher conceptions of student engagement expressed ambivalence regarding student empowerment.

The final chapter returns to the conceptual framework of the study to apply systems thinking to further investigate the student and teacher profiles of the student identity standard articulated here, and to compare and contrast them with the student identity standard derived from the student voice literature.

Secondary data sources, such as field notes, the SRT participant notes, and the closing interview with the SRT members, are used to evaluate the research design and to help identify next steps. Finally, data from all sources is reviewed to look for evidence that the study has induced the SRT participants and RHS community toward a broader vision of the student role and the potential of student voice to both inform and transform classroom and school practices and policies. 


\section{Discussion}

"All week, every day, all kids can come up with very unique ideas. They should have every chance they can get to influence their school in a good way" (Student $32)$.

"Rules, policies, assemblies, dances, books to read, practical application, community involvement, relevancy of curriculum, what to write about...all of this should be opportunities for students [to] influence their environment. Really, they should run it" (Teacher 19).

"The [student] role just needs to be more expanded" (Student 5).

The goal of this research was to develop a situated description of the student role within the organizational context of a rural high school from the perspective of students and teachers toward identifying barriers and abetments to the facilitation of student voice. As a critical ethnography, a secondary goal of the research was to further the student voice agenda at RHS toward reconsidering and reimagining what it means to be a student, and by implication a staff member, at RHS.

The answer to the core research question, "How do students and teachers from a rural high school conceptualize the role of "student" in the organizational context of the school?" elaborated a list of characteristics expressing both traditional ideas of what it means to be a high school student and more agentic qualities aligned with student voice principles. There was significant alignment in most of the student role characteristics between the student and teacher conceptions. Corresponding student role characteristics 
among student and teacher responses included being a role model, respectful and responsible. Both groups saw active participation in academics and extracurriculars, personal exploration and development, and following rules and policies, as behavior norms. Voicing opinions, voting, influencing policies and an influential student government were likewise identified as shared student role expectations. And accordingly, the values inferred from these norms were similar for both groups.

The responses revealed three distinct loci of the student role identity: an internal psychological dimension - character development; an external behavioral dimension participation in academics and extracurriculars; and a temporal dimension oriented toward future engagement in college, careers and adulthood. These role identity orientations, when considered within a systems framework, manifested the fundamental systemic qualities (Zwick, 2006) of structure (being - what a student is), function (behaving-what a student does) and history (becoming - contextualizing being and behaving in time - in this case, what a student will become) and suggest the relational nature of student role identity standards as responses to engagement with larger enveloping social, political, economic and environmental systems.

Significant areas of divergence between student and teacher constructs included the explicit temporal orientation toward the future exclusive to the student responses, the engagement in academics that dominated the teacher submissions and rankings, and the conception of the student as a citizen/community member that was found only in the teacher responses. Most noteworthy, however, was the lack of significant inclusion of thematic categories aligned with student voice principles in descriptions of the student 
role by either students or teachers.

Attention now turns to the conceptual framework of the study to better understand how the literature on role theory and acquisition, adolescent development, organizational dynamics, and student voice inform and are informed by the RHS student and teacher constructs of the student role identity standard. In the process, conclusions were drawn regarding the meanings of this study for the RHS community, including implications and recommendations for furthering the student voice agenda at RHS, as well as in regard to further research in the area of student roles and the greater student voice research and practices agenda.

\section{Student Role Identity Standards: Comparisons and Conclusions}

In Chapter II, a profile of the student role identity standard developed from themes in the student voice literature was presented. A review of the student voice literature revealed a range of observations, assumptions and expectations regarding student values and behaviors manifesting student voice principles from the perspectives of adolescent development, organizational dynamics, citizenship preparation and critical pedagogy. Themes identified in the research were organized according to role attributes as described in role theory (Major 2003; Thomas \& Biddle, as cited in Brookes, Davidson, Daly, and Halcomb, 2007). The results provided a profile of student role identity characteristics and were presented and summarized in Table 1.

Similarly, in Chapter V, thematic categories of RHS student and teacher responses to the online questions were organized to provide a profile of the student role identity standard. 
To compare and contrast features of the student role identity standard disclosed in the student and teacher responses with the characteristics derived from the student voice literature, thematic categories from all three perspectives were aligned. Only those student and teacher categories articulating student voice principles were included. Categories in bold are those that had related themes across groups. Student and teacher categories in italics are those whose correspondence with the student voice themes was nominal, and those in parenthesis had no corresponding theme across groups. See Table 17.

The table reveals many areas of apparent congruence, as well as significant zones of fractional development between RHS student and teacher conceptions of the student role and that found in the literature on student voice.

Conclusion 1: Student as participant. Student voice themes associated with behavior attributes describe a student who is actively participating in and managing their learning (Fredricks, Blumenfeld \& Paris, 2004; Levin, 2000) through negotiation and consultation with other members of the school community, both students and adults (Thiesen, 2006). This found parallels in both the student and teacher response categories. Student 29 posted that being involved in school means, "Actively engaged in classroom learning - participating and engaged." And Teacher 10 submitted, "I always say, learning is not a spectator sport. You are a player and conductor of your own education and future." These submissions suggest an agentic student identity role and strongly correlate with student voice principles.

However, unlike the teacher postings that often included a sense of student 


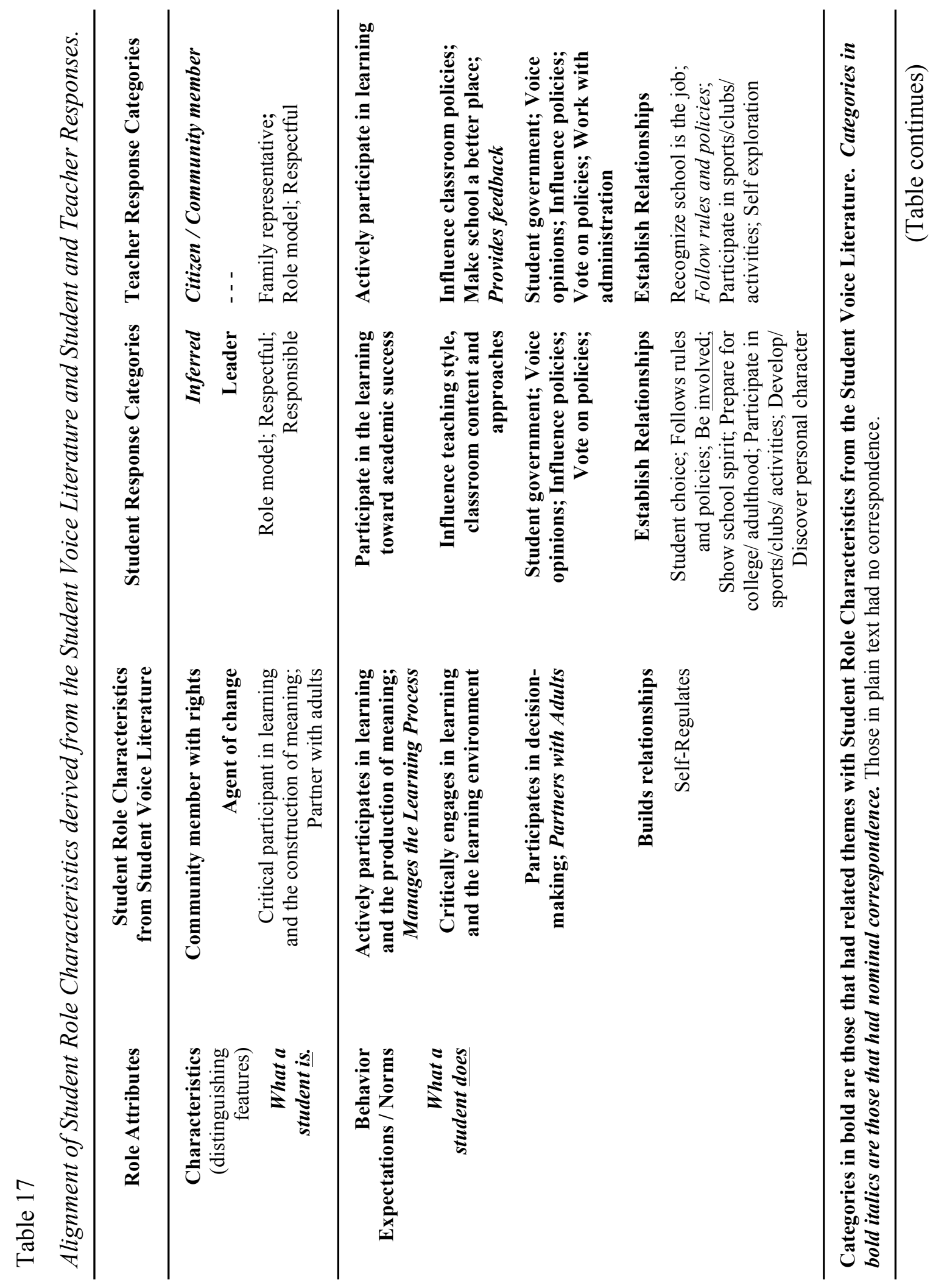




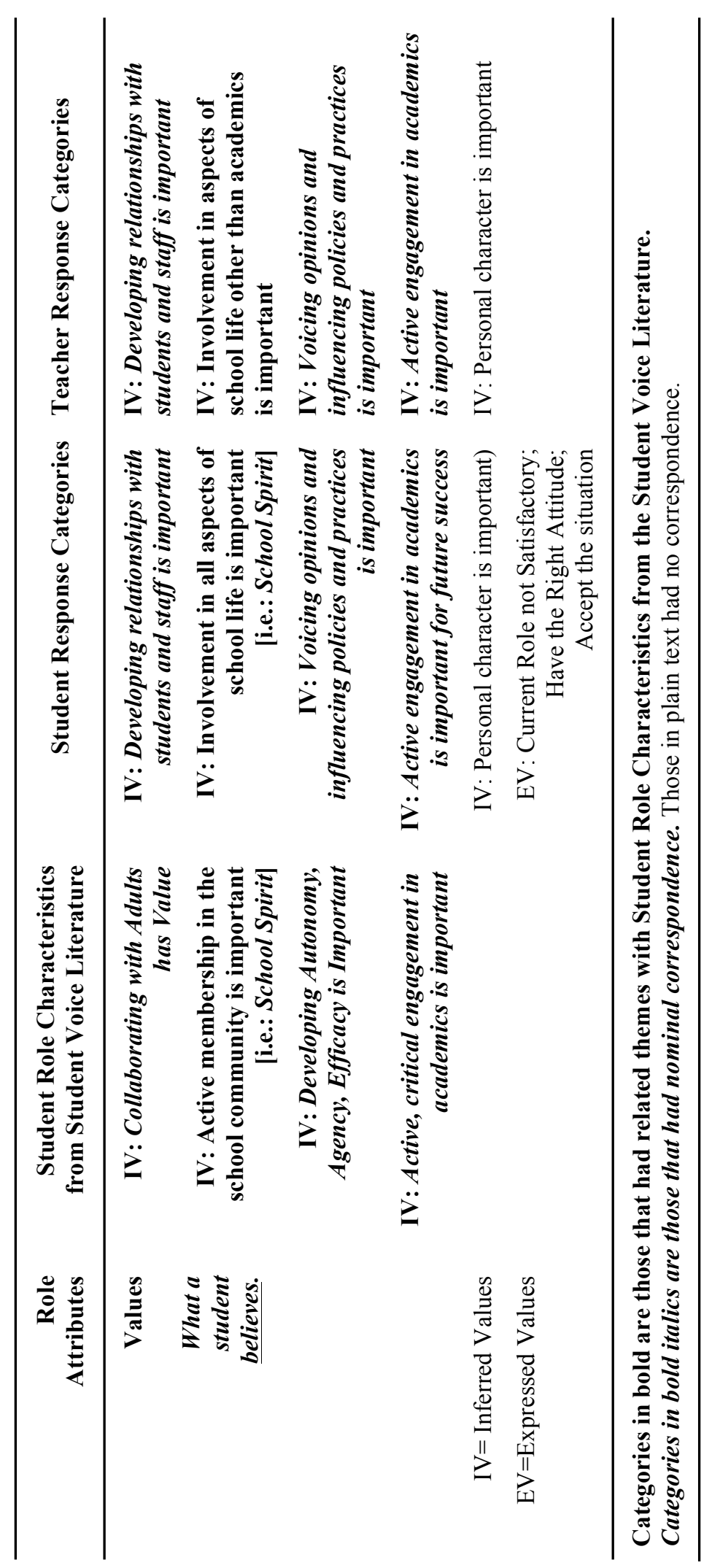


ownership of the learning process, the student responses generally reflected a more passive orientation, reactive to the authority of the teacher. This subordinate position was captured in the many student comments framing learning as doing the work (Student 6; Student 7; Student 33; Student 44), and getting good grades (Student 11; Student 23; Student 24; Student 25; Student 27; Student 41; Student 45). By inference these comments, echoing the teacher response category describing school as a job, frame the teacher as boss, and grades as a paycheck. Meanwhile, student comments suggesting a more influential role in managing their learning were always framed as an expression of how things should be (Student 13; Student 15; Student 19; Student 37; Student 39), as captured in the following comment. "Students should be allowed to influence the style of teaching [that] works best for them. A teacher should adjust their style according to what is the most helpful to that particular group of kids" (Student 15).

Indeed, the aspiring orientation toward what "should be" dominated nearly all the thematic categories of student and teacher responses expressing an agentic role of student engagement, being expressed in $38 \%$ of student responses and in $56 \%$ of teacher responses. This cannot be explained away simply by the phrasing of the survey question that asked, "What opportunities should high school students have to have their voices heard in order to influence classroom and/or school policies and practices?" (italics added). Rather, it reflects the reality that while students and teachers at RHS see value in increasing meaningful student involvement, they have yet to incorporate the idea into a practice of expanded student involvement. This further explains the lack of a strong presence of expanded student engagement in the responses to the other online questions, 
as was pointed out in Chapter V and depicted in Figures 13 and 14. This disconnect between what is, and what should be, is likewise captured in this comment from Teacher 10. "To influence classroom and school policies, students should feel some ownership in their learning by having choice." What choices to inform and influence are students currently given? What is the current state of student ownership in their learning? The student and teacher responses in this study suggest that for the most part, the current answer is: little.

Beyond managing their learning, according to the student voice literature, active participation in the learning also includes critically engaging in school to research, evaluate and transform the learning environment (Mitra \& Gross, 2009; Fletcher, 2003). Additionally, it includes partnering with adults to enhance teaching and learning (Mitra \& Gross, 2009; Cook-Sather, as cited in Bryn Mawr Now, 2011) and participating in decision making at the administrative level through membership in school and district committees in order to influence processes that affect the student and the school community (Levin, 2000). As in the previous case, student and teacher responses suggest a perceived value in having students participate in informing and influencing policies and practices, but again, this remains an unfulfilled aspiration at this time. Several comments by both students and teachers referenced the student senate that was formed as part of the 2012 RHS School Improvement Plan to give students a voice (River High School, SIP, 2012). "There should be some kind of forum for discussion of issues at the school," suggested Teacher 17, "Students need a safe place to constructively raise issues that are important to them or their peers...Student Senate is a good place to start." And Student 
42 expressed hopefully, "Student Senate, It's new, but it may offer slightly more student voice."

But following its late inception in the spring of 2013, the senate agenda was hijacked by the staff in order to organize a school-wide community service project, after which it was not reactivated. Only since the Student Research Team shared some results of this study with the community was activation of the student senate being considered.

Supporting the notion of student as active participant, was one attribute which seemed to translate relatively intact across the student, teacher, and student voice categories, the belief in the importance of school involvement, or school spirit, as an expression of community belonging and engagement. Dominant themes from the student voice literature suggested that a student values a sense of belonging and active membership in the school community (Angus, 2006; Fredricks, Blumenfeld \& Paris, 2004). Likewise, the importance of this sense of belonging and membership were themes found in both the student and teacher submissions. "Show school spirit," submitted Student 22. Being involved means "school spirit," posted Teacher 11. This value in involvement was pervasive in the student and teacher responses with regard to academics, sports, clubs, organizations, events and activities - including leadership, and was suggested in the many submissions around the opportunities students should have to influence policies and practices. Mitra and Gross (2009) emphatically declare that the student voice sense of membership in community is fundamentally different than traditional conceptions of school spirit. But the expressed belief in the value of involvement by students and teachers, even if the opportunities for involvement do not 
yet rise to student voice standards, remains valid and suggests a trajectory that could well lead there.

Conclusion 2: Student as co-constructor of meaning. While both students and teachers describe active participation as a student behavior, what a student does, the student voice conception of student identity as being a critical participant engaged in the active construction of meaning (Fredricks, Blumenfeld \& Paris, 2004; Fletcher 2003) includes dimensions not found in the student or teacher responses. Recognizing that learning is an active process of meaning making on the part of the learner is central to a constructivist approach to learning (Levin, 2000), which in turn supports youth efficacy, agency, belonging, knowledge and competence (Osberg, Pope, \& Galloway, 2006; Mitra, 2009), core values identified in the student voice literature (Mitra, 2004; Eccles \& Roeser, 2011). The lack of expressed recognition of this feature of student identity, particularly by RHS teachers, may be indicative of the depth of their enculturation into traditional notions of the student as a generally passive recipient of prescribed curriculum, a situation reinforced daily by the current standards and accountability environment in which teachers operate (Labaree, 2005). The additional attribute of critical awareness amplifies the constructivist approach to recognize and support the student's ongoing evaluation of curriculum, content and instruction in the process of meaning making, and as a precursor to transforming those elements - an important component of critical pedagogy (Cook-Sather, 2007a). This kind of critical engagement can be threatening to teachers who may not want to be questioned regarding the relevance and value of their curriculum and instruction and feel powerless themselves within the 
larger systems within which they must operate. As Teacher 4 offered, "Teachers themselves have little control over school policies. We teach what we must and work within the curriculum boundaries of the state of Oregon. We also do our duty within the requirements set by the school. My freedom and control is over the agenda that I set for my students every day. Students' freedom and control is over the kind of work that they choose to do in school." Such feelings of teacher disempowerment create yet another boundary for expanding the student role (Mitra and Gross, 2009). This limiting of student freedom to the quality of their work reveals the pressure teachers can experience around meeting their professional responsibilities and how this translates into the conceptual boundaries constructed around student engagement. To support student voice, teachers themselves must have a voice in shaping their school experience. While the current administration provides multiple avenues for teacher involvement, such opportunities must translate into the teachers' internal sense of personal agency. Ultimately localized opportunities for teacher engagement may be inadequate in developing such agency given the larger context of district, state and national norms and standards within which teacher roles are acted out.

One factor that could further teachers embracing the level of critical engagement in learning suggested by student voice principles is the value that teachers placed on student participation in learning as described in Chapters IV and V, where it garnered $40 \%$ of the submissions and $48 \%$ of the ranking stars. Building on this teacher priority and the evidence of the benefits of expanded academic engagement described in the literature (Levin, 2000; Lundy 2007; Sands, Guzman, Stephens \& Boggs, 2007; Fletcher, 
2004) could provide another way of supporting the development of student voice at RHS and result in students choosing to engage at a level that meets both personal and institutional needs.

Conclusion 3: Student as partner. One student role attribute describing who a student is, not found in either student or teacher conceptions of student role characteristics, identifies the student as a partner with adults in the social production of meaning (Lensmire, 1998), and a collaborator in decision making processes and school reform (Mitra \& Gross, 2009) to enhance teaching and learning (Cook-Sather, as cited in Bryn Mawr Now, 2011). This notion of the student as partner is not found anywhere in the responses of RHS students or teachers, and yet is a fundamental feature of the student role as described in the student voice literature (Fletcher, 2008; Mitra \& Gross 2009). Despite the multiple student and teacher thematic categories describing student opportunities to inform and influence classroom and school policies and practices, nowhere is the student explicitly described as a partner - a co-creator of meaning and change. This sense of partnership, of mutual engagement in the organization of school, is central to transforming the student-teacher-institution power dynamic (Mitra, 2009; Schultz \& Oyler, 2006). Reimagining the student as partner also has the potential for mitigating teacher anxieties regarding the imagined loss of power that comes from sharing it. Howe and Covell (2013) found that contrary to educators concerns that expanding students power and voice would lead to chaos, the students became increasingly respectful of rights and cognizant of the responsibilities that accompany them. 
Encouragingly, relationships were one area in which student, teacher and student voice conceptions of student behavior aligned closely. The student voice literature recognizes building relationships with adults as a behavioral norm (Field and Braggs as cited in Noyes, 2005; Fredricks, Blumenfeld \& Paris, 2004). And both students and teachers described a student being actively involved in school as developing supportive relationships with peers, teachers, and the community in general. "You have to be social enough to interact with fellow students and teachers. That means talking to everyone," submitted Student 11. "A great deal of education is made up of the interactions students have with those around them," posted Teacher 22, adding, "I believe education is primarily relational...Students learn best when they are connected to others."

Although both students and teachers recognized the value of relationship, the RHS student and teacher construct of relationship within the community will need to expand to more fully express the student identity role standard suggested in the student voice literature and to realize its potential for personal and institutional transformation. Relationships aligned with student voice principles are rooted in an equality of personhood enabling students and teachers to communicate with and learn from one another (Cook-Sather, 2006) and are a prerequisite for agentic membership in community (Quicke, 2003). While the student voice literature frames such relationships and collaboration as a necessary means to enhance teaching and learning (Mitra \& Gross, 2009; Cook-Sather, as cited in Bryn Mawr Now, 2011; Beattie, 2012), the relationships communicated in the student and teacher responses were more narrowly framed as a positive expression of the social nature of schooling. Realizing the capacity of such 
collaborative relationships for creating more satisfying relationships and for improving teaching and learning remains another area for growth in the RHS community.

Conclusion 4: Student as citizen. The idea that a student is a valued member of the community (Angus 2006; Fredricks, Blumenfeld, and Paris 2004), and a citizen with rights (Bragg 2007; Cook-Sather 2006; Fielding 2004; Mitra \& Gross 2009) also found no equivalent theme in the student responses, and only a tenuous correlation in the teacher responses.

While there was no thematic category in the student responses regarding identity as a community member/citizen with rights, the idea did surface obliquely within individual responses. For example, several student responses did identify one right that students felt they should have, freedom of speech (Student 10; Student 31; Student 39). "Let us use our right for freedom of speech," submitted Student 10. The issue of rights was also suggested by the many student submissions regarding having opportunities to have their opinions heard and acted upon, including through voting - the most basic expression of citizen participation (Torney-Purta, Lehmann, \& Schulz, 2004). Another post from Student 10 captured this sentiment, "Let us vote on local issues. Having us vote on local issues in our school district lets us make a decision that is best for the school."

Within the teacher submissions the role of the student as a community member was specific, but the associated attributes, inconsistent. "A student is a member of the community," submitted Teacher 22. "Like it or not, as a member of a community, one has responsibilities to live "within the lines" to the extent that other members continue to 
pursue their own success, both adults and students." Teacher 3 elaborated adding, "To know and understand the "role" of community member is quite another thing than embracing it, and so goes the continuous tension of community." These responses seem to recognize the tension between rights and responsibilities of membership within a community, as indicated by the implied right of students and adults to "pursue their own success" (Teacher 22). At the same time these submissions fall short of acknowledging the parallel between membership in the school community and that of citizenship in the body politic. Teacher 9 makes this connection more explicit, "A community is full of citizens co-existing together to create a positive, productive environment for ALL students. Community means people come together to ensure that all citizens are treated as equals and included." All of these submissions point to a student identity that includes that of community member or citizen. They also declare that membership carries responsibilities to other members of the community. The right to be treated as an equal is implied, as is the right to pursue success. Beyond these there is no overt recognition of additional rights accompanying this membership.

Other responses expressed a view of community membership and citizenship more focused on the responsibilities rather than the rights of such association. Teacher 17 suggested, "A high school student is both a citizen of a community and a student. A school is a small city. Kids must be good citizens within the city to make it a healthy place. Schools are to educate kids, both as citizen and as a scholar. Each student must make positive contributions." And Teacher 32 submitted, "Students need to be a citizen in their own community and support their community and school." Even Teacher 9, in an 
apparent narrowing of an earlier comment, defined a student citizen as "someone who actively cares and helps the community they are involved in. They help teachers, students, etc. to be successful and to learn." The model of citizenship presented in these responses seems to be one of membership in a totalitarian community where the role carries expectations of responsibility for the welfare of the school-as-state, devoid of any corresponding rights to influence or shape its policies and practices. The emphasis in these comments, as in many similar teacher postings, is on having students accept and step into a community role that adults have imagined for them and primarily meets adult needs, rather than recognizing them as co-creators of a role that expresses their own needs, wants and desires.

The disempowered construction of the student role revealed here is amplified in the metaphor used in the thematic category, school is the job, expressed in $11 \%$ of the submissions and garnering $19 \%$ of the ranking stars. "School is their job," posted Teacher 30, "they should try hard, get involved and be on time." And, "This is the students' job. They should be professionals as if they are at a job and they should expect to be treated professionally by the school staff as if they were a valued employee," submitted Teacher 7. The model of student-as-employee by implication defines the teacher as boss, reinforcing a power differential in the student-teacher relationship that is the antithesis of the youth-adult partnerships envisioned by student voice advocates (Lensmire, 1998; Fletcher, 2001; Quicke, 2003; Cook-Sather, 2006; Mitra, 2009). This gap is captured definitively by Teacher 7 who declared, "Teachers are the bosses, but will get no productivity from unhappy employees." What makes for a happy student 
employee? "There should be positive interaction," Teacher 7 explained. "They are all employees and thus equals. Students should treat each other with the respect they would expect." While declaring the equality of the student-class and the right to be respected within it, the teacher seems to suggest that positive interaction between students as equals will inoculate them from being unhappy. There is no indication of awareness that unhappiness might arise from the students' subordinate and disempowered position, a position captured in other student descriptions of the student role as being a "Follower" (Student 13), “Test subject" (Student 16), or "Prisoner" (Student 2).

Further revealing the lack of empowerment implicit in the current student role were comments by some students that saw adults, not themselves or fellow students, as the means to have their voices heard. Student 42 suggested, "Talking to teachers and getting them to voice your ideas." And Student 11 offered, "Counselors, they can help us have a voice."

The subordinate and narrow view of student membership in the school community presented in these responses of students and teachers runs counter to two significant justifications of expanding the student role: preparation for citizenship (Warwick, 2008; Bragg, 2007), and the expectation of youth rights expressed in the United Nations Convention on the Rights of the Child (UNCRC), (von Wright, 2006). Morgan and Streb (2001) and Bandura (2005) have advocated for the importance of developing efficacy in youth as an important preparation for citizenship. The Center for Information and Research on Civic Learning and Engagement has suggested that schools adopt policies and practices that model democratic principles (Carnegie Corporation of 
New York and CIRCLE, 2003). Howe and Covell (2013) have documented the positive outcomes resulting from reforming school culture around student rights.

Addressing these areas will require a significant shift in the thinking of students and teachers at RHS toward contextualizing the student role in school as an extension of democratic membership that recognizes the rights as well as the responsibilities of participation in the school community. The Rights, Respect, and Responsibility (RRR) initiative in England could serve as a successful model of just such a policy (Howe \& Covell, 2013). The program involves reshaping school culture by building a sharedvalues framework based on the rights of the child as defined in the UNCRC.

Conclusion 5: Student as agent of change. Another characteristic of the student role articulated in the student voice literature that presents a challenge to current conceptions at RHS is that of the student as a knowledgeable agent of change (CookSather 2006; Fletcher 2003), researching the learning environment and transforming it (Cook-Sather 2007a; Mitra \& Gross 2009). The current absence of systemic opportunities for students to inform and influence school policies and practices was apparent in the many comments from students suggesting procedures for engaging the system and having their voices heard. Student 29 posted, "It would be beneficial if the administration, the teachers, and at least some students would meet regularly to discuss decisions in the school." Student 17 suggested, "There should be a committee for student ideas to look over ideas from students about the school." Student 23 proposed, “Open student night. A night where students who care would come in and talk with the staff about ideas they have to improve or help the school." And Student 37 recommended, 
"Every Friday there should be a meeting that allows students to be heard with ideas they have." These student submissions reveal the inadequacies of the current system to provide structured opportunities for student engagement toward meeting their developmental needs for connection, increased autonomy, respect, and agency (Mitra, 2004; Eccles \& Roeser, 2011) and confirm the general lack opportunities available to adolescents in school described in the student voice literature and summarized in Fielding's (2004a) declaration, “There are no spaces, physical or metaphorical, where staff and students meet one another as equals, as genuine partners in the shared undertaking of making meaning of their work together" (p.309).

These systemic failings at RHS are further fueled by teacher ambivalence captured in two recurring themes found in the teacher submissions - one recognizing and supporting the developing autonomy and agency of students, and the other seeking to control and direct this expanding role toward adult ends.

One thematic category in the student responses that reinforces the identity of student as agent was the concept of the student as leader. "As young adults, it is important for high school students to take on leadership roles so that they have the opportunity to change the world to better suit them and future generations," submitted Student 29. "Making petitions and following it up with some research would have a lot of influence on the school," suggested Student 9. These expressions of agentic identity, along with the declarations of the right to speak and vote described previously, offer a possible antidote, if cultivated, to the notions of powerlessness captured in other descriptions of the student role by both students and teachers. 
One model for building on the idea of student as change agent can be found in a statewide initiative in Vermont called Youth and Adults Transforming Schools Together (YATST) (Beattie, 2012). YATST employs a participatory action research approach where students and educators evaluate students' educational experiences and implement reforms, in the process transforming the student-teacher relationship to one of collaboration for school improvement. The effectiveness of such programs requires a strong commitment on the part of educational leaders, effective training of students and staff, and ongoing support (2012). Whether RHS is willing to make such commitments and investments remains to be seen.

Conclusion 6: Shared values. Considered together, comments making up both student and teacher response categories that aligned with student voice principles, expressed an unfulfilled, but palpable inclination toward having students engage more fully, more collaboratively, more equitably and more influentially, in the learning and organizational processes of schooling. These expressed behavioral norms, like others in the study, imply a shared set of values. As values that have the capability to inform future actions, these shared beliefs in the importance of belonging, the significance of relationships, and the unrealized potential of collaboration and student involvement and influence, carry real promise toward increasing meaningful student engagement at RHS. If they are communicated to the community, they hold the possibility of establishing a common ground upon which students and staff might reimagine and recreate their roles and relationships. As one of the SRT members remarked upon first viewing a summary of the study data, "What surprised me was how alike the student and teacher ideas were 
about student involvement." Identifying, disseminating, and building on the shared values, beliefs and concepts of the student role derived from the student and teacher responses remains an important goal of this research.

In order to gather additional insight into the present status and future possibilities for meaningful student involvement at RHS, a typology of student engagement developed by Mitra and Gross (2009) was applied to the student and teacher response categories presented previously to generate additional recommendations for furthering the student voice agenda in RHS community.

\section{A Review of Student Engagement}

Mitra and Gross (2009) created a typology of student voice application that recognizes three levels of expanding youth engagement: being heard, collaborating with adults, and building capacity for leadership (See Figure 6). To further interpret features of the student role identity standard disclosed in the student and teacher responses, the revised response categories derived from the student and teacher responses described in Chapter V were classified according to this typology. Only response categories aligned with student voice principles were included in the ordering. See Table 18.

The placement of response categories in this typology of student engagement provide another perspective on the vision of student engagement at RHS, reinforcing barriers to student engagement described previously while identifying new challenges and access points.

Recommendation 1: Create a culture that empowers students. The most basic expression of student engagement - "being heard" is located at the bottom. At this level 
Table 18

Alignment of Student and Teacher Response Categories with Typology of Student

Engagement

Typology of Student

Engagement

(Mitra and Gross, 2009, p. 523)

Building Capacity for

Leadership: student agency

and efficacy is enabled toward

the critique and transformation

of schools and communities

\section{Student Response Categories Teacher Response Categories}

Leader: The role of students is - - -

to be a leader, voicing opinions

and impacting school policy.

Collaborating with Adults:

students partner with adults in

school reform

Being Heard: students sought out as sources of information and feedback
Use Student Government: Students should be able to use student government to represent their opinions and influence school policies.

$$
--
$$

Voice opinions: Students should have real opportunities to voice ideas and opinions without censorship.

Vote on policies: Students should have opportunities to vote on policy decisions that affect them.
Use Student Government and Leadership: Students should be able to use student government and other leadership roles to voice their ideas.

Provide feedback: The role of students is to provide inputs to the system to make it more effective.

Voice opinions: Students should have real opportunities to voice ideas and opinions.

Vote on policies: Students should have opportunities to vote on policy decisions that affect them

Work with administration: Ask/Survey student for what they would like to see more of or less of in the school climate. Then determine what can be done to accommodate the requests. 
students are sought out as sources of information and feedback to various scales of educational system. In essence all but one of the student and teacher response categories correspond with this level. This aligns with my review of sixty research studies involving student voice published in peer-reviewed journals between 1999 and 2012 revealing that over $70 \%$ used student voice as an information source.

At first glance, it might appear that some of the categories have been misplaced. Surely student government and working with administrators represent higher levels of student engagement - collaborating with adults, and/or building capacity for leadership. But a closer look at the expanded descriptions of the categories distilled from the grouped responses reveals a narrower vision of student engagement than these higher levels of student involvement suggest. In most cases, whether working with administrators or through student government, the responses lack an expression of initiating and cocreating as characteristics of the student role. Rather, students are seen as voicing opinions and voting on issues as responses to adult policies and practices. Thus, even though student and teacher responses aligned with student voice principles made up a total of nearly $70 \%$ of student submissions, and over $80 \%$ of teacher submissions, the vision of student engagement they capture is a relatively passive one.

The new standardized end-of-course student survey recently initiated at RHS exemplifies this role of student-as-information-source. This is not to suggest that surveys such as this do not have value. Rather, that without being framed within a larger system of student involvement they risk reinforcing the subordinate role of students rather than expanding it. For example, students could be asked to compile the survey data 
themselves using their knowledge of the classroom context to interpret the results and make recommendations (Raphael, 2008), which in turn would support their efficacy, agency and collaboration with the teacher.

The current status at RHS is that there are no systemic opportunities for students to engage the system in order to raise issues, ask questions, propose policy or initiate change. An administrator having an open-door policy that depends on student initiative is not enough. Reactivating the Student Senate, while valuable, is symbol more than substance, and will not flourish if additional policies and practices are not put in place to give it a viable role in the community. For student voice to be actualized at RHS will require a cultural shift in the values, beliefs, norms, assumptions and expectations that inform and guide the relationships between students and teachers and the school organization (Cook-Sather, 2006). Getting there will require building a shared vision of what it means to be a member of the RHS community. It will require that the adults initiate the policies and practices and create structures, times and places that invite student participation. And it will require that they maintain them, until such time as the students themselves see the value in engaging the system, a system that has traditionally sidelined their participation. Then, perhaps, they will co-create their own avenues to meaningful involvement.

Recommendation 2: Build youth-adult partnerships. Students collaborating with adults occurs at level two. At this level, students partner with adults in classroom and school reform. Much of the current research on student voice involves this approach (Mitra \& Gross, 2009). Nearly one third of the research studies conducted since 2007 
that I reviewed engaged students in the research as participants or initiators.

The lack of a single thematic category at this level reinforces the issues raised previously regarding the absence of student or teacher responses expressing unequivocally a vision of student partnership and collaboration. While the value of relationship already described holds promise, without addressing the central issue of how students and teachers conceptualize the student-teacher relationship, there is little hope of the RHS community moving intentionally to the next level.

I suspect that most teachers at RHS attempt to engage their students in a way that is respectful of them as both students and persons. But both students and teachers recognize the inequitable power structure inherent in the student-teacher roles they are conditioned to play in the school organization. As Teacher 32 expressed, "Many kids are afraid of retaliation by the staff for their opinions." Student 7 explained it, “...there are some teachers that are just not very understanding and do not take insight and observations from their students very well."

The power differential implicit in the conventional student-teacher relationship impedes the expression of an authentic voice (Freire \& Giroux, as cited in Sands et al., 2007) that is a precondition for the collective work of the classroom community (Lensmire, 1998). Democratizing talk must be part of classroom practices if student voice is to be developed and maintained (Johnston \& Nichols, 1995).

One way to address this is through dialogue. The Student Research Team's response to presenting the initial research findings to the staff demonstrates the promise of open dialogue. In a post presentation interview, the SRT members described their 
initial anxiety at presenting to teachers, their delight at the engaged response, and their surprise in the discovery of how similar the teachers thoughts and concerns were to their own. This kind of structured dialogue is rare at RHS, but needn't be.

Additionally, accessing the metaphors that students and teachers use to define their identities and roles can be important access points for helping both reconsider those roles. Lakoff and Johnson (1980) describe how metaphors both reveal and inform how we perceive, interpret, and respond to people and events. The student and teacher conceptions of a delimited and subordinate student role reveal schemata around student identity that must be addressed to further the student voice agenda. Metaphors that describe school as a job, teacher as a boss, students as employees, test-subjects, and prisoners, expose the depth of the challenges toward developing an expanded view of student engagement. It is not that such metaphors are inherently wrong, but rather what they reveal about the boundaries of appropriate student engagement they communicate and reinforce. At the same time, if disclosed and openly discussed, they may offer opportunities for dialogue and collaboratively rethinking how students and teachers are perceived, and for reconsidering the limits imposed on the roles of students and teachers as members of the school community. A simple activity that the high school might engage in is to have students and teachers make a list of metaphors describing themselves, each other, the classroom and the school. Collated and shared the responses could make for some interesting homeroom dialogue and begin to make transparent the many schemata that shape our perceptions, interpretations and responses to one another as members of the school community and act as a first step toward reconsidering them. 
Recommendation 3: Build Capacity. Building capacity for leadership, located at the top of the topology of student voice, is the least common expression of meaningful student involvement found in the literature and at RHS. At this level, student agency and efficacy is enabled toward the critique and transformation of schools and communities (Mitra \& Gross, 2009). The only corresponding category was the student response category, Leader. But even its placement was tenuous. While the responses in this category did express a more agentic notion of student involvement than others, the key descriptors, voicing and impacting, while suggesting the possibility to critique, still lack a stronger declaration of ability to initiate and transform.

In contrast to building capacity for leadership within the educational dimension of schooling, Teacher 22 proposed, "Being involved in activities outside of class is a way for students to take charge of their lives." Such a comment suggests that at least for some, students taking charge of their lives within the classroom and school does not yet lie within their conceptual boundary of the student role.

Considered through the lens of this disbursement of student and teacher response categories, it would appear that the current reality and future projections of the student role in the RHS school community show little expression of the expanded role of student engagement outlined in this typology or the larger student voice agenda. Looking beyond the categories, a review of all the individual student and teacher responses, also revealed very few individual examples of responses that aligned with the higher levels in the typology.

With regards to collaborating and partnering with adults, several teacher 
responses implied a collaborative role for students. "Participate with the instructor to come up with a set of norms for various activities and functions in the classroom," suggested Teacher 5. Other teachers suggested having students participate in Site Council (Teacher 15; Teacher 29) or working with school administrators and with the school board (Teacher 21), all of which would involve working closely with adults. There were no similar submissions in the student responses, suggesting the effectiveness of the students' socialization into conventional adult-youth power inequities.

Similarly, the teacher responses included submissions strongly aligned with Building Capacity for Leadership. No analogous postings from students outside the leadership category were submitted. Teacher 20 suggested, "Giving students a chance to create their own classroom setting can be empowering and motivating. Students need to be able to feel that they are being heard by their teachers." And Teacher 22 submitted that students "Have a meaningful voice in school decisions. Too often students are given only perfunctory opportunities to provide input into what happens in their lives while at school. Teachers and administrators need to be willing to really listen to what their students think." Teacher 3, capturing the essence of critiquing and transforming the learning environment, submitted:

As an active member of the school community who owns their own learning, a student would be in a position to evaluate that community for ways it could be improved. If the school can be improved, it only follows that the student would be involved in causing those improvements to come about. If our goal is powerful and confident young adults who control their own destiny and influence their world, they must experience a world now (school community) where control and influence are practiced.

While these thoughts did not garner individual thematic categories during earlier 
stages of this research, grouped here, they do reveal key points of correspondence between staff and an expanding vision of student engagement at RHS. The lack of comparable submissions from students reinforces the challenges facing the students regarding reimagining their own role within the school organization while at the same time reinforcing the responsibility of teachers and administrators for fostering this re-

creation. Perhaps the dissemination of these study results in the RHS community can help foster this transformation.

\section{The Impact of the Study on the Status of Student Voice at RHS}

A secondary goal of the research was to further the student voice agenda at RHS toward reconsidering and reimagining what it means to be a student, and by implication a staff member, at RHS. The choice of critical ethnography as a research design was intentional, expanding the role of the research team to include advocating for the empowerment of RHS students and the invocation of student voice. The notion of "voice" as an expression of personal and group efficacy is central in critical research, particularly as it applies to student voice (Arnot \& Reay, 2007).

This study sought to expand the student voice agenda at RHS based on the following assumptions:

1. Participation of the school community in the study would support further dialogue around issues of student voice.

2. Inclusion of both student participants and student researchers in the study would validate the power of student voices - not merely as rich sources of information, but as valuable co-creators of meaning. 
3. Participation of students as co-researchers throughout the process would increase their sense of agency, belonging and competence (Osberg, Pope \& Galloway, 2006; Rubin \& Jones, 2007; Mitra, 2009).

As a form of action research, including students as researchers addressed the issue of student empowerment directly by fully engaging students as equals in a collaborative process aimed at school transformation (Noyes, 2005). In this way the focus of the research was reoriented from product - the answer to the research questions, to process egalitarian participation and discourse, and therefore modeled the student partnerships described and advocated for elsewhere in the study.

The participation of the Student Research Team was instrumental in addressing the secondary research goal. The SRT was composed of three students who have maintained their participation throughout the study, which included co-facilitating the entire Thoughtstream process, reviewing initial results, and presenting a summary of the results to students and staff.

In order to capture their thoughts about the experience, data was collected in two ways. First, a Thought Stream was set up for the SRT members to record responses to guiding questions at both the midpoint and end of the initial phase of the study. The following questions made up the Thought Stream.

1. Overall, how has your experience been working with the Student Research Team on the Student Role Study?

2. What do you like most about your participation in this study? List 2-3 experiences you had that you enjoyed most or believe are the most important.

3. What do you like least about your participation in this study? List the things you dislike, want changed or find the least value in.

4. What impacts is your participation in this study having on you, what you 
understand, think, and/or believe about yourself and others?

5. What are your thoughts about the study itself - the goals and the methods we are using? Share 3-5 ideas.

6. Is there anything else you would like to add or is there anything we should do differently?

After the SRT had viewed an initial summary of the research data and presented the results to the community, I conducted and recorded a semi-structured interview with the researchers using the guiding questions.

I kept a weekly journal throughout the process using the same guiding questions. In addition, I took notes during and following three presentations that the SRT made to the school community.

Data was drawn from all these sources to address the three assumptions, beginning with the last as it holds the key to reviewing the other two.

Assumption 3: Impacts of participation on the SRT members. I approached the study with the belief that participation of students as co-researchers throughout the process was would increase their sense of agency, belonging and competence. The data and personal observation supports the conclusion that is has.

All three participants acknowledged both through their journal entries and in the interview their sense of connection to the research team and appreciation of their coresearchers. Researcher 1 submitted: "I really enjoy the people on the team. They're very nice, fun to be around, and analytical." In the final interview, Researcher 2 offered that one of the things that was most enjoyable about the experience was "working with the team." Researcher 3 summed up the experience, posting, "Being able to work as a team is really amazing! I feel like I could rely on my teammates, for example when it came 
down to choosing which category a thought should go into, we were able to figure out where it belonged by talking to each other."

This sense of camaraderie was captured in several entries in my journal as well, such as this one from week six. "I have enjoyed the degree to which I see how the SRT students treat each other - asking for opinions "what do you think," and listening to each other, "sorry - go ahead - I didn't mean to cut you off."

As the research team interacted with the study data, this sense of connection expanded to include the RHS community. In the closing interview, Researcher 2 described how participation in the study "made me care more, about the education system and my fellow students." And Researchers 1 and 2 commented, "I was able to connect with how teachers thought."

The researchers' sense of agency and competence was not so much apparent in their written or interview comments as it was in their actions as participants. All three students maintained a commitment to the project throughout the initial 11 weeks of data collection and sorting, meeting once, sometimes twice a week for two to three hours. Then again, the following year, all three maintained their commitment to disseminating the research results, have made presentations to the staff and students, and are committed to making a presentation of the study findings to the school board.

During the teacher presentation, after being introduced to thirty plus members of the RHS staff, the research team took over, summarizing initial results and responding to questions. Their professionalism was apparent and appreciated by the staff and myself. Following this first presentation, all three participants shared with me their initial anxiety 
at standing up before the teachers, and their delight at the high level of interest displayed. Their sense of pride was palpable.

The researchers' sense of agency and competency was again apparent in their commitment to present to fellow students. Interestingly, the researchers expressed more anxiety in the student presentation. "It was more nerve-wracking presenting to peers," shared Researcher 2. Still, they did it.

The most overt indication of a growing sense of agency, belonging, and competence, was displayed by Researcher 2. Immediately following the teacher presentation the SRT member approached the administration about reactivating the student senate. Since then, Researcher 2 has written a thorough charter for the senate, including articles and bylaws, and presented it to both the Site Council and the RHS staff in separate meetings. As of this writing, Researcher 3 made a follow up presentation to Site Council and received final approval for reinstating the student senate.

Reflecting on the effects of participating in the study and the motivation to restart the student senate, Researcher 2 offered, "I felt that way too [disempowered], but now I can do something about it."

Assumption 2: Participation validates the power of student voice. The second assumption was that inclusion of both student participants and student researchers in the study would validate the power of their voices - not merely as rich sources of information, but as valuable co-creators of meaning. Findings that support the conclusion that the power of student voice has been validated have already been suggested in the reflections and actions of the student research team just presented. The RHS 
administration has demonstrated the value they see in student voice by opening up space and time for the SRT to present the research results.

The staff and student responses to the research team presentations are another example. In each case, both the voices of the research team, and the voices of students communicated from the data, sparked interest and discussion. After the teacher presentation, the staff conversation immediately focused on the implications of the student voice results to classroom practices and student-teacher relationships. "I see kids afraid to talk to teachers," observed one teacher. "Kids apologize for asking questions..." confirmed another. "We need to give permission to our students to speak up," suggested yet another.

Likewise, the presentation to students also provoked discussion. But whereas the teachers focused on the immediate implications of the research for classroom practices, the student interest focused on next steps, particularly the student senate. They wanted to know if it would really happen and when it would start. When asked who would want to participate, a dozen hands of the forty-or-so students in attendance were raised.

In the closing interview, Student 3 shared, "Going through this process has made me realize that the students want to have a voice." And Student 2 reflected, "If you give students the ability to make changes, they will become more interested [in school]."

Beyond validating the voices of students, the project has also validated the voices of teachers. "As students, we don't get to see how teachers think. It was really exciting," stated Researcher 3, adding, "It changed how I think about teachers. They really care about having our voices heard, and they're really interested in our thoughts." "It gave me 
insight into the caring hearts of the teachers," shared Researcher 2, "and made me realize that teachers care what I think."

\section{Assumption 1: Community participation fosters dialogue on student voice.}

Lastly, the first assumption regarding impacts of the study on the community was that participation would support further dialogue around issues of student voice. Everything presented in this section so far supports the conclusion that it has, from the continued participation of the members of the SRT, to the support of the admin team toward disseminating and acting on the data, to the dialogue generated in the presentations, and the re-constitution of the student senate. Everything points to an expansion of student voice at RHS.

Returning to the research team, a submission by one of the team members seemed to capture the essence of the intent and impact of the study. When asked what was most enjoyable and valuable about participating in the research, Researcher 3 submitted, "Understanding. For me, working on this study has really helped me understand where a student stands in the community. This study has helped me understand what students think of themselves. It has also helped me learn how valuable communication is for a team." Previous comments and actions suggest that that team now includes the staff and students of River High School.

\section{Limitations and Recommendations}

Like the student roles it describes, these results are bounded by limitations both real and imagined. A review of the research process and results, including an examination of the weekly journals, the SRT participant notes, and the closing interview 
with the SRT members, were used to evaluate the research design and in the process generated responses and recommendations.

The limitations identified and presented in the methodology section of Chapter III are addressed first.

Issue 1. SRT abilities. The age-specific abilities of student researchers may have impacted the construction of survey questions and background information, the interpretation of responses, and evaluation of results (Symunds, 2008).

Response. The effectiveness of the SRT to develop effective questions and conduct the initial categorization of the responses is evident in the quality of the results produced and confirms both the value and efficacy of students as researchers described in the student voice literature (Bragg, 2007).

During the Thought Stream development phase the team field-tested a variety of questions and versions of questions before mutually agreeing on the final three. Disagreements during the categorization process were resolved successfully through negotiation as captured in this post from Researcher 3, "During the categorizing, it was great to see the different arguments each member had about a thought. It helps me see the thoughts they have from a different perspective."

The one frustration expressed by all the team members was the size of the research team. While eight were invited, only the three were able to complete the study, due primarily to scheduling conflicts and other commitments. Researcher 1 admitted, "I might be a little distraught about the shrinking of our group, but now we are in a group of people who are committed to the research and its future impact." Researcher 2 posted, "Disappointment in those who left. They might have their reasons for leaving, but I 
still can't help feeling that way. They tried to see the opportunity that this research is giving and tried to commit. Then end up leaving for conflicts that just happen to be on Tuesdays." And Researcher 3 shared, "Truth be told I wished we did have more people for the SRT team, because it is truly an awesome experience. But it could be more fun if we had more people on the team."

Recommendations. Conduct research with students in the context of a class, club, or part of a student leadership organization, this could alleviate some scheduling conflicts. Homeroom, a psychology class or psychology club, a student leadership organization, even an independent study class scheduled during a teacher's prep period all could provide opportunities for students to engage in researching the school environment.

Issue 2. Use of an online platform. The use of an online platform to present background information and questions requiring typed responses may have impeded the full participation and quality of responses of some participants.

Response. There is no indication that the use of the Thoughtstream platform in the case of this study impeded participation in any discernible way. No negative feedback of any kind was received from participants. The SRT members all commented on the effectiveness of the platform to deliver the survey content and facilitate the categorization and presentation of results. "It's a very good program for this research," posted Researcher 1.

While not the case in this study, the use of an online platform such as Thoughtstream for participants with special needs would require additional consideration. 
Recommendations. Online platforms such as Thoughtstream can be a useful and effective tool for collecting, collating and communicating the thoughts of a community for the benefit of both the participants and the researchers.

Issue 3. Self-selected participation. Though initially intended as a random sampling based on alphabetized homeroom assignments, the student participation group became self-selected based upon which students were motivated and/or organized enough to return the Informed Consent forms and thus may not adequately represent the thoughts and feelings of the general student population.

Response. Developing interest in participating in the study turned out to be a challenge - among students, teachers, and especially parents. My earlier assumptions that my relationship with the community would somehow generate interest and commitment were incorrect. I have been humbled!

Did the self-selected participation limit the breadth of study content? Perhaps. Did it limit the value of the content to inform and inspire further consideration of the student role? The community response thus far suggests that it did not.

Recommendations. As the most informed, committed and enthusiastic participants, the research team should present information to potential participants. Because of time and logistical constraints, we depended upon homeroom teachers to describe the study, recruit participants, and to distribute, collect and follow up on IC forms. The SRT suggested that making the pitch to homerooms ourselves would have been more effective.

Issue 4. Low ICF return rate. The number of student respondents who 
submitted the required Informed Consent forms was lower than anticipated (n44). This smaller sample size could impact the validity of their responses to represent the thoughts and feelings of the general student population.

Response. There is no question that collecting completed IC forms presented a barrier to participation in the study, not unlike the daily struggle to get homework turned in on time! During the dissertation defense the committee raised the issue of including incentives to support participation. The homeroom teacher with the highest participation rate did provide incentives for returning the IC forms, but still achieved less than a 50\% rate of return. This issue is similar to Issue 3, and the response the same: While the number of participants was smaller than anticipated, the richness of the data and the value to the community are evident. On the other hand, greater participation could have amplified the potential impacts of the study both on the participants and in the community. That said, if the number of participants had been much greater it could have impacted the timeline to complete the study.

Recommendations. 1) Consider carefully the amount of data necessary to capture the information being sought, the amount of time required to collect and analyze it, and the potential benefits of participation. 2) Include incentives for participation, but don't overestimate their effectiveness. Particularly with regard to the lack of parent participation in this study, I have concluded that including an incentive, such as a dollar in the home mailings, might have increased involvement.

Issue 5. Lack of participant crossover. The number of student and teacher participants that completed both steps of the Thoughtstream process was minimal making 
up essentially two distinct subgroups of participants and diminishing the sample size for each step. For survey questions one and two, the crossover rate for students was $24 \%$ and $22 \%$ respectively. For question three it was $25 \%$. For the teachers, the crossover rate was even lower, at $15 \%$ for question one, $0 \%$ for question two, and $5 \%$ for question three.

Response. The limited crossover between the participants contributing thoughts, and those ranking the categories was not anticipated and was not revealed until after the data collection was complete. This situation diminished the number of actual participants contributing thoughts and those who ranked them and raises the greatest possible threat to the validity of the results and analysis presented here. The original protocol for collecting data, which had homeroom teachers bringing entire classes to the computer lab, could have minimized this risk. But this approach was dropped due to the reduced participation rate from individual homerooms already described. Having an open computer lab and allowing students to log on at home reduced on-time tracking of participants.

Finally, the two-step Thoughtstream process itself may have been a contributing factor. It may not have been clear to participants that participation in the online survey required two distinct steps. For teachers who have multiple demands on their time, the deadline for completing step one of the Thoughtstream process may have excluded otherwise interested participants from submitting responses.

Recommendations. 1) Communicate clearly research protocols and deadlines for procedures that require participants to complete multiple steps, particularly if the steps appear to be similar - as in returning to the same online platform. 2) Create protocols that 
support accurate and on-time tracking of participation.

Issue 6. Limits of generalizability. As a critical ethnography, the data generated is too limited in focus, duration and sample size, as well as too site specific, to be generalizable to other individuals, groups and contexts beyond RHS.

Response. As a critical ethnography involving participatory action research, the primary audience for the study was the RHS community itself. Sharing the early results of the study with RHS students and staff has already begun. However, insights gained from a more thorough examination of the data were not part of this initial offering and provide additional content that could have value to the community.

Additionally, the topic of research and the methods used do have value to the greater research community. The results of this research reveal the importance of understanding the boundaries of the roles students and teachers create and act through within the organizational context of school. Also, the conclusions drawn invite further investigation.

Recommendations. Continue disseminating the research results within the RHS community. In particular, follow up on addressing the school board and identify additional opportunities for sharing the results, such as returning to the Site council, a staff meeting, a student senate meeting, an open-invitation meeting to students during homeroom or lunch, or after school gathering open to students and teachers. Also, find out about having a summary of the conclusions posted on the high school and/or district website. 


\section{Additional Recommendations}

In addition to recommendations included elsewhere in the study, the following stand out as particularly significant in validating, expanding, and acting on the results described here.

1) Apply the research questions and protocol developed here to other settings.

The three online questions developed by the Student Research Team to investigate student and teacher conceptions of the student role generated data rich in content toward investigating and understanding both the limits and aspirations of the RHS participants'

conceptions of the student role. Applying this research agenda to other settings could add value to the findings generated here, generate value to other school communities, and inform and further the greater student voice agenda.

Currently, there is lack of research in the area where student role identity and student voice intersect. An examination of peer-reviewed student voice literature dating back to 1981 revealed only two instances in which the study was framed as an investigation of student identity. The results of this research study suggest this could be a rich area for further investigation.

2) Work with other researchers, educators, youth and adult groups committed to expanding student voice and engage local, state and national organizations to develop policy on this issue. The most significant personal outcome from this research is the awareness of the systemic nature of student role identity. Both teachers and students operate within a local school system embedded in state and national systems that have placed no discernible value or expectation of developing students as citizens. The current 
school narrative of standards and accountability demands a limited role for student engagement that can subjugate student needs to the needs of the educational system (Crick et al., 2007) and consequently constricts both student and teacher relationships to a managerial one - the boss and employee model so clearly articulated in so many student and teacher responses. Every relationship between systems defines and therefore constrains the system (Zwick, 2006). The constraints that the current system places on conceptions of the student identity role and by implication, the role of teachers is evident throughout this study. If values and beliefs are the basis for action, then the values and beliefs that inspired and informed this study demand an expanded engagement of this researcher with the larger systems shaping the policies and practices that currently impede a fuller realization of what it means to be a student and a teacher.

\section{Conclusions}

The goal of this research was to develop a situated description of the student role within the organizational context of a rural high school from the perspective of students and teachers toward identifying barriers and abetments to the facilitation of student voice. The literature on student voice identifies three categories of obstacles to creating and sustaining student voice: structural barriers, resistance by educators, and student resistance (Fletcher, 2004). This research sought to expand our understanding of the issue of student and teacher resistance by focusing on the boundaries of appropriate student engagement that students and teachers have constructed around student roles. In the process, structural barriers would also be brought into relief. The research agenda was predicated on the hypothesis that the diminishing student engagement that characterizes 
the adolescent years (Yazzie-Mintz, 2007) stems at least in part from a failure to establish viable roles within the organizational context of schooling that allow youth to meet their developmental needs for connection, increased autonomy, respect, and agency (Mitra, 2004; Eccles \& Roeser, 2011) in meaningful ways.

As a critical ethnography, a secondary goal of the research was to further the student voice agenda at RHS toward reconsidering and reimagining what it means to be a student, and by implication a staff member, at RHS. Keeping with student voice values and participatory action research protocols, students took a central role in developing and piloting survey questions, interpreting and organizing responses, reviewing the results, and presenting them to the school community.

The answer to the core research question, "How do students and teachers from a rural high school conceptualize the role of "student" in the organizational context of the school?" elaborated a list of characteristics expressing both traditional ideas of what it means to be a high school student and more agentic qualities aligned with student voice principles. There was significant alignment in most of the student role characteristics between the student and teacher conceptions. Corresponding student role characteristics among student and teacher responses included being a role model, respectful and responsible. Both groups saw active participation in academics and extracurriculars, personal exploration and development, and following rules and policies, as behavior norms. Voicing opinions, voting, influencing policies and an influential student government were likewise identified as shared student role expectations. And accordingly, the values inferred from these norms were similar for both groups. 
Significant areas of divergence between student and teacher constructs included the explicit temporal orientation toward the future exclusive to the student responses, the engagement in academics that dominated the teacher submissions and rankings, and the conception of the student as a citizen/community member that was found only in the teacher responses. Most noteworthy, however, was the lack of significant inclusion of thematic categories aligned with student voice principles in descriptions of the student role by either students or teachers.

The student role identity standard disclosed in the student and teacher responses was then compared and contrasted with student role characteristics and a typology of student engagement derived from the student voice literature in order to gather additional insight into the present status and future possibilities for meaningful student involvement at RHS. Overall, it revealed the gap between the practices and general aspirations of the RHS community and those suggested in the student voice literature as supporting meaningful student involvement.

The secondary goal of the research was to further the student voice agenda at RHS toward reconsidering and reimagining what it means to be a student, and by implication a staff member, at RHS. Overall the results suggested an inclination on the part of both students and teachers to increase opportunities for students to inform and influence policies and practices at all levels of the school organization. Presentations of the results to the school community by the student researchers have induced some systemic action toward promoting student voice, most notably the reactivation of the student senate. 
The larger issue identified from the study, is the greater context - the macrosystems - within which the student and teacher roles at RHS are created and acted out. The Rights, Respect, and Responsibility (RRR) initiative (Howe \& Covell, 2013) mentioned previously as a model of shaping school culture to support student voice, reflects England's ratification of the United Nations Convention on the Rights of the Child which legally binds it to recognize the rights of youth to be heard in relation to decisions affecting them. In signatory countries such as make up the UK, policies and structures are being developed at all levels of the political system, including the public schools, creating a child-rights ecology within which the roles of youth and adults are necessarily restructured. No such orientation exists within Oregon or the United States. This lack of context is perhaps the greatest challenge (O'Donoghue, Kirshner \& Milbrey, 2002) facing RHS if it is serious about furthering a student voice agenda. Systemic change toward reinventing the student - teacher - school relationship, the deeply held norms, values, and beliefs that shape schools as social systems must be addressed (Parsons, 2007).

As long as the roles of students, teachers and administrators are developed and expressed in relationship to state and federal systems focused myopically on academic standards to the exclusion of other education purposes, such as rights and preparation for citizenship, it is unlikely that the student identity role standard can develop the attributes suggested either in the student voice literature, or in the highest aspirations included in the student and teacher responses disclosed in this study.

Educators serious about expanding pathways for meaningful student engagement 
will have to address these larger systemic issues if they hope to be successful. Studies such as this that delineate the boundaries of student and teacher roles in relation to enveloping systems can serve to expose the systemic nature of student disengagement, and challenge adults and youth to engage the systems that reinforce the limitations on the roles of youth that impede development, relationship, and learning. 


\section{References}

American Youth Policy Forum. (2000). High schools of the millennium report. Washington, DC: Author. Retrieved from http://www.aypf.org/publications/index.htm

Angus, L. (2006). Educational leadership and the imperative of including student voices, student interests, and students' lives in the mainstream. International Journal of Leadership in Education, 9(4), 369-379.

Apple, M. W. (2004). Creating difference: Neo-liberalism, neo-conservatism and the politics of educational reform. Educational Policy, 18(1), 12-44.

Apple, M. W., \& Beane, J. A. (Eds.). (1995). Democratic schools. Alexandria: Association for Supervision and Curriculum Development.

Arnot, M., \& Reay, D. (2007). A sociology of pedagogic voice: Power, inequality and pupil consultation. Discourse: Studies in the Cultural Politics of Education, 28(3), 311-325.

Authentic Education. (2010). Four beliefs. Retrieved from http://www.authenticeducation.org/whoweare/fourbeliefs.lasso

Baer, J. (1999). Adolescent development and the junior high school environment. Social Work in Education, 21(4), 238-249.

Bandura, A. (2001). Social cognitive theory: An agentic perspective. Annual Review of Psychology 52, 1-26.

Bandura, A. (2005). Adolescent development from an agentic perspective. In Urban, T., \& Pajarea, F. (Eds.) Self-Efficacy Beliefs of Adolescents, (pp. 1-45). Greenwich, CT: Information Age Publishing.

Barton, R. (2008). A clear signal. Northwest Education 13(3), 30-36c Retrieved from educationnorthwest.org/webfm_send/434

Beattie, H. (2012). Amplifying student voice: the missing link in school transformation. Management in Education 26(3), 158-160. 
Biddel, B. J. (1986). Recent development in role theory. Annual Review of Sociology, 12, 67-92.

Biddel, B. J. (2001). Analyzing schools as organizations: Long term permanence and short-term change. Sociology of Education, 74, 100-114.

Bill and Melinda Gates Foundation (2001). High schools for the new millennium: Imagine the possibilities. Retrieved from http://www.gatesfoundation.org

Bolman, L. G., \& Deal, T. E. (2003). Reframing organizations: Artistry, choice, and leadership (3rd ed.). San Francisco: Jossey-Bass.

Boulding, K. E. (1956). General systems theory - The skeleton of science. Management Science, 2(3), 197-208. Retrieved from http://www.jstor.org/stable/2627132

Bragg, S. (2007). "Student voice" and governmentality: The production of enterprising subjects? Discourse: Studies in the Cultural Politics of Education, 28(3), 343-358.

Bridgeland, J. M., DiIulio Jr, J. J., \& Morison, K. B. (2006). The silent epidemic. Washington, DC: Civic Enterprises. Retrieved from http://www.ignitelearning.com/pdf/TheSilentEpidemic3-06FINAL.pdf

Brookes, K., Davidson, P. M., Daly, J. \& Halcomb, E. J. (2007, May-June). Role theory: A framework to investigate the community nurse role. Contemporary Nurse, 25(1-2), 146-155.

Brooker, R., \& Macdonald, D. (1999). Did we hear you?: Issues of student voice in a curriculum innovation. Journal Of Curriculum Studies, 31(1), 83.

Bryn Mawr Now. (2011, December, 8). Alison Cook-Sather named Jean Rudduck Visiting Scholar at the University of Cambridge. Retrieved from http://news.brynmawr.edu/2011/12/08/alison-cook-sather-named-jean-rudduckvisiting-scholar-at-the-university-of-cambridge/

Burke, P. J. (2006). Identity change. Social Psychology Quarterly, 69(1), 81-96.

Burke, P. J. \& Reitzes, D. C. (1981). The link between identity and role performance. Social Psychology Quarterly, 44(2), 83-92. 
Burton, D., Smith, M., Woods, K. (2010). Working with teachers to promote children's participation through pupil-led research [Abstract]. Educational Psychology In Practice, 26(2), 91-104.

Carnegie Corporation of New York and CIRCLE: The Center for Information and Research on Civic Learning and Engagement. (2003). The civic mission of schools. Retrieved from http://www.carnegie.org/pdf/CivicMissionofSchools.pdf

Center for Information and Research on Civic Learning and Engagement (CIRCLE). (2010). A voter turnout time series for 1972-2010. Retrieved from http://www.civicyouth.org/

Chapman, C., Laird, J., Ifill, N. \& KewalRamani, A. (2011). Trends in high school dropout and completion rates in the United States: 1972-2009 (NCES 2012-006). U.S. Department of Education. Washington, DC: National Center for Education Statistics. Retrieved from http://nces.ed.gov/pubsearch

Checkland, P. (1999). Systems thinking, systems practice. Wiley: New York.

Chiel, H. J. \& Beer, R. D. (1997). The brain has a body: Adaptive behavior emerges from interactions of nervous system, body and environment. Trends in Neuroscience, 20,553-557.

Collier, P. (2001). A differentiated model of role identity acquisition. Symbolic Interaction, 24(2), 217-235.

Collier, P. \& Callero, P. (2005). Role theory and social cognition: Learning to think like a recycler. Self and Identity, 4, 45-58.

Commeyras, M. (1995). What can we learn from students' questions? Theory Into Practice, 34(2), 101-106.

Cook-Sather, A. (2006). Sound, presence, and power: "Student voice" in educational research and reform. Curriculum Inquiry, 36(4), 359-390.

Cook-Sather, A. (2007a). Resisting the impositional potential of student voice work: Lessons from liberatory educational research from poststructuralist feminist critiques of critical pedagogy. Discourse: Studies in the cultural politics of education, 28(3), 389-403. 
Cook-Sather, A. (2007b). What would happen if we treated students as those with opinions that matter? The benefits to principals and teachers of supporting youth engagement in school. NASSP Bulletin, 91(4), 343-362.

Creswell, J. W. (2007). Qualitative inquiry \& research design: Choosing among five approaches. Thousand Oaks, CA: Sage Publications.

Crick, R. D., McCombs, B., Haddon, A., Broadfoot, P. \& Tew, M. (2007). The ecology of learning: factors contributing to learner-centred classroom culture. Research Papers in Education, 22(3), 267-307.

Cuban, L. (1983). How did teachers teach, 1890-1980. Theory Into Practice, 22(3), 159-165.

Cuban, L. (1993). How teachers taught: Constancy and change in American classrooms, 1890-1990 (2nd ed.). New York: Teachers College Press.

Dahl, K. L. (1995). Challenges in understanding the learner's perspective. Theory Into Practice, 34(2), 124-130.

Dewey, J. (1938). Experience and education (Touchstone 1997 ed.). New York: Touchstone.

Dillon, S. (2010, December, 10). What works in the classroom? Ask the students. New York Times. Retrieved from www.nytimes.com/2010/12/11/education/11education.html

Doyle, M. C. \& Feldman, J. (2006). Student voice and school choice in the Boston pilot high schools. Educational Policy, 20(2), 367-398.

Durlak, J. A., Taylor, R. D., Kawashima, K., Pachan, M. K., DuPre, E. P., Celio, C. I., et al. (2007). Effects of positive youth development programs on school, family, and community systems. American Journal of Community Psychology, 39(3-4), 405-409.

Eccles, J. S. \& Roeser, R. W. (2011). Schools as developmental contexts during adolescence. Journal Of Research On Adolescence, 21(1), 225-241.

Elen, J., Clarebout, G., Léonard, R. \& Lowyck, J. (2007). Student-centered and 
teacher-centered learning environments: What students think. Teaching in Higher Education, 12(1), 105-117.

Erikson, E. H. (1968). Identity youth and crisis. New York, NY: W. W. Norton.

Faircloth, B. S. (2012). "Wearing a mask" vs. connecting identity with learning. Contemporary Educational Psychology, 37, 186-194.

Fenwick, T. (2004). The practice-based learning of educators: A co-emergent perspective. Scholar-Practitioner Quarterly, 2(4), 43-59.

Fielding, M. (2004a). Transformative approaches to student voice: Theoretical underpinnings, recalcitrant realities. British Educational Research Journal, 30(2), 295-311.

Fielding, M. (2004b). "New wave" student voice and the renewal of civic society. London Review of Education, 2(3), 197-217.

Fielding, M. (2006). Leadership, radical student engagement and the necessity of person-centered education. International Journal of Leadership in Education, 9(4), 299-313.

Fielding, M. (2007). Beyond "voice": New roles, relations, and contexts in researching with young people. Discourse: Studies in the Cultural Politics of Education, 28(3), 301-310.

Fletcher, A. (2003). Meaningful student involvement: A guide to inclusive school change. Retrieved from http://www.soundout.org/MSIGuideNew.pdf

Fletcher, A. (2004). Meaningful student involvement: Research guide. Retrieved from http://www.soundout.org/MSIResearch.pdf

Fletcher, A. (2008, Spring-Summer). Students as partners in learning. Northwest Education, 13(3), 28-29. Retrieved from http://www.nwrel.org/nwedu/

Fletcher, A. (2011). Ladder of youth voice. The FreeChild Project. Retrieved from http://www.freechild.org/ladder.htm

Flutter, J. (2007). Teacher development and pupil voice. The Curriculum Journal, 18(3), 343-354. 
Fox, S. (1985). The vitality of theory in Schwab's conception of the practical. Curriculum Inquiry, 55(1), 63-89.

Freire, P. (2003). Pedagogy of the oppressed: 30th anniversary edition. New York, NY: Continuum.

International Fulcrum Management Solutions. (2012). THOUGHTstream, Introduction [v.1.6]. Retrieved from www.thoughtstream.ca/downloads/ThoughtStreamIntroduction.pdf

Garcia, F., Kilgore, J., Rodriguez, P. \& Thomas, S. (1995). "It's like having a metal detector at the door": A conversation with students about voice. Theory Into Practice, 34(2), 138-144.

Garnsey, E. (1993). Exploring a critical systems perspective. Innovation in Social Sciences Research, 6(2), 229-256.

Giroux, H., \& Simon, R. (1988). Schooling, popular culture, and a pedagogy of possibility. Journal of Education, 170(1), 9.

Giroux, H. A. (2010). Lessons from Paulo Freire. Chronicle Of Higher Education, 57(9), B15-B16.

Hammond, B. \& Lednicer, L. G. (2008, June 8). Oregon's small-school experiment slow to see results. The Oregonian, p. A1.

Hirsch, G. B., Levine, R. \& Miller, R. L. (2007). Using system dynamics modeling to understand the impact of social change initiatives. American Journal of Community Psychology, 39, 239-253.

Hogan, P. (2011, December, 7). Contest recognizes student perspective on education reform. Eastern Iowa. Source Media News Group. Retrieved from http://easterniowaschools.com/2011/12/07/contest-recognizes-studentperspective-on-education-reform

Howe, B. R. \& Covell, K. (2013). Education in the best interests of the child: A children's rights perspective on closing the achievement gap. Toronto: University of Toronto Press. 
Iowa Department of Education. (2011). One unshakeable vision: World-class schools for Iowa. Retrieved from http://educateiowa.gov/index.php?option $=$ com_content\&view $=$ article \&id $=2524: 0$ ne-unshakeable-vision-world-class-schools-for-iowa

Jackson, A. W. \& Davis, G. A. (2000). Turning points 2000: Educating adolescents in the 21st century. New York: Teachers College Press.

Jenkins, E. W. \& Nelson, N. W. (2005). Important but not for me: Students' attitudes towards secondary school science in England. Research in Science \& Technological Education, 23(1), 41-57.

Jenks, C. L. (2004). Missing links in the public school curriculum. World Futures Journal of General Evolution, 60(3), 195-216.

Johnston, P. H., \& Nicholls, J. G. (1995). Voices we want to hear and voices we don't. Theory Into Practice, 34(2), 94-100.

Kinchin, I. (2004). Investigating students' beliefs about their preferred role as learners. Educational Research, 46(3), 301-312.

Kyle, K., \& Jenks, C. (2002). The theoretical and historical case for democratic education in the United States. Educational Studies, 33(2), 150.

Labaree, D. (1997). Public goods, private goods: The American struggle over educational goals. American Educational Research Journal, 34(1), 39-81.

Labaree, D. (2005). Progressivism, schools and schools of education: An American romance. Paedagogica Historica, 41(1\&2), 275-288.

Labaree, D. (2006). Innovation, nostalgia, and the politics of educational change. Educational Administration Quarterly, 42(1), 157-164.

Lakofi, G., \& Johnson, M. (1980). Metaphors we live by. Chicago, IL: University of Chicago.

Lensmire, T. (1998). Rewriting student voice. Journal of Curriculum Studies, 30(3), 261-291.

Levin, B. (2000). Putting students at the centre in education reform. Journal of 
Educational Change, 1(2), 155-172.

Levine, J. M. \& Wang, M. C. (1983). Teacher and student perceptions: Implications for learning. Hillsdale, N.J.: Erlbaum.

Lincoln, Y. (1995). In search of students' voices. Theory Into Practice, 34(2), 88-93.

Lundy, L. (2007). 'Voice' is not enough: Conceptualizing Article 12 of the United Nations Convention on the Rights of the Child. British Educational Research Journal, 33(6), 927-942.

Lynch, K. D. (2007). Modeling role enactment: Linking role theory and social cognition. Journal for the Theory of Social Behaviour, 37(4), 379-399.

Mathis, W. J. (2011). International Test Scores, Educational Policy, and the American Dream. Encounter: Education for Meaning and Social Justice, 24(1), 31-33.

Maxwell, J. (2005). Qualitative research design: An interactive approach. Thousand Oaks, CA: Sage Publications.

McCombs, B. L. (2003). A framework for the redesign of k-12 education in the context of current educational reform. Theory Into Practice, 42(2), 93-101.

McGregor, G. (2011). Engaging Gen Y in schooling: The need for an egalitarian ethos of education. Pedagogy, Culture \& Society, 19(1), 1-20.

McInerney, P. (2006, November). 'Blame the student or blame the system?': Educational policy and the dilemmas of student engagement and retention - $a$ Freirean perspective. Paper presented at the Australian Association for Research in Education (AARE) Annual Conference, Adelaide, Australia.

McIntyre, D., Pedder, D., \& Rudduck, J. (2005). Pupil voice: Comfortable and uncomfortable learnings for teachers. Research Papers In Education, 20(2), 149-168.

McMurrer, J. (2007). Choices, changes, and challenges: Curriculum and instruction in the NCLB era. Center for Education Policy. Retrieved from http://www.cepdc.org/cfcontent file.cfm?Attachment=McMurrer_Fullreport CurricAndInstructi on_072407.pdf 
Mitra, D. (2004). The significance of students: Can increasing "student voice" in schools lead to gains in youth development? Teachers College Record, 106(4), 651-688.

Mitra, D. (2006). Student voice from the inside and outside: The positioning of challenges. International Journal of Leadership in Education, 9(4), 315-328.

Mitra, D. (2007). The role of administrators in enabling youth-adult partnerships in schools. NASSP Bulletin, 91, 237.

Mitra, D. (2009). Strengthening student voice initiatives in high schools: An examination of the supports needed for school-based youth-adult partnerships. Youth \& Society, 40(3), 311-335.

Mitra, D. L., \& Gross, S. (2009). Increasing student voice in high school reform. Educational Management Administration \& Leadership, 37(4), 522-543.

Mitra, D. \& Kirshner, B. (2011). Insiders versus outsiders: Examining variability in student voice initiatives and their consequences for school change. Manuscript submitted for publication.

Moran, P. \& Murphy, M. (2012). Habermas, pupil voice, rationalism, and their meeting with Lacan's objet petit a. Studies in the Philosophy of Education, 31, 171-181.

Morgan, W. \& Streb, M. (2001). Building citizenship: How student voice in service-learning develops civic values. Social Science Quarterly, 82(1), 154-170.

National Council for the Social Studies. (2010). The National Curriculum Standards for Social Studies. Retrieved from http://www.socialstudies.org/standards

Newmann, F. M. (Ed.). (1992). Student engagement and achievement in American secondary schools. New York, NY: Teachers College Press.

Nolfi, S. (2005). Behavior as a complex adaptive system: On the role of selforganization in the development of individual and collective behavior. ComplexUs, 2(3-4), 195-203. Retrieved from:

http://content.karger.com/ProdukteDB/produkte.asp?Aktion=ShowAbstract\&Arti $\underline{\mathrm{kelNr}}=93690 \&$ Ausgabe $=232006 \& \mathrm{ProduktNr}=227088$ 
Noyes, A. (2005). Pupil voice: Purpose, power and the possibilities for democratic schooling. British Educational Research Journal, 31(4), 533-540.

O'Connell Schmakel, P. (2008). Culturally responsive teaching as an ethics-and carebased approach to urban education. Urban Education 47, 1086-1105.

O’Donoghue, J. L., Kirshner, B. \& McLaughlin, M. (2002 ). Introduction: Moving youth participation forward. New Directions for Youth Development, 96, 15-26.

Orner, M. (1992). Interpreting the calls for student voice in "liberatory" education: A feminist poststructuralist perspective. In C. Luke \& J. Gore (Eds.), Feminisms and Critical Pedagogies, (pp. 74-89), New York: Routledge.

Osberg, J., Pope, D. \& Galloway, M. (2006). Students matter in school reform: Leaving fingerprints and becoming leaders. International Journal of Leadership in Education, 9(4), 329-343.

Owens, R. G., \& Valesky, T. C. (1995). Organizational behavior in education. Boston: Allyn and Bacon.

Parsons, B. A. (2007). The state of methods and tools for social systems change. American Journal of Community Psychology, 39(3-4), 405-409.

Pasek, J., Feldman, L., Romer, D. \& Jamieson, K. H. (2008). Schools as incubators of democratic participation: Building long-term political efficacy with civic education. Applied Development Science, 12(1), 26-37.

Plutzer. E. (2002). Becoming a habitual voter: Inertia, resources, and growth in young adulthood. American Political Science Review, 96, 41-56.

Quicke, J. (2003). Educating the pupil voice. Support for Learning, 18(2), 51-57.

Raphel, J (2008). Learning by listening to students: Slow and steady growth. Northwest Education 13(3), 18-22. Retrieved from educationnorthwest.org/webfm send/434

Reason, P. \& Bradbury, H. (Eds.). (2006). Introduction. Handbook of action research: Participative inquiry and practice. Retrieved from http://faculty.mu.edu.sa/public/uploads/1346012794.621handbook_of_action_rese arch.pdf 
Reese, W. J. (2001). The origins of progressive education. History of Education Quarterly, 41(1), vi+1-24.

River High School. (2012). School Improvement Plan. Unpublished document.

Rodr' 1guez, L. F. (2008). Struggling to recognize their existence: Examining student-adult relationships in the urban high school context. Urban Review, 40, 436-453.

Rubin, B. C. \& Jones, M. (2007). Student action research: Reaping the benefits for students and school leaders. NASSP Bulletin, 91(4), 363-378. Retrieved from www.sagepub.com/mertler2study/articles/Rubin\%20Jones.pdf

Rudduck, J. \& Flutter, J. (2004). How to improve your school: Giving pupils a voice. London: Continuum.

Sands, D. I., Guzman, L., Stephens, L., \& Boggs, A. (2007). Including student voices in school reform: Students speak out. Journal Of Latinos And Education, 6(4), 323345.

Schachter, R. (2010, May). Power to the students. District Administration. Retrieved from http://www.districtadministration.com/article/power-students

Schultz, B. D. \& Oyler, C. (2006). We make this road as we walk together: Sharing teacher authority in a social action curriculum project. Curriculum Inquiry $36(4), 423-451$.

Schunk, D. H. \& Meece, J. L. (Eds.). (1992). Student perceptions in the classroom. Hillsdale, NJ: Erlbaum.

Schwab, J. J. (1973). The practical 3: Translation into curriculum. The School Review, 81(4). 501-522.

Selby, M. (2011, April). The power of student voice. The Middle Level Leader. Retrieved from http://www.nassp.org/tabid/3788/default.aspx?topic= The_Power_of_Student_Voice

Shier, H. (2001). Pathways to participation: Openings, opportunities and obligations. A new model for enhancing children's participation in decision-making, in line with Article 12.1 of the United Nations Convention on the Rights of the Child. 
Children and Society, 13, 107-117.

Silva, E. (2001). Squeaky wheels and flat tires: A case study of students as reform participants. Forum, 43(2), 95-99.

Simon, H. A. (1991). Bounded rationality and organizational learning. Organizational Science, 2(1), 125-134.

Smyth, J. (2006a). Educational leadership that fosters 'student voice'. International Journal of Leadership in Education, 9(4), 279-284.

Smyth, J. (2006b, October-December). 'When students have power': Student engagement, student voice, and the possibility for school reform around 'dropping out' of school. International Journal of Leadership in Education, 9(4), 285-98.

Steinberg, L. (2005). Adolescence (7th ed.). Boston: McGraw-Hill.

Steinberg, L., \& Morris, A. S. (2001). Adolescent development. Annual Review of Psychology, 52(1), 83-111.

Stedman, L. C. (2009, March). The NAEP long-term trend assessment: A review of its transformation, use, and findings. Retrieved from http://www.nagb.org/publications/reports-papers/assessment-design/long-termtrend-assessment-review.html

Sterman, J. (2006). Learning from evidence in a complex world. American Journal of Public Health, 96(3), 505-514.

Stone, D. (2002). Policy paradox: the art of political decision making (Revised ed.). New York: NY: W. W. Norton \& Company.

Symonds, J. E. (2008). Pupil researchers generation X: Educating pupils as active participants. Research in Education, 80(1), 63-74.

Taylor, C. \& Robinson, C. (2009). Student voice: Theorising power and participation. Pedagogy, Culture \& Society, 17(2), 161-175.

Thiessen, D. (2006). Student knowledge, engagement, and voice in educational reform. Curriculum Inquiry, 36(4), 345-358. 
Torney-Purta, J., Lehmann, H.O., \& Schulz, W. (2004). Adolescents' trust and civic participation in the United States: Analysis of data from the IEA civic education study. CIRCLE Fact Sheet. Retrieved from http://www.civicyouth.org/PopUps/FactSheets/FS_Trust_CivicPart.pdf

von Wright, M. (2006). The punctual fallacy of participation. Educational Philosophy and Theory, 38(2), 159-170.

Wang, M-T. \& Eccles, J. S. (2011). Adolescent behavioral, emotional, and cognitive engagement trajectories in school and their differential relations to educational success. Journal of Research on Adolescence, 22(1), 31-39.

Warwick, P. (2008). The development of apt citizenship education through listening to young people's voices. Educational Action Research, 16(3), 321-333.

Weiss, J. A. \& Piderit, S. K. (1999). The value of mission statements in public agencies. Journal of Public Administration Research and Theory, 2, 199-223.

Wright, K. (2008). Researching the views of pupils with multiple and complex needs. Is it worth doing and whose interests are served by it? Support for Learning, 23(1), 32-40.

Yazzie-Mintz, E. (2007). Voices of students on engagement: A report on the 2006 high school survey of student engagement. Bloomington, IN: Center for Evaluation \& Education Policy, Indiana University. Retrieved from http://eric.ed.gov/?id=ED495758

Yolles, M. I. (2000). Viable learning systems. Interactive Learning Environments, $8(1), 51-71$.

Zwick, M. (2006). Elements and relations: Aspects of a scientific metaphysics. Unpublished manuscript. 
Appendix A

Student Research Team Application

\section{Student Research Team Application}

Date Returned:

\section{Contact Information}

\begin{tabular}{l|ll}
\hline Name & \\
\hline Street Address & & \\
\hline City ST ZIP Code & & \\
\hline Home Phone & & \\
\hline Cell Phone & & \\
\hline E-Mail Address & & \\
\hline \multicolumn{1}{c}{ Current Year } & Freshmen Sophomore Junior Senior \\
\hline
\end{tabular}

\section{Availability}

During which afternoons are you available to meet after school for 1-2 hours? Mark as many as necessary.
Monday
Wednesday
Friday
Start at 3:00 PM
Tuesday
Thursday
ANY day
Start at 3:30 PM

\section{Statement of Interest}

Explain why you are interested in joining the Student Research Team. What do you hope to get out of the experience? 


\section{Previous Related Experiences}

Summarize any experiences you may have had related to conducting research, working as a team member, or completing a long-term project.

\section{Person to Notify in Case of Emergency (Parent/Guardian)}

\begin{tabular}{|l|l|}
\hline Name & \\
\hline Street Address & \\
\hline City ST ZIP Code & \\
\hline Home Phone & \\
\hline Work Phone & \\
\hline E-Mail Address & \\
\hline
\end{tabular}

\section{Agreement and Signature}

By submitting this application, I affirm that the facts set forth in it are true and complete.

\begin{tabular}{|l|l|}
\hline Signature & \\
\hline Name (printed) & \\
\hline Date \\
\hline
\end{tabular}

\section{References}

You will be given three recommendation forms to distribute to teachers of your choice. The teachers will return the forms to me directly, but please list their names below so I can follow up if necessary.

\begin{tabular}{|r|r|r|}
\hline Name & \\
\hline Subject Area & & \\
\hline
\end{tabular}




\title{
Appendix B
}

\author{
SRT Informed Consent Packet
}

\section{BE PART OF AN IMPORTANT PROJECT!}

An Investigation of Student Roles in the High School Community STUDENT RESEARCH TEAM INFORMED CONSENT

You are invited to participate as a Student Research Team member in a research study conducted by RHS teacher Joe Zenisek in connection with his doctoral studies at Portland State University. As a Student Research Team member you will work with Mr. Z as a co-researcher to learn how students, parents and teachers understand the role students have in the school community.

\section{What Will I Have To Do?}

If you decide to join the Student Research Team (SRT) in this study, you will meet with the other SRT members and Mr. Zenisek weekly after school for 1 to 2 hours over a period of twelve weeks. There may also be tasks associated with the meeting activities including regular online journal entries reflecting on your experiences as a researcher.

The following is a summary of the Student Research Team activities:

- First Team Meeting Activities: Overview of the research goals; explanation of confidentiality issues; introduction to "role theory"; introduction to THOUGHTstream (Ts) the internet software tool which will be used in the study.

- After-meeting task: Try the Ts web software to post suggestions for research questions; complete online journal entry.

- Second Team Meeting Activities: Overview of purpose and set up of "pilot study" to test survey questions; continued practice using the Ts web software to review suggested research questions.

- After-meeting task: Go online and use the Ts web software to pilot the research questions; complete online journal entry.

- Third Team Meeting Activities: Using the Ts web software to review the pilot group's responses to the research questions; finalizing the research questions and background information for posting to Ts.

- After-meeting task: Decide if you have any related research questions to include in the study; complete online journal entry. 
- Fourth Team Meeting Activities: Preparing for first Homeroom presentations to explain Ts survey process to participating students.

- After-meeting tasks: Review Ts online process to prepare for Homeroom presentations; complete online journal entry.

- Make two Homeroom presentations.

- Fifth Team Meeting Activities: Browse first posted responses to survey questions; begin developing categories for grouping responses.

- After-meeting task: Complete online journal entry.

- Sixth and Seventh Team Meeting Activities: Sorting responses to survey questions.

- After-meeting tasks: Review next Ts online process to prepare for Homeroom presentations; complete online journal entry.

- Make two Homeroom presentations to explain next Ts survey steps.

- Eighth Team Meeting Activities: Finalize survey response summaries and groupings; review the next Ts process which is used to rank the response summaries/groupings.

- After-meeting task: Practice using the next Ts online process to prepare for Homeroom presentations; complete online journal entry.

- Make two Homeroom presentations to explain next Ts survey steps.

- Ninth Team Meeting Activities: Browse first posted rankings of the survey response summaries; prepare for final presentations to homerooms and teaching staff.

- After-meeting task: Prepare for homeroom presentations; online journal entry.

- Make two Homeroom presentations to explain Ts final survey steps.

- Tenth Team Meeting Activities: Review final posted rankings of the survey response summaries; prepare for final presentations to homerooms and teaching staff.

- After-meeting task: Prepare for homeroom presentations; online journal entry.

- Make final two Homeroom presentations and presentation to staff at Friday Late Start to share survey highlights and to say "Thanks" for participating.

- Eleventh Team Meeting Activities: Closing interview with Mr. Zenisek and planning for celebration.

○ After-meeting task: Complete final online journal entry.

- Twelfth Team Meeting Activities: Celebration at a location and time to be determined.

\section{Are There Any Risks?}

There is the possibility of discomfort, embarrassment and/or stress related to carrying out the duties and responsibilities of co-researcher, working with peers and adults, and/or finishing tasks within the timeline and deadlines necessary to complete the study.

If you do agree to take part, and later you feel unable to complete any of the tasks, you may choose to leave the study at any time. 


\section{What Will I Get In Return?}

Students participating on the Research Team will have opportunities to:

1) meet mandatory graduation requirements by earning Career Related Learning

Experience (CRLE) hours;

2) meet related course requirements in Psychology or Sociology classes in which they may be enrolled; and

3 ) enhance their college application resumes.

Additionally, students will experience and develop skills as a researcher, including working on a team, developing research questions, organizing and analyzing data, and communicating results.

Other than any personal benefits from taking part in this study, this study may help the RHS community get a better understanding about the changing roles of students and how to better support them.

\section{What Are You Doing To Protect Me?}

Your privacy is very important to us. We have done many things to protect you:

- Your postings will be anonymous. We will not ask for your name or any personal information when you log in to participate. You will develop your own confidential username for online journal entries.

- Your responses to the survey activities will be kept private to the extent allowed by law. (By "kept private" we mean that we will only reveal your responses in a way that no one could ever guess or know it was you who said it.)

- Your name and other personal information, which we need in order to keep track of who participated, will be kept in a locked file cabinet or in a locked file on the computer so that no one other than $\mathrm{Mr} Z$ will be able to see it. For example, this form (which has your name on it) will be kept in a locked file cabinet.

- When we write or talk about what we learned in this study, we will leave things out so no one will be able to tell who we are talking about. Team members will be assigned pseudonyms in reports, presentations and discussions about the study.

- In addition, we will develop Team Agreements to guide our work, and to establish and maintain respect and confidentiality among team members.

\section{Any Questions?}

If you have any questions about this study, this form, or the survey process, you can talk to Mr. Zenisek directly or by using the contact information below. You can also contact the Chair of the Human Subjects Committee of Portland State University about your rights as a research participant (someone who takes part in a study). Hours are 9:00 a.m. to 5:00 p.m. The office is located at Portland State University, Market Center Building, $6^{\text {th }}$ floor, Portland, OR 97201. The telephone number is (503) 725-4288.

\section{If I Sign, What Does It Mean?}

This is a consent form. Your signature below means that:

- You have read and understand what this form says.

- You know that you do not have to take part in this study. 
- You have carefully considered the tasks and time commitments required to successfully finish the study and are willing to commit to their completion to the best of your ability.

- Even if you agree to commit, you can change your mind and stop at any time without affecting your relationship with Mr. Zenisek, River High School, River School District, or its staff.

- You will get a copy of this form to keep for yourself.

Student Signature

Date

Print name

- You will also need your parent/guardian to read and sign the attached Parent Permission form if you wish to participate.

Thank you for your consideration.

Joe Zenisek

RHS Science/Yearbook

(+ RHS Contact Info)

An Investigation of Student Roles in the High School Community

\section{PARENT PERMISSION}

Your child is invited to participate as a Student Research Team member in a research study conducted by RHS teacher Joe Zenisek in partial fulfillment of the requirements for a doctoral degree in Curriculum and Instruction at Portland State University under the supervision of Professor Emily de la Cruz. The researcher hopes to learn how students, parents and teachers understand the role students have in the school community. Your child has volunteered to be a participant in this study.

If you decide to let your child join the Student Research Team (SRT) in this study, he/she will meet with the other SRT members and Mr. Zenisek weekly after school for 1 to 2 hours over a period of twelve weeks. There will also be tasks associated with the meeting activities including weekly online journal entries reflecting on his/her experiences as a researcher.

The following is a summary of the Student Research Team activities:

- First Team Meeting Activities: Overview of the research goals; explanation of confidentiality issues; introduction to "role theory"; introduction to THOUGHTstream (Ts) the internet software which will be used in the study.

- After-meeting task: Try the Ts web software to post suggestions for research questions; online journal entry. 
- Second Team Meeting Activities: Overview of purpose and set up of a "pilot study" to test survey questions; continued practice using the Ts web software to review suggested research questions.

- After-meeting task: Go online and use the Ts web software to pilot the research questions; online journal entry.

- Third Team Meeting Activities: Using the Ts web software to review the pilot group's responses to the research questions; finalizing the research questions and background information for posting to Ts .

- After-meeting task: Decide if you have any related research questions to include in the study; online journal entry.

- Fourth Team Meeting Activities: Preparing for first Homeroom presentations to explain Ts survey process to participating students.

- After-meeting tasks: Review Ts online process to prepare for Homeroom presentation; online journal entry.

- Make two Homeroom presentations.

- Fifth Team Meeting Activities: Browse first posted responses to survey questions; begin developing categories for grouping responses.

- After-meeting task: Online journal entry.

- Sixth and Seventh Team Meeting Activities: Sorting responses to survey questions.

- After-meeting tasks: Review next Ts online process to prepare for Homeroom presentation; online journal entry.

- Make two Homeroom presentations to explain next Ts survey steps.

- Eighth Team Meeting Activities: Finalize survey response summaries and groupings; review the next Ts process which is used to rank the response summaries/groupings.

- After-meeting task: Practice using the next Ts online process to prepare for Homeroom presentation; online journal entry.

- Make two Homeroom presentations to explain next Ts survey steps.

- Ninth Team Meeting Activities: Browse first posted rankings of the survey response summaries; prepare for final presentations to homerooms and teaching staff.

- After-meeting task: Prepare for homeroom presentations; online journal entry.

- Make two Homeroom presentations to explain Ts final survey steps.

- Tenth Team Meeting Activities: Review final posted rankings of the survey response summaries; prepare for final presentations to homerooms and teaching staff.

- After-meeting task: Prepare for homeroom presentations; online journal entry.

- Make final two Homeroom presentations and presentation to staff at Friday Late Start to share survey highlights and to say "Thanks" for participating. 
- Eleventh Team Meeting Activities: Closing interview with Mr. Zenisek and planning for celebration.

- After-meeting task: Final online journal entry.

- Twelfth Team Meeting Activities: Celebration at a location and time to be determined.

There is a small possibility of risk to your child in participating in this study. This includes the possibility of discomfort, embarrassment and/or stress related to carrying out the duties and responsibilities of co-researcher, working with peers and adults, and/or finishing tasks within the timeline and deadlines necessary to complete the study. If he/she does agree to take part, and later feels unable to complete any of the tasks, he/she may choose to leave the study at any time.

There are possible personal benefits to participating in this study. Students will have opportunities to:

1) meet mandatory graduation requirements by earning Career Related Learning

Experience (CRLE) hours;

2) meet related course requirements in Psychology or Sociology classes in which they may be enrolled; and

3) enhance their college application resumes.

Additionally, students will experience and develop skills as a researcher including working on a team, developing research questions, organizing and analyzing data, and communicating results. Other than any personal benefits from taking part in this study, this study may help the RHS community get a better understanding about the changing roles of students and how to better support them.

Your child's privacy is very important to us. All online responses are anonymous - we will not ask for a name or any personal information when he/she logs in to participate. Other than the signed Student Informed Consent form, this Parent Permission form, and the Parent Informed Consent form (if you also choose to participate in the study), there is no information that is obtained in connection with this study that can be linked to your child or identify him/her. This Informed Consent document will be kept confidential by keeping it in a secure (locked) file cabinet for six months after the completion of the dissertation after which it will be destroyed. When discussing, presenting or publishing the results of this study, Research Team members will be assigned pseudonyms to protect their identities. In addition, during the study, we will develop Team Agreements to guide our work, and to establish and maintain respect and norms of confidentiality among team members.

Your child's participation is voluntary. He/she does not have to take part in this study, and it will not affect his/her grade or relationship with River High School, River School District or its staff. You may also withdraw your permission for your child to participate from this study at any time without affecting his/her grade or relationship with River High School, River School District or its staff. Likewise, your child may withdraw his/her assent at any time without affecting his/her grade or relationship with River High School, River School District or its staff. If you have questions or concerns about your child's participation in this study, contact the researcher, Joe Zenisek, using the contact information below. If you have concerns about your 
child's rights as a research subject, please contact Research and Strategic Partnerships, Market Center Building $6^{\text {th }}$ floor, Portland State University, (503) 725-4288.

Your signature indicates that you have read and understand the above information and agree to let your child take part in this study. The researcher should provide you with a copy of this form for your own records.

Parent Signature

Date

Print name

- If you would also like to participate in this study, please read and sign the attached Parent Informed Consent form.

Thank you for your consideration.

Joe Zenisek

Science/Yearbook

(+ RHS Contact Info) 
Appendix C

Student Informed Consent Packet

BE PART OF AN IMPORTANT PROJECT!

An Investigation of Student Roles in the High School Community

STUDENT INFORMED CONSENT

You are invited to participate in a research study conducted by RHS teacher Joe Zenisek in connection with his doctoral studies at Portland State University. Mr. Z hopes to learn how students, parents and teachers understand the role students have in the school community.

\section{What Will I Have To Do?}

If you decide to take part in this study, your Homeroom teacher will take you to a computer lab four times over an eight week period to use an online survey tool. All answers will be anonymous.

- First visit you will be asked to answer some questions about your thoughts on the roles high school students should play in the school community. Your answers will be anonymous - no one will know they are yours - not even the researchers.

- In the second visit you will get to see the types of answers other students gave and add any last thoughts.

- In the third visit you will have a chance to rank the types of answers students gave from most important to least important in describing the role of students.

- In the final visit you will have a chance to review and post comments on how other students, as well as parents and teachers, responded to and ranked their responses to the survey questions.

If you don't finish an activity during Homeroom, you will be given directions on how to log into the website to complete it later on your own time in the school library or at home. You will have one week to complete each step.

\section{Are There Any Risks?}

There are no risks to your participation in this study. You do not have to take part in this study. If you do agree to take part, and you feel uncomfortable or unable to answer any of the questions we ask or complete any of the steps, you may skip them. You don't have to answer any questions you don't want to. And if you don't want to go on, you can stop at any time.

\section{What Will I Get In Return?}

You may not receive any direct benefit from taking part in this study, but this study may help the RHS community of students, parents, and educators get a better understanding about the changing roles of students and how to better support them. 


\section{What Are You Doing To Protect Me?}

Your privacy is very important to us. We have done many things to protect you:

- Your answers will be anonymous. We will not ask for your name or any personal information when you log in to participate.

- Your responses to the survey activities will be kept private to the extent allowed by law. (By "kept private" we mean that we will only reveal your responses in a way that no one could ever guess or know it was you who said it.)

- Your name and other personal information, which we need in order to keep track of who participated, will be kept in a locked file cabinet or in a locked file on the computer so that no one other than $\mathrm{Mr} Z$ will be able to see it. For example, this form (which has your name on it) will be kept in a locked file cabinet.

- When we write or talk about what we learned in this study, we will leave things out so no one will be able to tell who we are talking about.

\section{Any Questions?}

If you have any questions about this study, this form, or the survey process, you can talk to Mr. Zenisek directly or through the contact information below. You can also contact the Chair of the Human Subjects Committee of Portland State University about your rights as a research participant (someone who takes part in a study). Hours are 9:00 a.m. to 5:00 p.m. The office is located at Portland State University, Market Center Building, $6^{\text {th }}$ floor, Portland, OR 97201. The telephone number is (503) 725-4288.

\section{If I Sign, What Does It Mean?}

This is a consent form. Your signature below means that:

- You have read and understand what this form says.

- You are willing to use four of your Homeroom periods to take part in the study.

- You know that you do not have to take part in this study. And even if you agree, you can change your mind and stop at any time. No problem.

- You will get a copy of this form to keep for yourself.

Student Participant Signature

Date

Print name

- You will also need your parent/guardian to read and sign the attached Parent Permission form if you wish to participate.

Thank you for your consideration.

Joe Zenisek

RHS Science/Yearbook

(+RHS Contact Info) 
An Investigation of Student Roles in the High School Community

\section{PARENT PERMISSION}

Your child is invited to participate in a research study conducted by RHS teacher Joe Zenisek in partial fulfillment of the requirements for a doctoral degree in Curriculum and Instruction at Portland State University under the supervision of Professor Emily de la Cruz. The researcher hopes to learn how students, parents and teachers understand the role students have in the school community. Your child has volunteered to be a participant in this study.

If you decide to let your child participate, he/she will be brought to a computer lab by the Homeroom teacher four times over an eight week period to use an online survey tool. All responses to the online survey will be anonymous.

- During the first visit he/she will be asked to answer some questions about his/her thoughts on the roles high school students play in the school community.

- In the second visit he/she will get to see the types of answers other students gave and add any last thoughts.

- In the third visit he/she will have a chance to rank the types of answers students gave from most important to least important in describing the role of students.

- In the final visit he/she will have a chance to review and post comments on how other students, as well as parents and teachers, responded to and ranked their responses to the survey questions.

If he/she doesn't finish an activity during Homeroom, he/she will be given directions on how to log into the website to complete it later on his/her own time in the school library or at home. He/she will have one week to complete each step.

There are no anticipated risks to your child's participation in this study. He/she does not have to take part in this study. If he/she does agree to take part, and feels uncomfortable or unable to answer any of the questions or complete any of the steps, he/she may skip them. He/she doesn't have to answer any questions he/she doesn't want to. And if he/she doesn't want to go on, he/she can stop at any time.

$\mathrm{He} /$ she may not receive any direct benefit from taking part in this study, but this study may help the RHS community of students, parents, and educators gain a better understanding about the changing roles of students and how to better support them.

Your child's privacy is very important to us. All online response are anonymous - we will not ask for a name or any personal information when he/she logs in to participate. Other than the signed Student Informed Consent form, this Parent Permission form, and the Parent Informed Consent form (if you also choose to participate in the study), there is no information that is obtained in connection with this study that can be linked to your child or identify him/her. This Informed Consent document will be kept confidential by keeping it in a secure (locked) file cabinet for six months after the completion of the dissertation after which it will be destroyed.

Your child's participation is voluntary. He/she does not have to take part in this study, and it will not affect his/her grade or relationship with River High School, River School District or its staff. 
You may also withdraw your permission for your child to participate from this study at any time without affecting his/her grade or relationship with River High School, River School District or its staff. Likewise, your child may withdraw his/her assent at any time without affecting his/her grade or relationship with River High School, River School District or its staff.

If you have questions or concerns about your child's participation in this study, contact the researcher, Joe Zenisek, using the contact information below. If you have concerns about your child's rights as a research subject, please contact Research and Strategic Partnerships, Market Center Building $6^{\text {th }}$ floor, Portland State University, (503) 725-4288.

Your signature indicates that you have read and understand the above information and agree to let your child take part in this study. The researcher should provide you with a copy of this form for your own records.

Parent Signature

Date

Print name

- If you would also like to participate in this study, please read and sign the attached Parent Informed Consent form.

Thank you for your consideration.

Joe Zenisek

RHS Science/Yearbook

(+RHS Contact Info) 


\title{
Appendix D
}

\section{Parent Informed Consent Form}

\author{
An Investigation of Student Roles in the High School Community \\ PARENT INFORMED CONSENT FORM
}

\section{Dear RHS Parent/Guardian:}

You are invited to participate in a research study conducted by RHS teacher Joe Zenisek in partial fulfillment of the requirements for a doctoral degree in Curriculum and Instruction at Portland State University under the supervision of Professor Emily de la Cruz. The researcher hopes to learn how students, parents and teachers view the role students have in the school community. You were selected as a possible participant in this study because you are a parent or guardian of student at River High School who has also been invited to participate in this study.

If you decide to participate, you will be asked to use an online software tool to complete a fourstep survey process. Each step should take you no more than an hour and will be spread out over eight weeks to allow adequate time for you and the researchers to complete their tasks. Your responses will be anonymous.

1. In step one you will receive an email directing you to a website where you will answer several open-ended questions regarding your thoughts on the roles high school students should play in the school community. The web site will remain open to your response for one week.

2. Step two will take place approximately two weeks later. Again you will receive an email directing you to the website where you will have an opportunity to review and post comments on how the research team has summarized and grouped all the parent responses to the survey questions. The web site will remain open to your response for one week.

3. Step three will take place approximately two weeks later. Again you will receive an email directing you to the website where you will have an opportunity evaluate and rank the grouped responses from most important to least important in describing the role of students. The web site will remain open to your response for one week.

4. The last step will take place approximately two weeks later. Again you will receive an email directing you to the website where you will have an opportunity review and post comments on how students, parents and teachers responded to and ranked their responses to the survey questions. The web site will remain open to your response for one week.

There are no known risks associated with your participation in this study. You may not receive any direct benefit from taking part in this study, but this study may help the RHS Community of students, parents, and educators gain a better understanding of the changing role of students and 
how to better support there development

Other than this signed Informed Consent form, there is no information that is obtained in connection with this study that can be linked to you or identify you. This Informed Consent document will be kept confidential by keeping it in a secure (locked) file cabinet for six months after the completion of the dissertation after which it will be destroyed.

Your participation is voluntary. You do not have to take part in this study, and it will not affect your relationship with the researcher, River High School, River School District, or Portland State University. You may also withdraw from this study at any time without affecting your relationship with any of the above.

If you have questions or concerns about your participation in this study, contact the researcher, Joe Zenisek using the contact information below. If you have concerns about your rights as a research subject, please contact Research and Strategic Partnerships, Market Center Building $6^{\text {th }}$ floor, Portland State University, (503) 725-4288.

Your signature indicates that you have read and understand the above information and agree to take part in this study. The researcher should provide you with a copy of this form for your own records.

Signature

Date

Print name

Thank you for your consideration.

Joe Zenisek

RHS Science/Yearbook

(+RHS Contact Info) 
Appendix E

Teacher Informed Consent Form

\author{
An Investigation of Student Roles in the High School Community \\ RHS STAFF INFORMED CONSENT FORM
}

\title{
Dear RHS Staff:
}

You are invited to participate in a research study conducted by RHS teacher Joe Zenisek in partial fulfillment of the requirements for a doctoral degree in Curriculum and Instruction at Portland State University under the supervision of Professor Emily de la Cruz. The researcher hopes to learn how students, parents and teachers view the role students have in the school community. You were selected as a possible participant in this study because you are a certified teacher or administrator at River High School.

If you decide to participate, you will be asked to use an online software tool to complete a fourstep survey process. Each step should take you no more than an hour and will be spread out over eight weeks to allow adequate time for you and the researchers to complete their tasks. Your responses will be anonymous.

1. In step one you will receive an email directing you to a website where you will answer several open-ended questions regarding your thoughts on the roles high school students should play in the school community. The web site will remain open to your response for one week.

2. Step two will take place approximately two weeks later. Again you will receive an email directing you to the website where you will have an opportunity to review and post comments on how the research team has summarized and grouped all the teacher responses to the survey questions. The web site will remain open to your response for one week.

3. Step three will take place approximately two weeks later. Again you will receive an email directing you to the website where you will have an opportunity evaluate and rank the grouped responses from most important to least important in describing the role of students. The web site will remain open to your response for one week.

4. The last step will take place approximately two weeks later. Again you will receive an email directing you to the website where you will have an opportunity review and post comments on how students, parents and teachers responded to and ranked their responses to the survey questions. The web site will remain open to your response for one week.

There are no known risks associated with your participation in this study. You may not receive any direct benefit from taking part in this study, but this study may help the RHS Community of students, parents, and educators gain a better understanding of the changing role of students and 
how to better support there development.

Other than this signed Informed Consent form, there is no information that is obtained in connection with this study that can be linked to you or identify you. This Informed Consent document will be kept confidential by keeping it in a secure (locked) file cabinet for six months after the completion of the dissertation after which it will be destroyed.

Your participation is voluntary. You do not have to take part in this study, and it will not affect your relationship with the researcher, River High School, River School District, or Portland State University. You may also withdraw from this study at any time without affecting your relationship with any of the above.

If you have questions or concerns about your participation in this study, contact the researcher, Joe Zenisek using the contact information below. If you have concerns about your rights as a research subject, please contact Research and Strategic Partnerships, Market Center Building $6^{\text {th }}$ floor, Portland State University, (503) 725-4288.

Your signature indicates that you have read and understand the above information and agree to take part in this study. The researcher should provide you with a copy of this form for your own records.

Signature

Date

Print name

Thank you for your consideration.

Joe Zenisek

RHS Science/Yearbook

(+RHS Contact Info) 